NISTIR 6726

\title{
Mechanical Properties of High-Strength Concrete at Elevated Temperatures
}

Building and Fire Research Laboratory

Gaithersburg, Maryland 20899

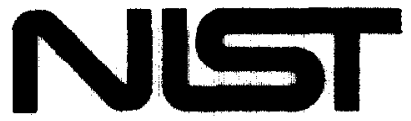

United States Department of Commerce Technology Administration

National Institute of Standards and Technology

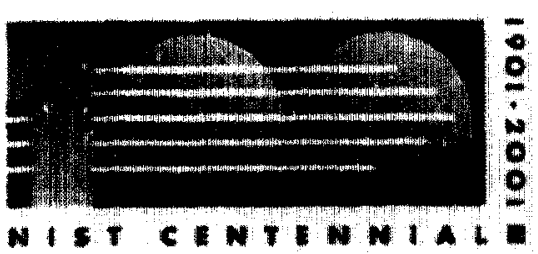





\section{Mechanical Properties of High-Strength Concrete at Elevated Temperatures}

Long T. Phan

Nicholas J. Carino

March 2001

Building and Fire Research Laboratory

National Institute of Standards and Technology

Gaithersburg, MD 20899

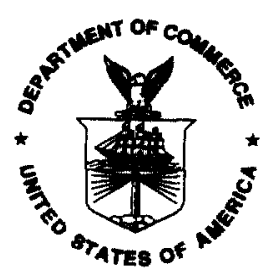

U.S. Department of Commerce

Donald L. Evans, Secretary

National Institute of Standards and Technology

Karen H. Brown, Acting Director 



\begin{abstract}
This report describes results of NIST's experimental program on the effects of elevated temperature exposure on the mechanical properties of high strength concrete (HSC). Mechanical properties were measured by heating, with and without preload, the $100 \mathrm{~mm}$ $x 200 \mathrm{~mm}$ HSC cylinders to different target temperatures, and loading them to failure while hot or after the specimens had cooled to room temperature. The specimens were heated at a slow heating rate of $5{ }^{\circ} \mathrm{C} / \mathrm{min}$ to prevent large thermal gradients. The maximum target temperature was $600^{\circ} \mathrm{C}$. The test specimens were made of four HSC mixtures with water-cementitious material ratios $(w / \mathrm{cm})$ ranging from 0.22 to 0.57 , and room-temperature compressive strength at time of testing ranging from $51 \mathrm{MPa}$ to 93 $\mathrm{MPa}$. Two of the four HSC mixtures contained silica fume. Experimental results indicate that HSC with lower $w / \mathrm{cm}$ and with silica fume have higher relative residual strength after elevated temperature exposure than those with higher $w / \mathrm{cm}$ and without silica fume. The differences in relative modulus of elasticity are less significant. The tendency for explosive spalling, however, was greater in HSC specimens with lower $w / \mathrm{cm}$. An examination of the internal heating characteristics of the cylinders indicated that the loss of capillary and chemically bound water was more restricted in the mixtures that had the higher tendency for spalling.
\end{abstract}

Keywords: building technology; compressive strength; concrete; experiment, elastic modulus; explosive spalling; fire; high-strength concrete; temperature. 


\section{Table of Contents}

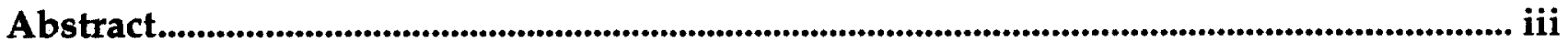

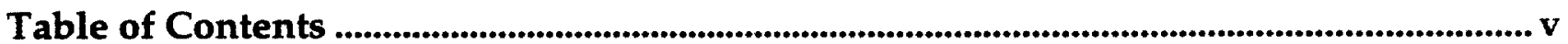

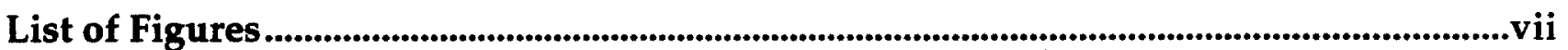

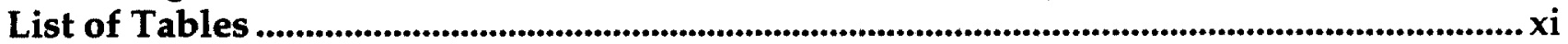

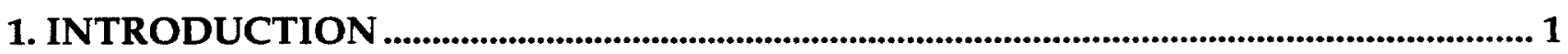

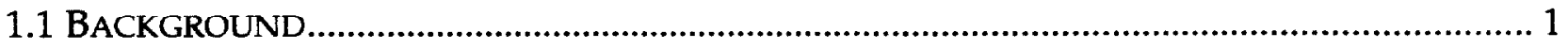

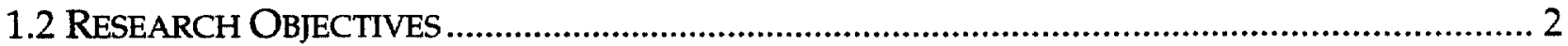

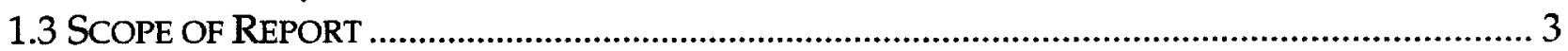

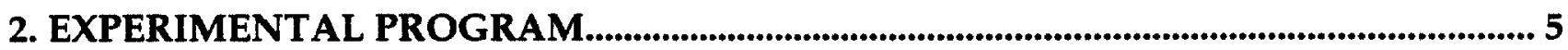

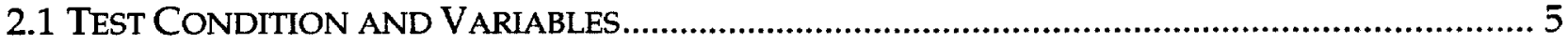

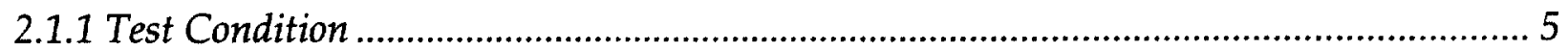

2.1.2 Test Variables ..................................................................................................... 5

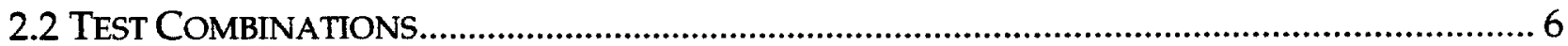

2.3 CONCRETE MAterials AND MixtUre ProportionS...................................................... 9

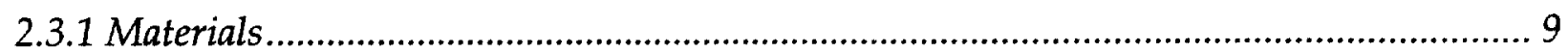

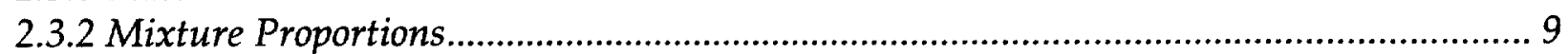

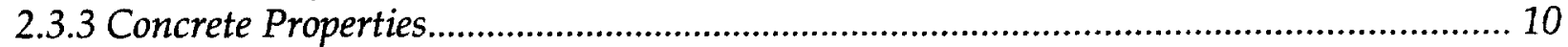

2.4 SPECIMEN PREPARATION AND INSTRUMENTATION ................................................... 13

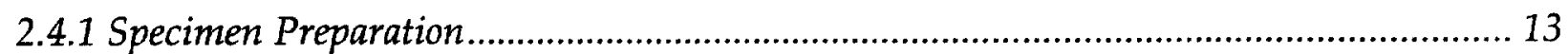

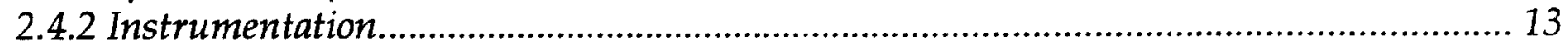

2.5 TEST METHODS, TEST SETUP, AND TEMPERATURE CONTROL ......................................... 14

2.5.1 Test Methods .................................................................................................. 14

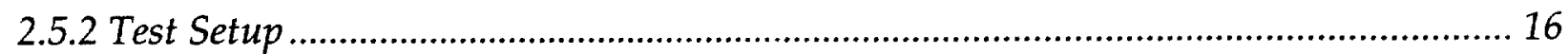

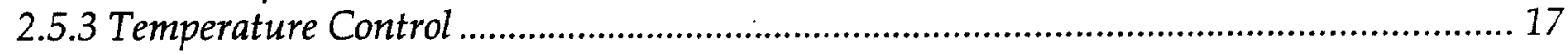

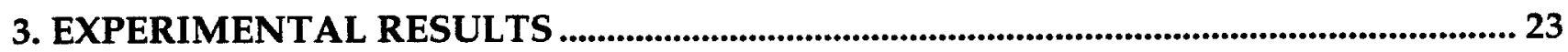

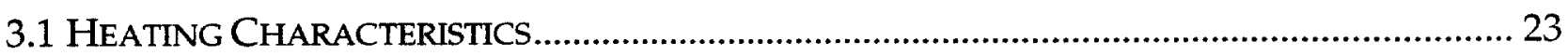

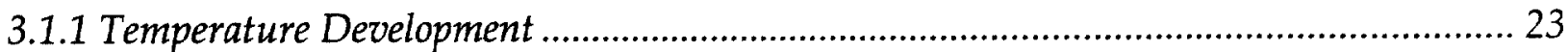

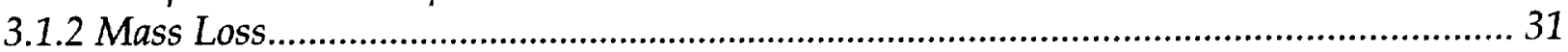

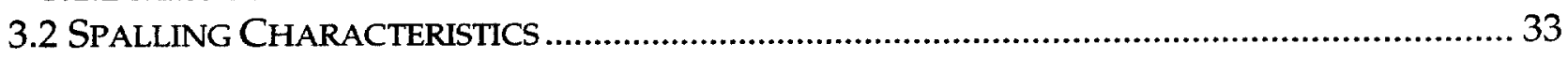

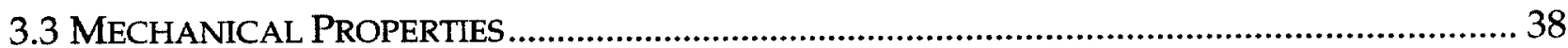

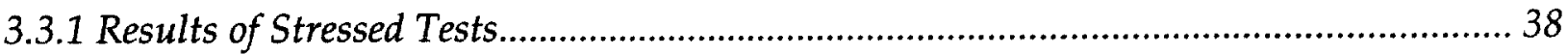

3.3.2 Results of Unstressed Tests ................................................................................. 44

3.3.3 Results of Unstressed Residual Property Tests .................................................. 50

3.4 EFFECTS OF TEST METHODS, w/CM, AND SILICA FUME ................................... 58

3.4.1 Effect of test methods .......................................................................................... 58

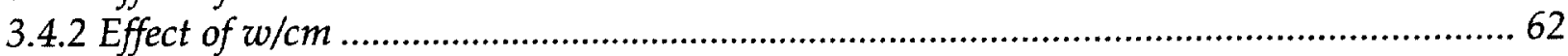

3.4.3 Effect of silica fume ...................................................................................... 64

4. COMPARISON OF NIST TEST RESULTS WITH OTHERS AND CODES............... 65 


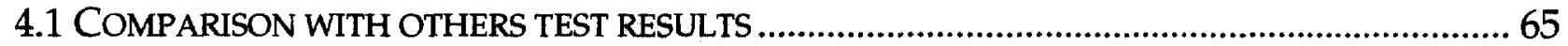

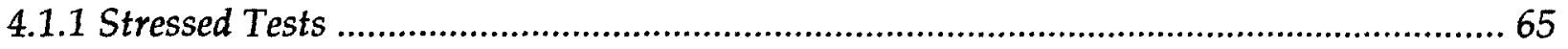

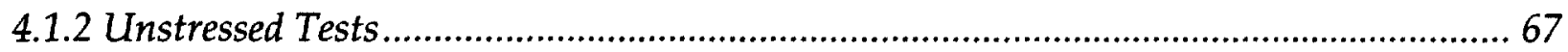

4.1.3 Unstressed Residual Property Tests............................................................................ 70

4.2 COMPARISONS OF TEST RESULTS WITH CODES ............................................................. 72

4.2.1 Comparisons with the Eurocode and CEB ............................................................... 73

4.2.2 Comparison with the Finnish Code .............................................................................. 74

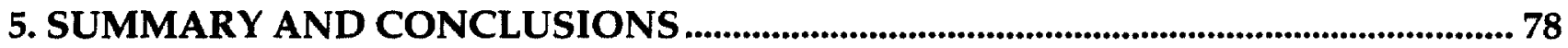

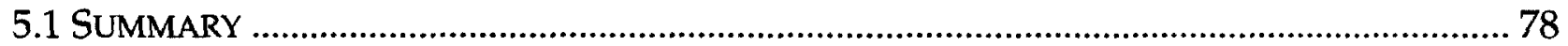

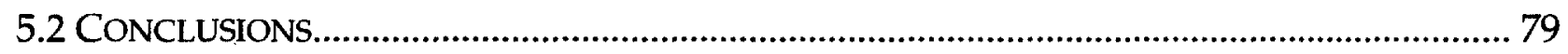

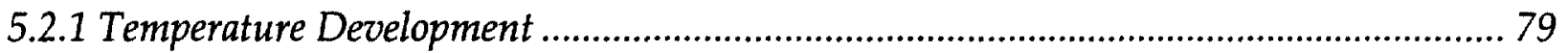

5.2.2 Effect of Test Method .................................................................................................. 79

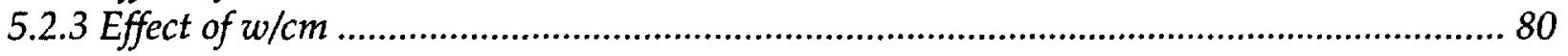

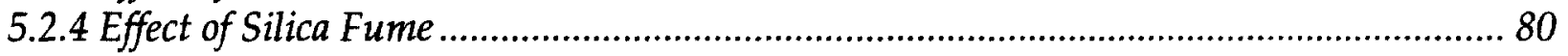

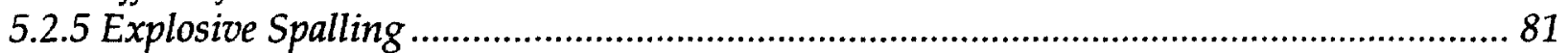

5.2.6 Comparison with Code Provisions ............................................................................ 81

6. ACKNOWLEDGEMENTS ......................................................................................................... 83

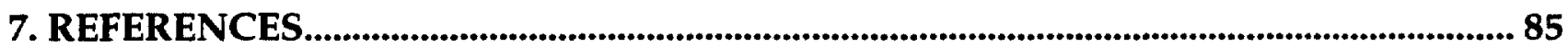

8. APPENDIX 


\section{List of Figures}

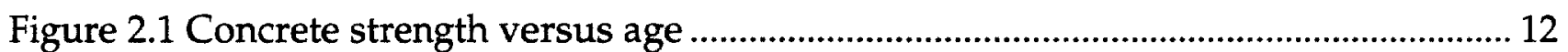

Figure 2.2 Dynamic Young's modulus of elasticity versus age .............................................. 12

Figure 2.3 End of Specimen after Grinding ............................................................................ 13

Figure 2.4 Specimen instrumented with thermocouples.......................................................... 13

Figure 2.5 Specimen dimensions and locations of thermocouples ....................................... 14

Figure 2.6 Schematic of temperature and loading histories for the three test methods....... 15

Figure 2.7 Picture of stressed and unstressed test setup .......................................................... 16

Figure 2.8 Schematic of stressed and unstressed test setup ...................................................... 16

Figure 2.9 Finite element modeling of heating of concrete cylinder..................................... 19

Figure 2.10 Calculated specimen temperature at steady-state as a function of

ambient furnace temperature.................................................................................................. 20

Figure 2.11 Temperature development in Mixture I cylinder, heated at $5^{\circ} \mathrm{C} / \mathrm{min}$............. 21

Figure 2.12 Temperature difference between surface and center of cylinder, heated

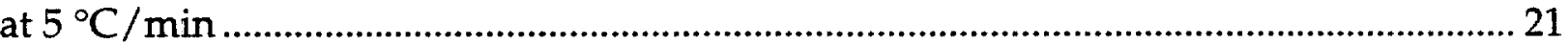

Figure 3.1 (a) Temperature development in Mixture I cylinder, heated at $5^{\circ} \mathrm{C} / \mathrm{min}$............ 26

Figure 3.1 (b) Temperature difference between surface and center of Mixture I

cylinder, heated at $5{ }^{\circ} \mathrm{C} / \mathrm{min}$

Figure 3.1 Schematics of rate of temperature rise at surface and center of cylinder:

(c) in the absence of moisture-induced perturbations

(d) with moisture-induced perturbations 27

Figure 3.2 (a) Temperature development in Mixture II cylinder, heated at $5{ }^{\circ} \mathrm{C} / \mathrm{min}$......... 28

Figure 3.2 (b) Temperature difference between surface and center of Mixture II

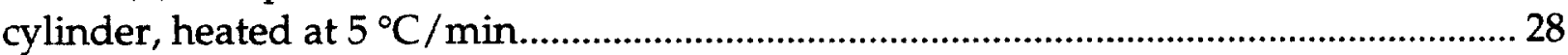

Figure 3.3 (a) Temperature development in Mixture III cylinder, heated at $5{ }^{\circ} \mathrm{C} / \mathrm{min}$........ 29

Figure 3.3 (b) Temperature difference between surface and center of Mixture III

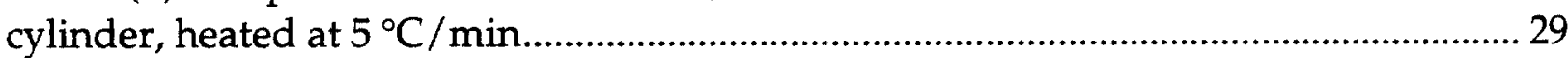

Figure 3.4 (a) Temperature development in Mixture IV cylinder, heated at $5{ }^{\circ} \mathrm{C} / \mathrm{min} \ldots \ldots . .30$

Figure 3.4 (b) Temperature difference between surface and center of Mixture IV

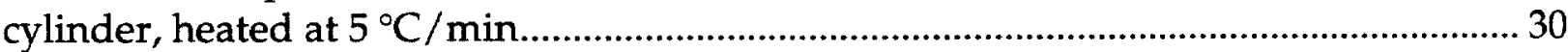

Figure 3.5 Mass losses from TGA.......................................................................................... 32

Figure 3.6 Mass losses from heating of full cylinders, shading represents initial free water

moisture content of concrete mixtures ...................................................................... 32

Figure 3.7 (a) Sequence of steps leading to fire induced spalling (reproduced after

Consolazio, McVay, and Rish [31]) ...................................................................................... 33

Figure 3.7 (b) Remnants of an exploded cylinder and rendering of the fracture................... 34

Figure 3.8 Core temperature and time ranges of observed explosive spalling in mixture I

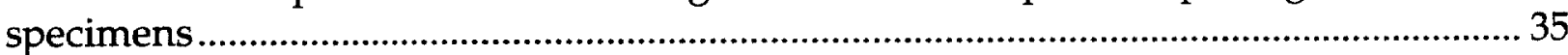

Figure 3.9 Range of temperature difference when explosive spalling occurred.................... 35

Figure 3.10(a) Compressive strengths as function of target temperatures under stressed test 
Figure 3.10(b) Relative compressive strengths as function of target temperature under

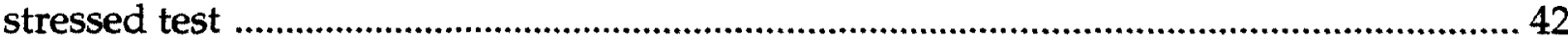

Figure 3.11(a) Young's modulus of elasticity as function of target temperatures under stressed test.

Figure 3.11(b) Relative Young's modulus of elasticity as function of target temperatures under unstressed test..

Figure 3.12(a) Compressive strengths as function of target temperatures under unstressed test.

Figure 3.12(b) Relative compressive strengths as function of target temperatures under unstressed test

Figure 3.13(a) Young's modulus of elasticity as function of target temperatures under unstressed test

Figure 3.13(b) Relative Young's modulus of elasticity as function of target temperatures under unstressed test.

Figure 3.14(a) Compressive strengths as function of target temperatures under unstressed residual property test

Figure 3.14(b) Relative compressive strengths as function of target temperatures under unstressed residual property test

Figure 3.15(a) Young's modulus of elasticity as function of target temperatures under unstressed residual property test

Figure 3.15(b) Relative Young's modulus of elasticity as function of target temperatures under unstressed residual property test.......................................................56

Figure 3.16 Relative strength versus test method for exposure temperatures of $100^{\circ} \mathrm{C}, 200^{\circ} \mathrm{C}, 300^{\circ} \mathrm{C}$, and $450^{\circ} \mathrm{C}$

Figure 3.17 Relative strength versus $w / \mathrm{cm}$ for exposure temperatures of $100^{\circ} \mathrm{C}, 200^{\circ} \mathrm{C}, 300^{\circ} \mathrm{C}$, and $450^{\circ} \mathrm{C}$

Figure 4.1 NIST Stressed Test Results versus Others' 66

Figure 4.2 NIST Unstressed Test Results versus Others'

Figure 4.3 NIST Unstressed Residual Property Test Results versus Others'......................... 71

Figure 4.4 Comparison of stressed test results versus the Eurocode and CEB ...................... 73

Figure 4.5 Comparison of stressed test results versus the Finnish Code ................................. 75

Figure 4.6 Comparison of unstressed test results versus the Finnish Code .......................... 77 


\section{List of Tables}

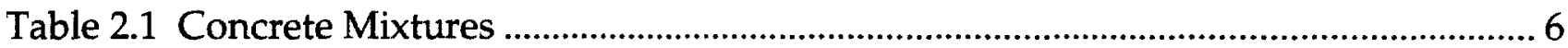

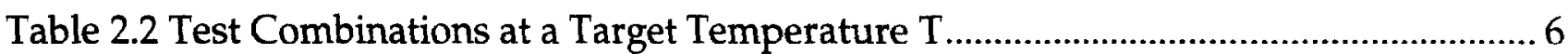

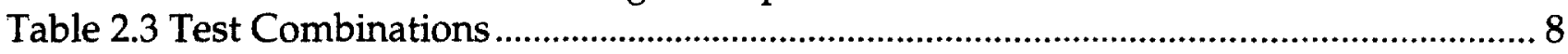

Table 2.4 Properties of Aggregates and Silica Fumes ……................................................... 9

Table 2.5 Concrete Mixture Proportions .............................................................................. 10

Table 2.6 Properties of Fresh and Hardened Concretes........................................................ 11

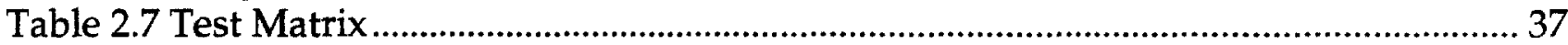

Table 3.1 Summary of Stressed Test Results ........................................................................... 40

Table 3.2 Summary of Unstressed Test Results ........................................................................46

Table 3.3 Summary of Residual Property Test Results .............................................................. 53

Table 3.4 Analysis of variance table of relative strength for exposure to

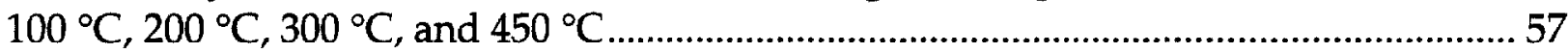

Table 3.5 Summary of relative strength values as a function of exposure

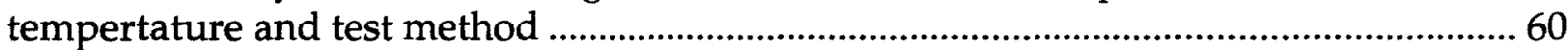

Table 3.6 Relative strength as a function of $w / \mathrm{cm}$ and test method.....................................61

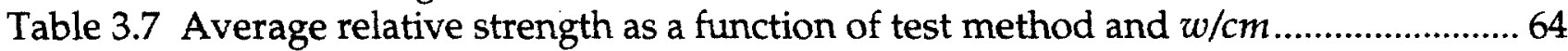

Table A.1 Data for Dynamic Modulus of Elasticity of Stressed Test Specimens ................... 89

Table A.2 Data for Dynamic Modulus of Elasticity of Unstressed Test Specimens ............. 91

Table A.3 Data for Dynamic Modulus of Elasticity of Residual Property Test Specimens. 93 


\section{INTRODUCTION}

\subsection{Background}

As a result of studies on the effects of elevated temperature exposure on engineering properties of concrete $[1,4,10-19,21-24,27-28,30]$, it has been concluded that the behavior of high-strength concrete (HSC) at high temperature differs from the behavior of normalstrength concrete (NSC) under the same heating condition. A recent review of the stateof-the-art on fire performance of HSC $[25,26]$ identified two main differences between HSC and NSC at elevated temperature: (1) the difference in heat-induced relative strength loss in the intermediate temperature range $\left(100^{\circ} \mathrm{C}\right.$ to $\left.400^{\circ} \mathrm{C}\right)$ and (2) the occurrence of explosive spalling failure in $\mathrm{HSC}$ specimens at similar temperatures $\left(200^{\circ} \mathrm{C}\right.$ to $\left.400^{\circ} \mathrm{C}\right)$.

In terms of strength loss, experimental results $[25,26]$ have shown that, in the intermediate temperature range of between $100^{\circ} \mathrm{C}$ and $400^{\circ} \mathrm{C}$ (this temperature range is considered "intermediate" because concrete's mechanical properties have been shown to be continually reduced with temperatures up to $800^{\circ} \mathrm{C}$ ), HSC's compressive strength could be reduced by close to $40 \%$ of the original, room-temperature strength - a reduction of approximately $20 \%$ to $30 \%$ larger than in NSC exposed to the same heating condition. More over, based on the limited amount of experimental data available to date, it has been found that this strength loss varied with a number of factors, including the combinations of loading and heating regimes (stressed test, unstressed test, and unstressed residual property test), the heating rates, original compressive strength, porosity or permeability which can vary with the use of silica fume, the types of aggregate (normal weight calcareous and siliceous, or lightweight), and moisture content.

In terms of explosive spalling, HSC, which is achieved typically by using a low watercementitious material $(w / \mathrm{cm})$ ratio and silica fume and thus possesses higher cementitious material content and lower permeability than NSC, has been experimentally observed, albeit inconsistently, to have a significantly higher potential for sudden, explosive spalling failure even when heated at a much slower heating rate $\left(1{ }^{\circ} \mathrm{C} / \mathrm{min}\right.$ to $\left.5{ }^{\circ} \mathrm{C} / \mathrm{min}\right)$ than that generated by a real fire $[4,10-12,15-19,27]$.

The behavioral differences between HSC and NSC at elevated temperatures have certain design implications and raise questions about the applicability of current fire design provisions, such as those prescribed by the Eurocodes [6,7] and the Comités EuroInternational Du Beton [5], to HSC structures. Since most of existing provisions are based on experience with NSC $[25,26]$, the larger strength loss incurred by HSC in the intermediate temperature range compared with NSC means that these design provisions are unconservative when applied to HSC. Furthermore, the tendency for explosive spalling failure associated with HSC means that HSC structural elements may be more susceptible than NSC to losing the concrete cover that provides thermal protection for the 
steel reinforcement. None of the current codes addresses the tendency for explosive spalling of HSC.

Given the many benefits of HSC, and its increased usage in structural applications, it is essential that the fundamental behavior of $\mathrm{HSC}$ at elevated temperatures is understood to ensure that structural fire design involving HSC will be safe. Thus, this research program aims to develop an understanding of the effects of elevated temperature exposure on the mechanical behavior and spalling potential of HSC. This program is part of a broader effort at NIST called Partnership for High Performance Concrete Technology (PHPCT), which is under the management of the Building Materials Division of the Building and Fire Research Laboratory. The goal of the PHPCT is to enable reliable application of High Performance Concrete inbuildings and civil infrastructures by developing, demonstrating, and providing assistance in implementing HYPERCON, a computer-integrated knowledge system (CIKS) incorporating verified multi-attribute model for predicting and optimizing the performance and life-cycle cost of High Performance Concrete. This report describes the results of phase I of the NIST research program, which deals with measurements of effects of elevated temperatures on engineering properties and potential for explosive spalling of HSC. In phase II, it is planned to use the measurements in phase I to provide the basis for developing analytical models for predicting the variation in engineering properties as a function of temperature and the occurrence of explosive spalling of HSC.

\subsection{Research Objectives}

Understanding the performance characteristics of HSC when exposed to high temperature is an important first step in maintaning adequate structural capacity in the event of fire, which is the long-term goal of this project. To achieve this long-term goal, this experimental program aims to develop experimental data for accurate characterization of the behavior of HSC when subjected to fire, including an understanding of the explosive spalling failure mechanism. These data can also be used for the validation of predictive models, which account for pore vapor pressure development and the moisture transport in HSC, and the sudden spalling failure mechanism of HSC. Thus, the overall research program aims to achieve the following objectives:

- To measure and evaluate the performance of HSC at elevated temperature.

- To use the measurements to support development of a Fire Endurance Model for predicting the structural performance of HSC structures at elevated temperature.

- To develop an understanding of spalling mechanism and methods to mitigate spalling in HSC.

- To develop draft standard provisions to account for the effect of fire on strength of HSC structural elements. 


\subsection{Scope of Report}

This report describes the first phase of the NIST experimental program on the fire performance of HSC and provides results of measurements on the effects of elevated temperature exposure on mechanical properties and explosive spalling of four HSC mixtures made with conventional concrete materials. The report also provides comparisons of NIST's measurements with results of other experiments and with relevant existing building code provisions. Chapter 2 describes the overall experimental program. Chapter 3 presents results of the measurements. Chapter 4 compares NIST's test results with results of other studies and with fire design provisions in current codes. Chapter 5 provides a summary of the experimental program and a discussion pertaining to the findings obtained from this study. 


\section{EXPERIMENTAL PROGRAM}

\subsection{Test Condition and Variables}

\subsubsection{Test Condition}

All elevated temperature tests are performed following the steady-state temperature test condition. For this study, "steady state" is defined as the temperature state when the temperature at the center of the specimen is within $10^{\circ} \mathrm{C}$ of the preselected target temperature $\mathrm{T}$ and the difference between the surface and center temperatures of the concrete specimen is less than $10^{\circ} \mathrm{C}$. Under this test condition, the ambient temperature is increased to a target temperature $T$ using a constant furnace heating rate (rate of temperature rise inside the furnace). The ambient temperature is then held constant at $T$ for a period of time $t$ until it is determined that the steady-state temperature is reached at the core of the specimen. The specimen is subsequently either loaded to failure in uniaxial compression at elevated temperature to obtain mechanical properties at elevated temperature $\mathrm{T}$, or allowed to cool to room temperature by natural cooling and then loaded to failure to obtain residual mechanical properties. The steady-state test condition provides property data associated with a controlled temperature exposure and allows the material properties of different concretes to be studied. It eliminates the complicating effect of differential thermally-induced stresses.

Temperatures of $100{ }^{\circ} \mathrm{C}, 200{ }^{\circ} \mathrm{C}, 300^{\circ} \mathrm{C}, 450{ }^{\circ} \mathrm{C}$, and $600{ }^{\circ} \mathrm{C}$ are selected as the target temperatures $\mathrm{T}$, and a furnace heating rate of $5{ }^{\circ} \mathrm{C} / \mathrm{min}$ is used for all tests. Properties measured at $25^{\circ} \mathrm{C}$ (room temperature) are used as reference values.

\subsubsection{Test Variables}

Effects of the following three test variables on properties of HSC at elevated temperature are studied:

1. Test methods: Three test methods, representing three thermomechanical loading combinations of the steady-state temperature condition, are examined. These test methods include the stressed test, the unstressed test, and the unstressed residual property test. Detailed descriptions of these three test methods are given in section 2.5.1.

2. $w / \mathrm{cm}$ ratios (or implicitly compressive strength): Three $w / \mathrm{cm}$ ratios $-0.22,0.33$, and 0.57 are examined.

3. Silica fume (or implicitly paste density): Two amounts of silica fume are studied: $0 \%$ and $10 \%$, used as cement replacement by mass.

The effects of $w / \mathrm{cm}$ ratio, compressive strength, and silica fume are interdependent, and are examined using four concrete mixtures, which are hereafter coded as mixtures I, II, III, 
and IV. For convenience, key parameters associated with each mixture are shown in Table 2.1.

Table 2.1 Concrete Mixtures

\begin{tabular}{|c|c|c|c|c|}
\hline Batgat & 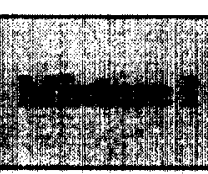 & 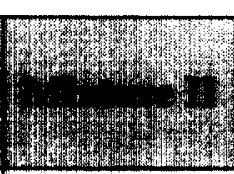 & 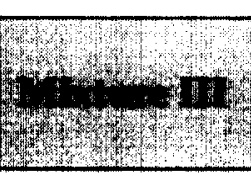 & 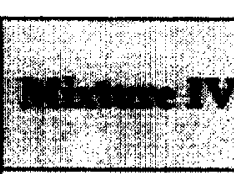 \\
\hline$w / c m$ & 0.22 & 0.33 & 0.33 & 0.57 \\
\hline $\begin{array}{l}\text { silica fume (\% cement } \\
\text { replacement by mass) }\end{array}$ & 10 & 10 & - & - \\
\hline
\end{tabular}

\subsection{Test Combinations}

Table 2.2 shows the 12 test combinations that were used to examine of the effects of the 4 concrete mixtures (which entails $3 \mathrm{w} / \mathrm{cm}$ ratios, 4 compressive strength levels, and 2 levels of silica fume), and the 3 steady-state test methods on mechanical properties of HSC for a target temperature $T$. For convenience, the test methods will be coded as $(+)$ for stressed test, $(-)$ for unstressed test, and ( 0 ) for unstressed residual properties test.

Table 2.2 Test Combinations at a Target Temperature $T$

\begin{tabular}{|c|c|c|}
\hline Combint & Mroterse & Thatheritiod \\
\hline 1 & I & + \\
\hline 2 & II & + \\
\hline 3 & III & + \\
\hline 4 & IV & + \\
\hline 5 & $\mathrm{I}$ & - \\
\hline 6 & II & - \\
\hline 7 & III & - \\
\hline 8 & IV & - \\
\hline 9 & I & 0 \\
\hline 10 & II & 0 \\
\hline 11 & III & 0 \\
\hline 12 & IV & 0 \\
\hline
\end{tabular}
$(+)=$ stressed test
$(-)=$ unstressed test
$(0)=$ unstressed residual property test 
For each test combination shown in Table 2.2, a minimum of three specimens are tested at the target temperature $T$ and one replication will be tested at room temperature. These test combinations facilitate the following comparisons:

- For the effect of silica fume:

Test combination: 2 vs. $3 \quad 1$ comparison under stressed test method

Test combination: 6 vs. $7 \quad 1$ comparison under unstressed test method

Test combination: 10 vs. 11 comparison under unstressed residual properties test method

- For the effect of $w / \mathrm{cm}$ ratio:

Test combination: 1 vs. 2 comparisons of test specimens with silica fume 5 vs. 6

9 vs. 10

Test combination: 3 vs. 4 7 vs. 8 11 vs. 12

- For the effect of test methods:

Test combination: 1 vs. 5 vs. 9
2 vs. 6 vs. 10
3 vs. 7 vs. 11
4 vs. 8 vs. 12

- For the effect of compressive strength:

Test number: 1 vs. $\operatorname{Avg}(2,3)$ vs. 4 5 vs. $\operatorname{Avg}(6,7)$ vs. 8

9 vs. $\operatorname{Avg}(10,11)$ vs. 12

6 comparisons under the $5^{\circ} \mathrm{C} / \mathrm{min}$ heating rate

Table 2.2 shows 12 test combinations for each of the five target temperature $\mathrm{T}$. For all five target temperatures $\left(100^{\circ} \mathrm{C}, 200^{\circ} \mathrm{C}, 300^{\circ} \mathrm{C}, 450^{\circ} \mathrm{C}\right.$, and $\left.600{ }^{\circ} \mathrm{C}\right)$, there are 60 test combinations. In addition, 4 test combinations are needed as control tests at room temperature. Comparing data at different temperature levels will provide relationships for mechanical properties of HSC versus temperature. Table 2.3 shows the 4 control test combinations plus the 60 elevated temperature test combinations planned for this test program. 
Table 2.3 Test Combinations

\begin{tabular}{|c|c|c|c|}
\hline 1 & & & 25 \\
\hline 2 & $\overline{\mathbf{H}}$ & & 25 \\
\hline 3 & III & & 25 \\
\hline 4 & IV & & 25 \\
\hline 5 & $\mathrm{I}$ & + & $\overline{100}$ \\
\hline 6 & $\bar{I}$ & + & 100 \\
\hline 7 & III & $t$ & 100 \\
\hline 8 & $\overline{I V}$ & + & 100 \\
\hline 9 & I & - & 100 \\
\hline 10 & II & - & 100 \\
\hline 11 & III & - & 100 \\
\hline 12 & IV & - & 100 \\
\hline 13 & $\bar{I}$ & 0 & 100 \\
\hline 14 & II & 0 & 100 \\
\hline 15 & III & 0 & 100 \\
\hline 16 & $\overline{I V}$ & 0 & 100 \\
\hline 17 & I & + & 200 \\
\hline 18 & II & \pm & 200 \\
\hline 19 & III & \pm & 200 \\
\hline 20 & IV & 7 & 200 \\
\hline 21 & $I$ & 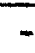 & 200 \\
\hline 22 & $\overline{\mathbf{I}}$ & - & 200 \\
\hline 23 & III & - & 200 \\
\hline 24 & $\mathbf{I V}$ & - & 200 \\
\hline 25 & $I$ & $\underline{0}$ & 200 \\
\hline 26 & II & 0 & 200 \\
\hline 27 & III & $\overline{0}$ & 200 \\
\hline 28 & IV & 0 & 200 \\
\hline 29 & I & + & 300 \\
\hline 30 & II & + & 300 \\
\hline 31 & III & + & 300 \\
\hline 32 & IV & + & 300 \\
\hline 33 & I & - & 300 \\
\hline
\end{tabular}

\begin{tabular}{|c|c|c|c|}
\hline 34 & II & - & 300 \\
\hline 35 & II & - & 300 \\
\hline 36 & IV & - & 300 \\
\hline 37 & I & 0 & 300 \\
\hline 38 & II & 0 & 300 \\
\hline 39 & III & 0 & 300 \\
\hline 40 & IV & 0 & 300 \\
\hline 41 & I & + & 450 \\
\hline 42 & II & + & 450 \\
\hline 43 & II & + & 450 \\
\hline 44 & IV & + & 450 \\
\hline 45 & I & - & 450 \\
\hline 46 & I & - & 450 \\
\hline 47 & III & - & 450 \\
\hline 48 & IV & - & 450 \\
\hline 49 & I & 0 & 450 \\
\hline 50 & II & 0 & 450 \\
\hline 51 & II & 0 & 450 \\
\hline 52 & IV & 0 & 450 \\
\hline 53 & I & + & 600 \\
\hline 54 & II & + & 600 \\
\hline 55 & III & + & 600 \\
\hline 56 & IV & + & 600 \\
\hline 57 & I & - & 600 \\
\hline 58 & II & - & 600 \\
\hline 59 & III & - & 600 \\
\hline 60 & IV & - & 600 \\
\hline 61 & I & 0 & 600 \\
\hline 62 & II & 0 & 600 \\
\hline 63 & III & 0 & 600 \\
\hline 64 & IV & 0 & 600 \\
\hline & & & \\
\hline
\end{tabular}

(+) Stressed test method.

(-) Unstressed test method.

(0) Unstressed residual properties test method. 


\subsection{Concrete Materials and Mixture Proportions}

\subsubsection{Materials}

All specimens were made using ASTM Type I portland cement, crushed limestone coarse aggregate (13 $\mathrm{mm}(1 / 2 \mathrm{in})$ nominal maximum size) with a finess modulus (FM) of 5.40 , natural sand fine aggregate with an FM of 2.85, silica fume, and a high range water-reducing admixture (HRWRA) based on sulfonated naphthalene. The silica fume is in the form of a slurry with a density of $1.42 \mathrm{~g} / \mathrm{cm}^{3}$ and a $54 \%$ silica fume concentration (mass fraction). Table 2.4 summarizes the properties of the aggregates and silica fume.

Table 2.4. Properties of Aggregates and Silica Fumes

\begin{tabular}{|c|c|c|c|}
\hline 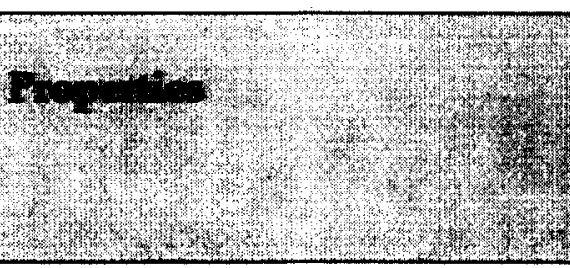 & 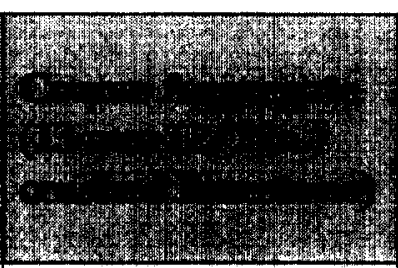 & 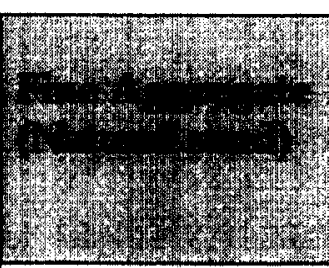 & $y^{2}$ \\
\hline Density & $\begin{array}{l}1520 \mathrm{~kg} / \mathrm{m}^{3(")} \\
\left(94.9 \mathrm{lb} / \mathrm{ft}^{3}\right)\end{array}$ & $\begin{array}{l}\left.1456 \mathrm{~kg} / \mathrm{m}^{3}()^{\circ}\right) \\
\left(90.9 \mathrm{lb} / \mathrm{ft}^{3}\right)\end{array}$ & $\begin{array}{l}1.42 \mathrm{~g} / \mathrm{cm}^{3} \\
\left(88.5 \mathrm{lb} / \mathrm{ft}^{3}\right)\end{array}$ \\
\hline Finess Modulus & 5.40 & 2.85 & \\
\hline Absorption (\%) & & 0.59 & \\
\hline Specific Gravity & 2.60 & 2.63 & 1.35 \\
\hline Solids Content (mass fraction) & & & 54 \\
\hline
\end{tabular}

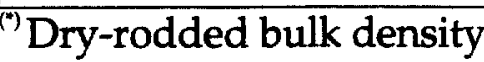

\subsubsection{Mixture Proportions}

Specimens were made from four concrete mixtures, designated mixtures I to IV. Mixture I had the lowest $w / \mathrm{cm}$ of 0.22 and contained $10 \%$ of silica fume by mass as cement replacement. Mixtures II and III had the same $w / \mathrm{cm}$ of 0.33 , and were designed to have similar strength but differ by the inclusion of silica fume (mixture II contained $10 \%$ of silica fume, while mixture III contained no silica fume). Mixture IV had the 
highest $w / \mathrm{cm}$ ratio of 0.57 and contained no silica fume. The mixture proportions for the four mixtures are shown in Table 2.5 .

Table 2.5 Concrete Mixture Proportions

\begin{tabular}{|c|c|c|c|c|}
\hline 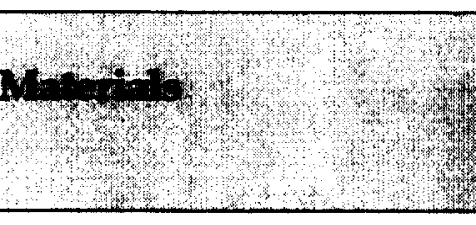 & 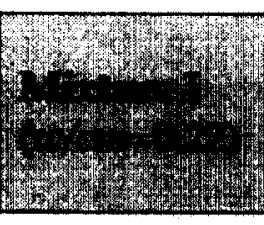 & (2) & 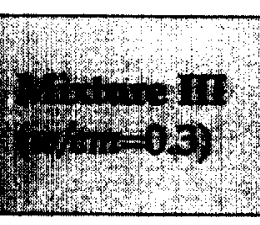 & (1) \\
\hline Cement & $\begin{array}{l}595.9 \mathrm{~kg} / \mathrm{m}^{3} \\
\left(37.2 \mathrm{lb} / \mathrm{ft}^{3}\right)\end{array}$ & $\begin{array}{l}595.9 \mathrm{~kg} / \mathrm{m}^{3} \\
\left(37.2 \mathrm{lb} / \mathrm{ft}^{3}\right)\end{array}$ & $\begin{array}{l}661.6 \mathrm{~kg} / \mathrm{m}^{3} \\
\left(41.3 \mathrm{lb} / \mathrm{ft}^{3}\right)\end{array}$ & $\begin{array}{l}376.4 \mathrm{~kg} / \mathrm{m}^{3} \\
\left(23.5 \mathrm{lb} / \mathrm{ft}^{3}\right)\end{array}$ \\
\hline Water & $\begin{array}{l}133.0 \mathrm{~kg} / \mathrm{m}^{3} \\
\left(8.3 \mathrm{lb} / \mathrm{ft}^{3}\right)\end{array}$ & $\begin{array}{l}198.6 \mathrm{~kg} / \mathrm{m}^{3} \\
\left(12.4 \mathrm{lb} / \mathrm{ft}^{3}\right)\end{array}$ & $\begin{array}{l}198.6 \mathrm{~kg} / \mathrm{m}^{3} \\
\left(12.4 \mathrm{lb} / \mathrm{ft}^{3}\right)\end{array}$ & $\begin{array}{l}213.0 \mathrm{~kg} / \mathrm{m}^{3} \\
\left(13.3 \mathrm{lb} / \mathrm{ft}^{3}\right)\end{array}$ \\
\hline $\begin{array}{l}\text { Coarse Aggregate } \\
\text { (13 mm (1/2 in) max. } \\
\text { crushed limestone, SSD) }\end{array}$ & $\begin{array}{l}845.8 \mathrm{~kg} / \mathrm{m}^{3} \\
\left(52.8 \mathrm{lb} / \mathrm{ft}^{3}\right)\end{array}$ & $\begin{array}{l}845.8 \mathrm{~kg} / \mathrm{m}^{3} \\
\left(52.8 \mathrm{lb} / \mathrm{ft}^{3}\right)\end{array}$ & $\begin{array}{l}845.8 \mathrm{~kg} / \mathrm{m}^{3} \\
\left(52.8 \mathrm{lb} / \mathrm{ft}^{3}\right)\end{array}$ & $\begin{array}{l}853.8 \mathrm{~kg} / \mathrm{m}^{3} \\
\left(53.3 \mathrm{lb} / \mathrm{ft}^{3}\right)\end{array}$ \\
\hline $\begin{array}{l}\text { Fine Aggregate } \\
(S S D)\end{array}$ & $\begin{array}{l}733.6 \mathrm{~kg} / \mathrm{m}^{3} \\
\left(45.8 \mathrm{lb} / \mathrm{ft}^{3}\right)\end{array}$ & $\begin{array}{l}733.6 \mathrm{~kg} / \mathrm{m}^{3} \\
\left(45.8 \mathrm{lb} / \mathrm{ft}^{3}\right)\end{array}$ & $\begin{array}{l}733.6 \mathrm{~kg} / \mathrm{m}^{3} \\
\left(45.8 \mathrm{lb} / \mathrm{ft}^{3}\right)\end{array}$ & $\begin{array}{l}868.2 \mathrm{~kg} / \mathrm{m}^{3} \\
\left(54.2 \mathrm{lb} / \mathrm{ft}^{3}\right)\end{array}$ \\
\hline Silica Fume & $\begin{array}{l}65.7 \mathrm{~kg} / \mathrm{m}^{3} \\
\left(4.1 \mathrm{lb} / \mathrm{ft}^{3}\right)\end{array}$ & $\begin{array}{l}65.7 \mathrm{~kg} / \mathrm{m}^{3} \\
\left(4.1 \mathrm{lb} / \mathrm{ft}^{3}\right)\end{array}$ & 0 & 0 \\
\hline HRWRA & $\begin{array}{l}400 \mathrm{~mL} \\
(13.5 \mathrm{oz})\end{array}$ & $\begin{array}{l}354 \mathrm{~mL} \\
(12.0 \mathrm{oz})\end{array}$ & $\begin{array}{l}154 \mathrm{~mL} \\
(5.2 \mathrm{oz})\end{array}$ & 0 \\
\hline
\end{tabular}

SSD = saturated surface dry condition

\subsubsection{Concrete Properties}

Properties of fresh and hardened concretes are summarized in Table 2.6. Initial moisture contents (IMC) represent the amount of free water in the concrete and were obtained by drying small concrete samples (400-day old samples) at $105^{\circ} \mathrm{C}$ until the difference in mass losses between measurements is negligible $(\leq 0.1 \%)$. Concrete roomtemperature strength and modulus of elasticity are measured periodically starting from 28 days after casting. The earliest specimens tested at elevated temperature were more 
than 200 days old, at which age the increases in strength and elastic modulus of all specimens have stabilized. Figures 2.1 and 2.2 show the development of compressive strength and elastic modulus of the four concrete mixtures.

Table 2.6 Properties of Fresh and Hardened Concretes

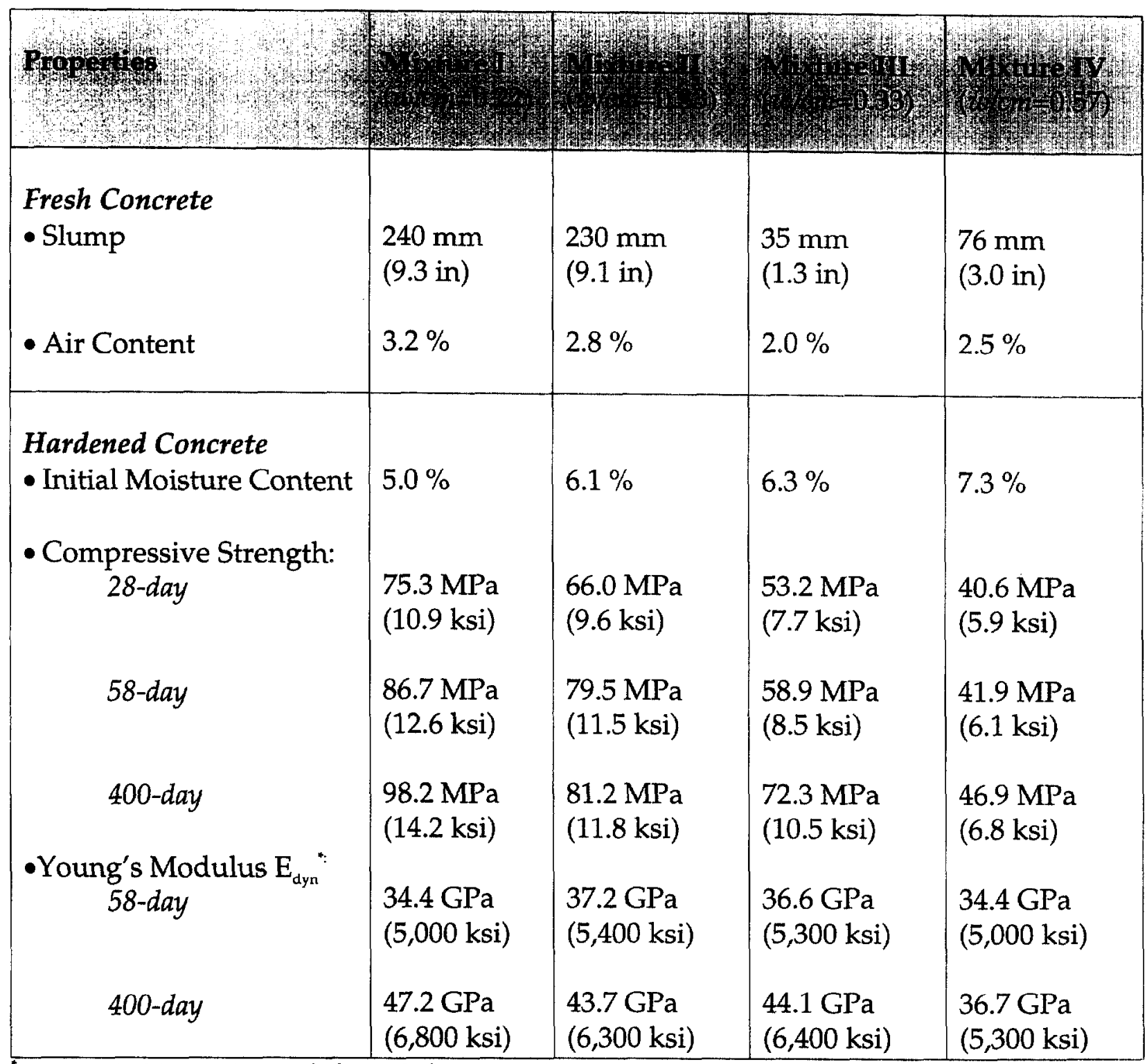

Dynamic Young's modulus of elasticity determined from the longitudinal resonant frequency using ASTM C 215. 


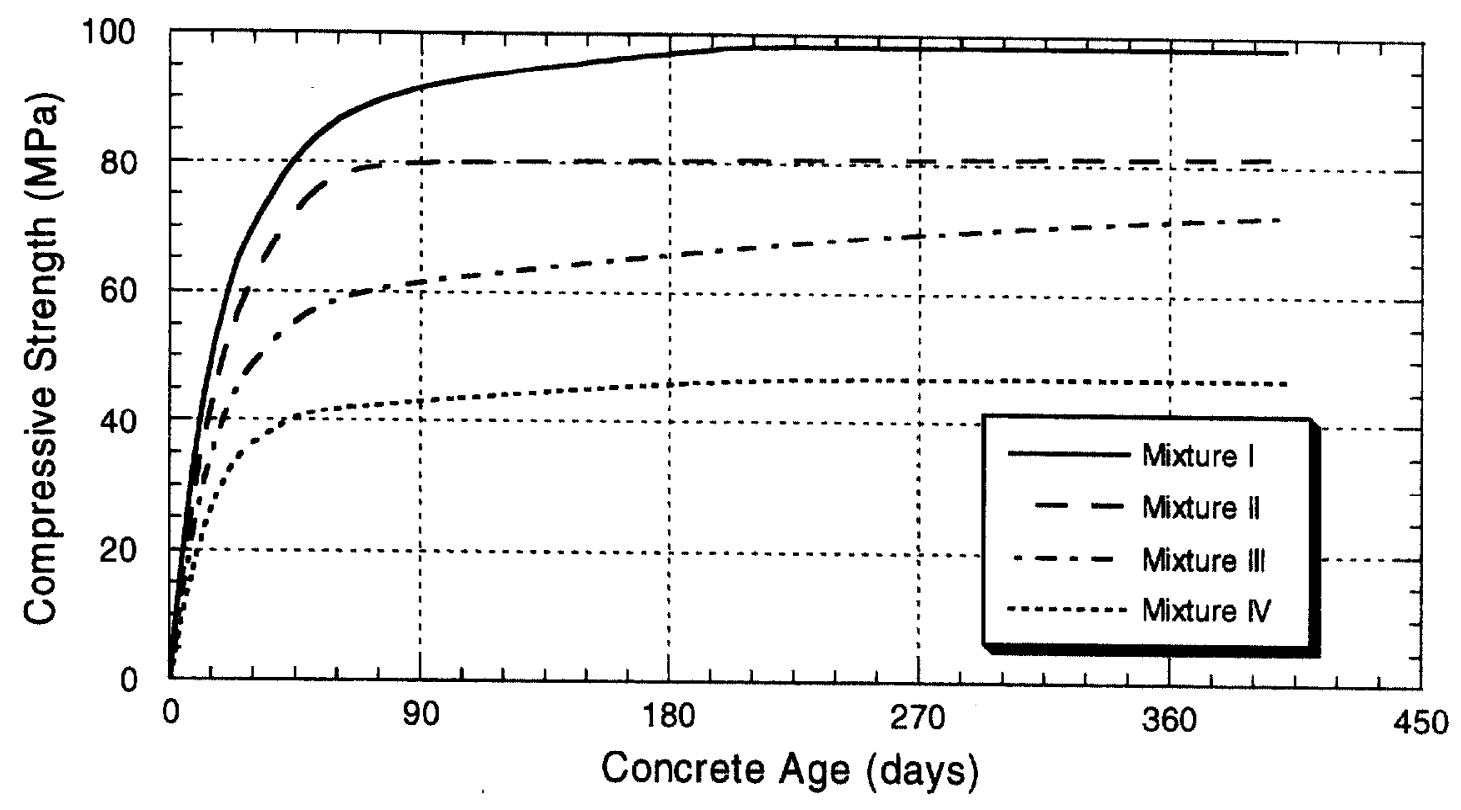

Figure 2.1 Concrete strength versus age

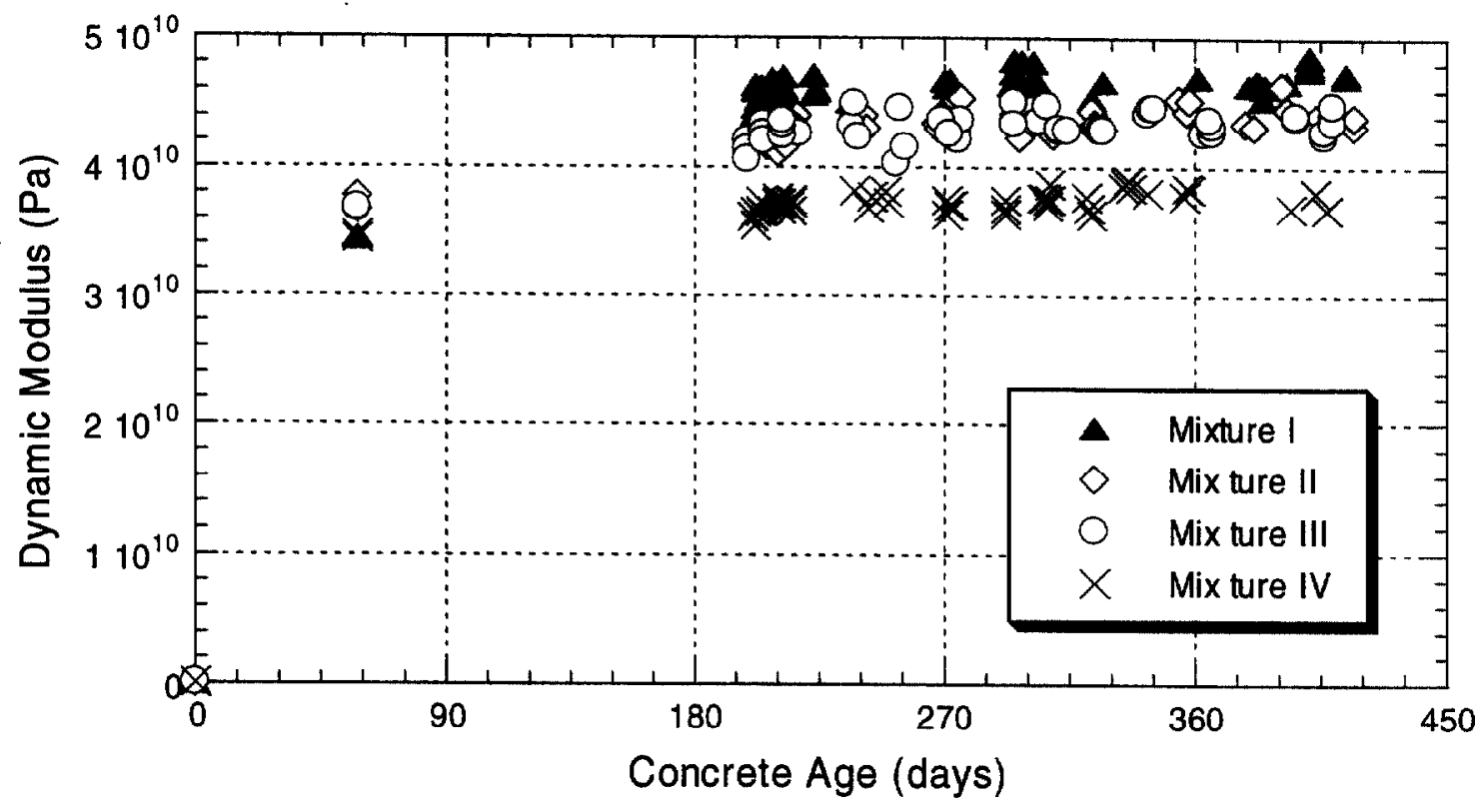

Figure 2.2 Dynamic Young's modulus of elasticity versus age 


\subsection{Specimen Preparation and Instrumentation}

\subsubsection{Specimen Preparation}

All test specimens were $100 \mathrm{~mm}$ by $200 \mathrm{~mm}$ (4 in by 8 in) cylinders. The specimens were removed from their molds one day after casting and were cured under water at room temperature (nominally $23^{\circ} \mathrm{C}$ ) until close to test time. About one week before testing, the specimens were removed from the curing tank and both ends of each specimen were ground to meet ASTM C 39 requirements for perpendicularity (ends are perpendicular to within $\pm 0.5^{\circ}$ relative to specimen's longitudinal axis) and planeness (all points on each end are plane within $0.050 \mathrm{~mm}(0.002 \mathrm{in})$ ). The ground specimens were then placed under water again until $1 \mathrm{~h}$ before testing. Figure 2.3 shows the end of a specimen after grinding.

\subsubsection{Instrumentation}

Two specimens from each concrete mixture were instrumented with three thermocouples to develop the internal temperature profiles on the cross section of the cylinders and establish the heating regimen (see Figures 2.4 and 2.5). One thermocouple was located at the center of the specimen ( $51 \mathrm{~mm}$ (2.0 in) from side surface and $100 \mathrm{~mm}$ (4.0 in) from ends). One was located midway between the center and the surface of the cylinder ( $25 \mathrm{~mm}$ (1.0 in) from side surface and $100 \mathrm{~mm}$ (4.0 in) from ends). The third thermocouple was attached to the surface at the midheight of the cylinder (100 $\mathrm{mm}$ (4.0 in.) from ends). The thermocouples were 20 -gage $(0.8 \mathrm{~mm})$ solid wire, type $K$ (nickel-chrome, nickel) with ceramic insulation. The thermocouples' maximum temperature is $980{ }^{\circ} \mathrm{C}$ with a specified limit of error of $\pm 2.2^{\circ} \mathrm{C}$ or $\pm 0.75 \%$ for temperature above $0{ }^{\circ} \mathrm{C}$. To place the two thermocouples that are located inside the specimen, two 6.4

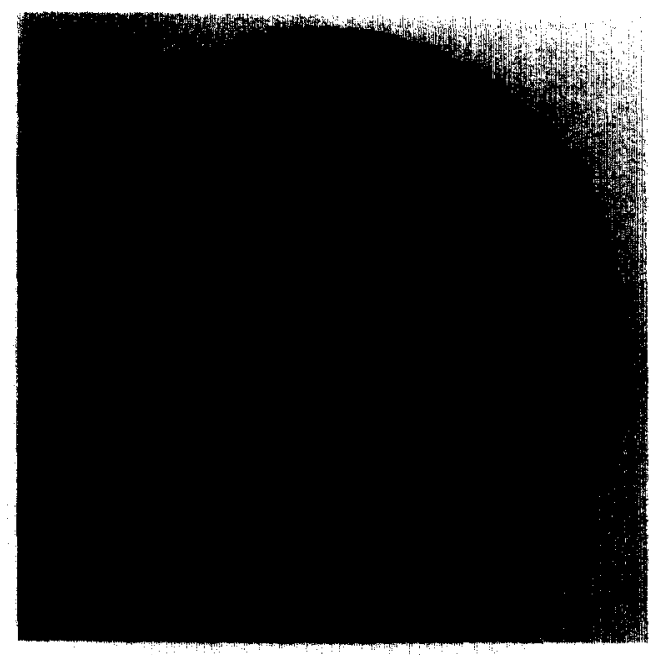

Figure 2.3 End of Specimen after Grinding

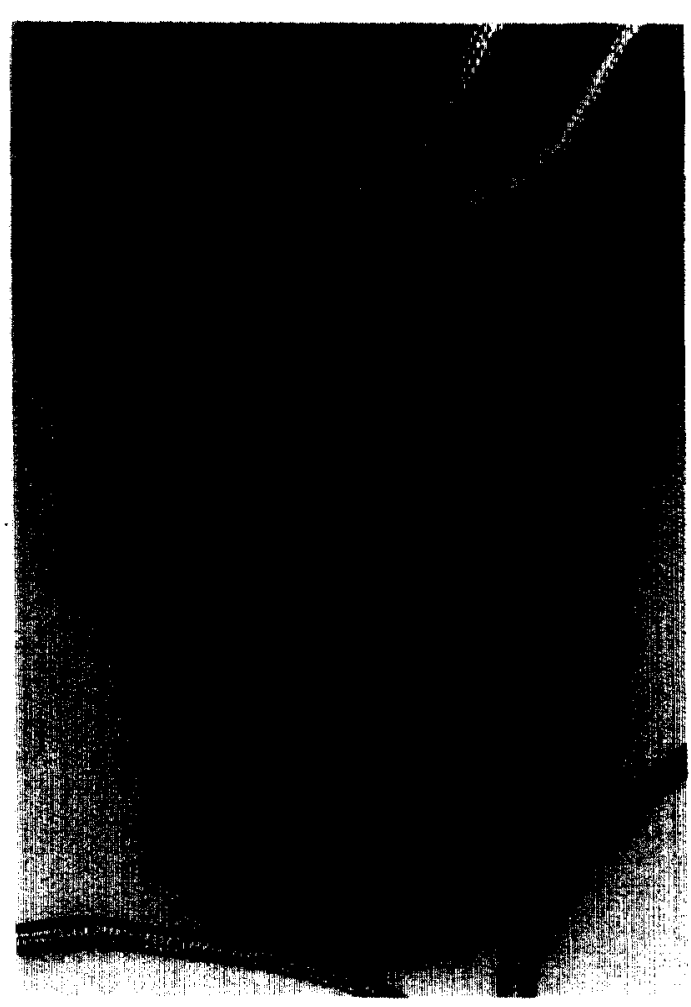

Figure 2.4 Specimen instrumented with thermocouples 
$\mathrm{mm}(1 / 4$ in) holes were drilled, within three days of testing, from one end to half the length of the specimen ( $100 \mathrm{~mm}$ ( $4.0 \mathrm{in})$ from end). The thermocouples were inserted into the holes, which were then filled with furnace cement. The surface thermocouple was kept attached to the concrete surface by using a high temperature wire to tie it in place.

The instrumented specimens were heated using a heating rate of $5^{\circ} \mathrm{C} / \mathrm{min}$. This heating rate refers to the temperature rise inside the furnace, and not the temperature rise inside the concrete specimen. The concrete temperatures were recorded and used to provide information for temperature control, i.e., the temperature exposure time, $t$, necessary for the specimen to attain the steady-state thermal condition. The steady-state thermal condition is defined in section 2.1 .1 as when the specimen core temperature is within $10^{\circ} \mathrm{C}$ of the target temperature $\mathrm{T}$ and the difference between the surface and core temperatures is less than $10^{\circ} \mathrm{C}$.

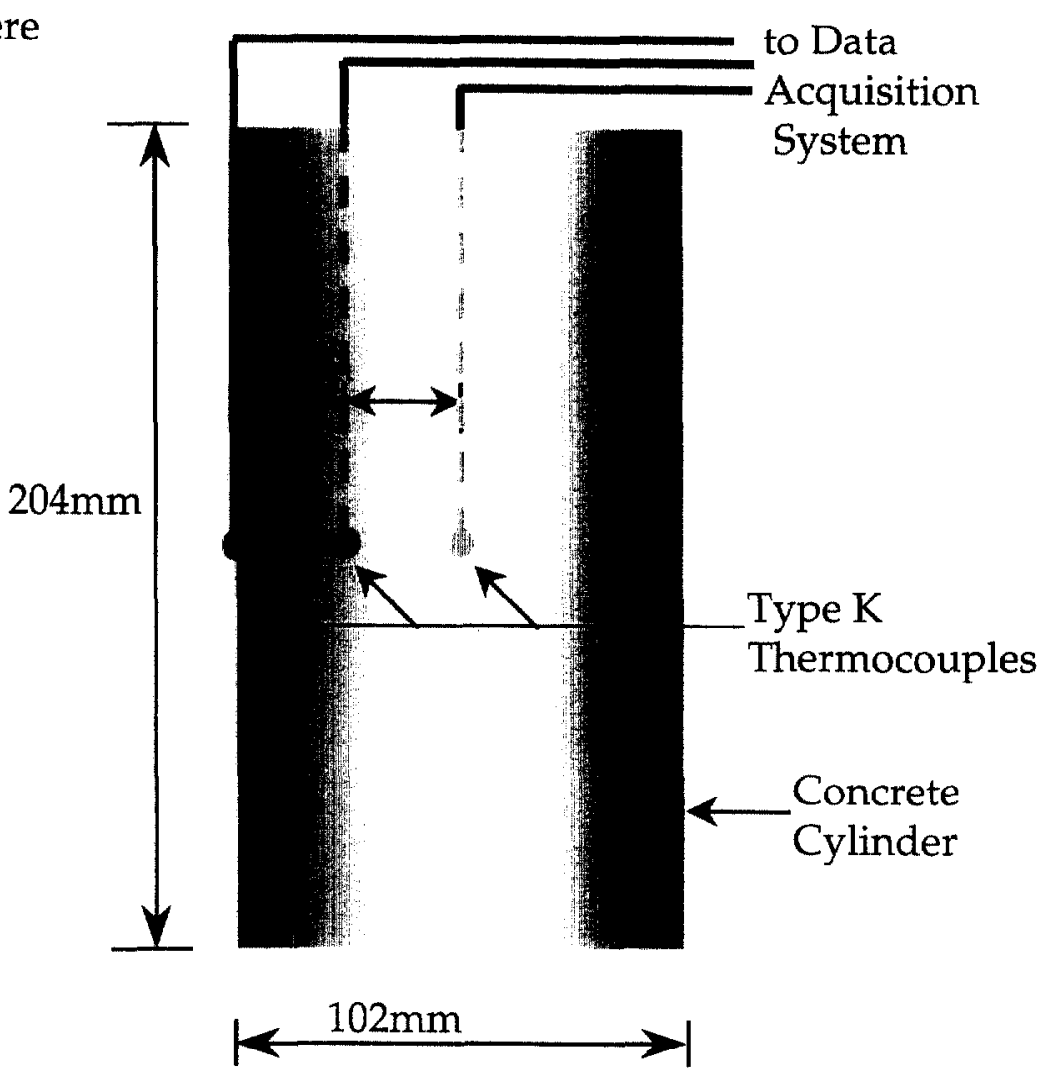

Figure 2.5 Specimen dimensions and location of thermocouples

\subsection{Test Methods, Test Setup, and Temperature Control}

\subsubsection{Test Methods}

As mentioned in section 2.1.2, three test methods, representing three thermomechanical loading conditions are used in this study. These are the stressed, unstressed, and unstressed residual property tests.

Figure 2.6(a) is a schematic showing stressed test method under a steady-state test condition. In this method, the specimen is subjected to a preload equal to $40 \%$ of the room-temperature concrete strength before heating. This preload is applied at a constant machine crosshead movement rate of $0.25 \mathrm{~mm} / \mathrm{min}(0.01 \mathrm{in} / \mathrm{min})$. The preload is maintained while the specimen is heated to the target core temperature $T$. The furnace temperature rise is maintained at $5{ }^{\circ} \mathrm{C} / \mathrm{min}$ until time $t$ when the target 
temperature $T$ is reached and a steady-state temperature is achieved. The specimen is then loaded to failure under uniaxial compression at a constant rate of machine crosshead movement of $0.25 \mathrm{~mm} / \mathrm{min}(0.01 \mathrm{in} / \mathrm{min})$.

Figure 2.6(b) is a schematic showing the unstressed test method. In this test method, the specimen is heated, without any external load, to the target temperature $\mathrm{T}$ using a furnace heating rate of $5{ }^{\circ} \mathrm{C} / \mathrm{min}$. The temperature is maintained at this target level until time $t$, when the steady-state temperature condition is achieved. The specimen is then loaded to failure under uniaxial compression at a constant rate of machine crosshead movement of $0.25 \mathrm{~mm} / \mathrm{min}(0.01 \mathrm{in} / \mathrm{min})$.

Figure 2.6(c) is a schematic showing the residual property test method. In this test method, the specimen is heated without loading to the target core temperature $\mathrm{T}$ using a constant furnace heating rate of $5{ }^{\circ} \mathrm{C} / \mathrm{min}$. The ambient temperature is then held constant for a period of time $t_{1}$ until it is determined that the steady-state temperature in the specimen has been reached. The specimen is then allowed to cool to room temperature by natural cooling (with furnace door opened), and then loaded to failure at room temperature under uniaxial compression at time $t_{2}$. The specimen is tested within $6 \mathrm{~h}$ of the concrete core attaining room temperature. The loading of the specimen follows the deformation control technique with a constant rate of machine crosshead movement of $0.25 \mathrm{~mm} / \mathrm{min}(0.01 \mathrm{in} / \mathrm{min})$.
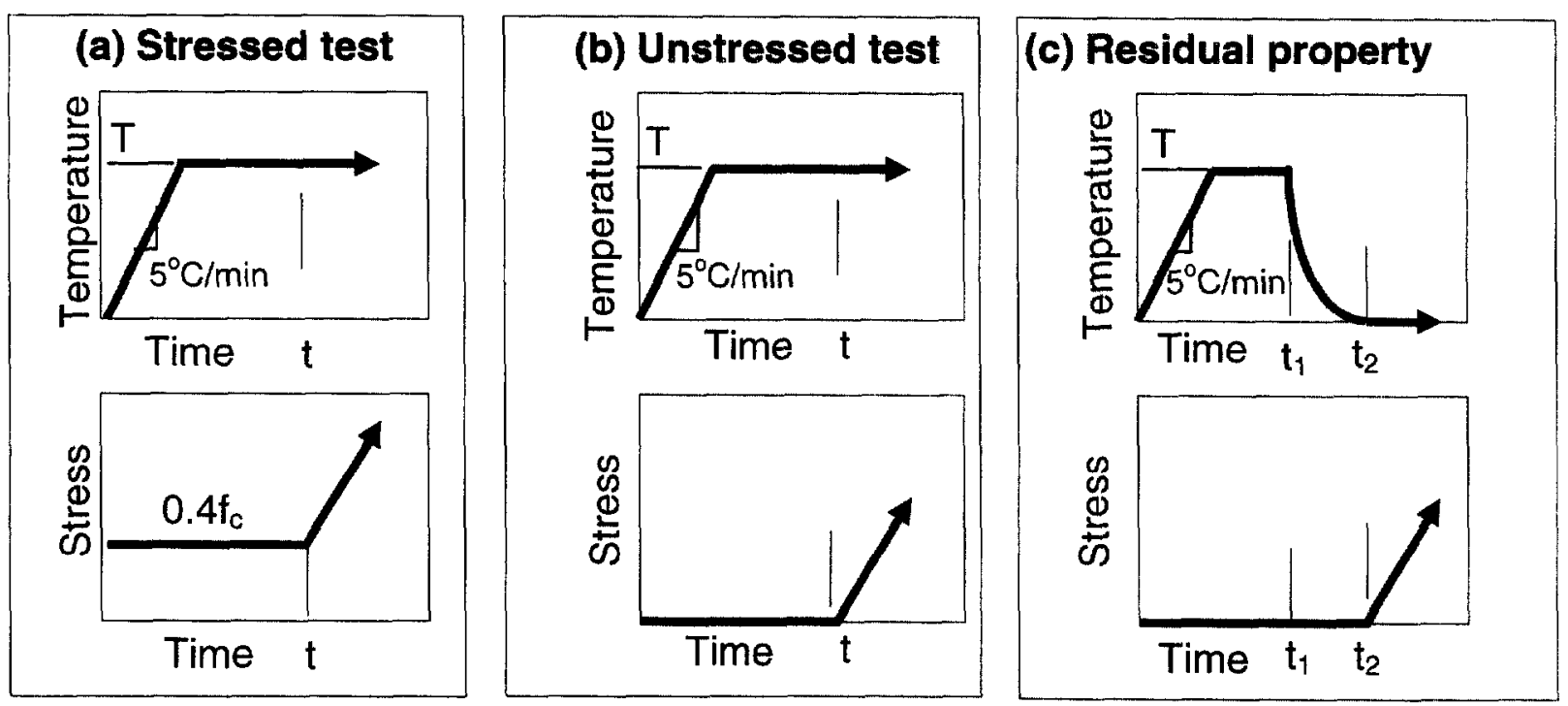

Figure 2.6 Schematic of temperature and loading histories for the three test methods 


\subsubsection{Test Setup}

Figures 2.7 and 2.8 show the testing arrangement used for the stressed, unstressed, and unstressed residual property tests.

The $100 \mathrm{~mm} \times 200 \mathrm{~mm}$ (4 in $\times 8 \mathrm{in}$ ) cylindrical specimen is placed at the center of the computer-controlled, single zone, electric split-tube furnace. The interior of the furnace is cylindrical with dimensions of $260 \mathrm{~mm}$ (10 1/4 in) in diameter and $380 \mathrm{~mm}$ (15 in) in height. The furnace has two $165 \mathrm{~mm}\left(6 \frac{12}{2} \mathrm{in}\right)$ diameter openings, at the top and at the bottom, to allow two high-temperature alloy steel loading rams to transmit compressive load provided by the $1.34 \mathrm{MN}$ (300 kip), servo-controlled compression test machine. The gaps between the loading rams and the furnace openings are filled with thermal insulation material to reduce heat loss. Cooling plates are inserted between the loading ram and testing machine platens to keep the platens from being heated through contact with the loading ram. Each cooling plate is made from a $38 \mathrm{~mm} \times 190 \mathrm{~mm} \times 190 \mathrm{~mm}(1.5$ in $\times 7.5$ in $\times 7.5$ in) steel plate with interconnected internal channels that form a continuous passage way for cooling water to run through. During testing, cold water is continuously run through the cooling plates to dissipate the heat from the loading rams.

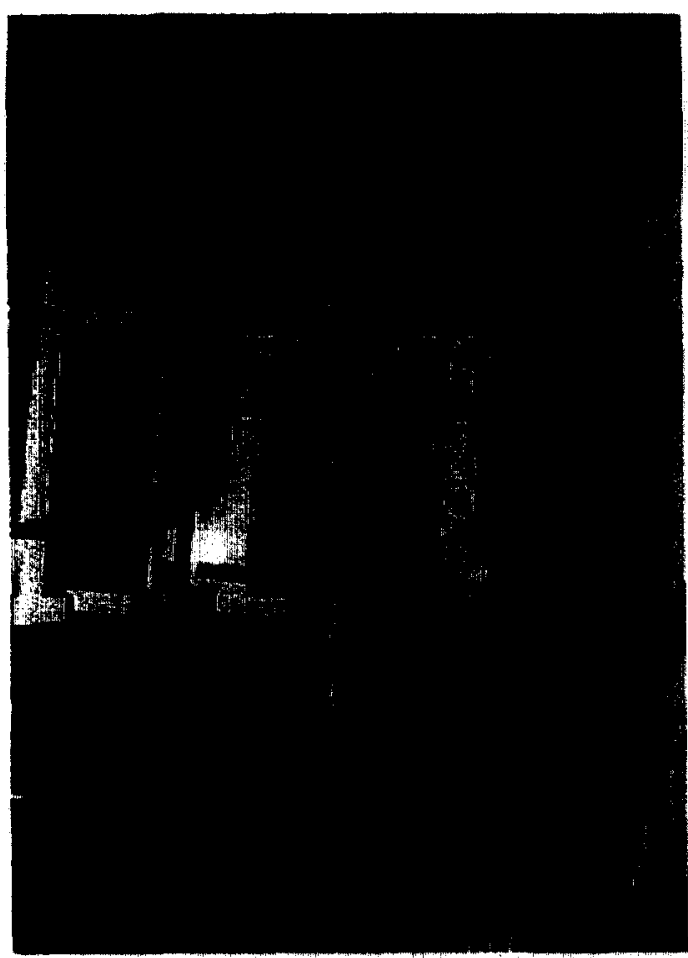

Figure 2.7 Picture of stressed and unstressed test setup

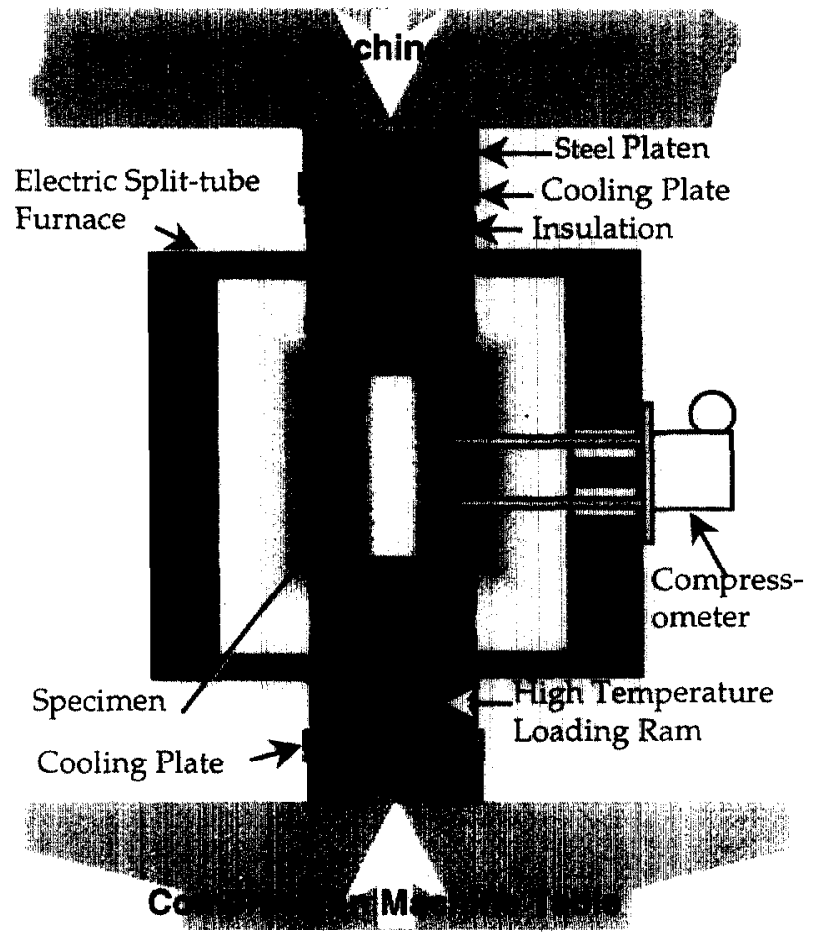

Figure 2.8 Schematic of stressed and unstressed test setup 
Strain is measured by a high temperature compressometer that uses inconel rods to monitor the shortening of the specimen. The compressometer is mounted on the outside of the split-tube furnace at mid-height (see Figures 2.7 and 2.8). The inconel rods are placed in contact with the specimen through cutout slots on the side of the furnace. Water cooling is provided to protect the electronic sensor located on the mounting bracket. The compressomoter has a $102 \mathrm{~mm} \mathrm{(4} \mathrm{in)} \mathrm{gage} \mathrm{length,} \mathrm{a} \mathrm{travel} \mathrm{length}$ of $\pm 20 \mathrm{~mm}( \pm 0.8 \mathrm{in})$, and a maximum operating temperature of $1200^{\circ} \mathrm{C}$.

\subsubsection{Temperature Control}

To develop information for temperature control, i.e., how long a specimen should be exposed to a target temperature to achieve the steady-state thermal condition, a finiteelement program, FIRES-T3 (Iding, et. al., 1996), was used to model the heating of a concrete cylinders. In addition, specimens instrumented with themocouples were heated to various temperature levels to validate the results of the finite element analyses. Figure 2.9 (a) shows the grid of 142 nodes and 107 elements used to model the furnace, specimen, supporting loading rams, and the compression machine table. Because of symmetry only one-fourth of the actual geometry is required for the simulation. Nodal temperatures at the center of the concrete specimen, near the surface of the loading ram in contact with the testing machine and a profile of temperature from the surface to the center of the concrete cylinder provide appropriate estimates of specimen response during heating.

Figures 2.9 (b) and (c) show the calculated histories of concrete core temperature and testing machine surface temperature for a range of target temperatures (up to $1000^{\circ} \mathrm{C}$ ) and three heating rates $\left(30^{\circ} \mathrm{C} / \mathrm{min}\right.$ : dotted lines, $5{ }^{\circ} \mathrm{C} / \mathrm{min}$ : dashed lines, $1{ }^{\circ} \mathrm{C} / \mathrm{min}$ : solid lines). These results indicate that, for an ambient heating rate of $5{ }^{\circ} \mathrm{C} / \mathrm{min}$, it would take at least $5 \mathrm{~h}$ of heating to develop the steady-state temperature condition in the concrete cylinder. As expected, the heating rate affects the time to reach steady-state conditions. Steady-state temperatures at the center of the concrete specimen are lower than the furnace temperature due to heat losses from the ends of the concrete specimen to the alloy loading rams. For high target temperatures, the testing machine surface, Figure 2.9 (c), can reach significantly high temperatures, thus validating the need for the cooling plates to keep the loading machine from being heated excessively.

Figure 2.10 shows the calculated temperature on the surface and at the center of the concrete cylinder for a range of ambient furnace temperatures $\left(100^{\circ} \mathrm{C}\right.$ to $\left.1000^{\circ} \mathrm{C}\right)$. Note that the interior temperature of the cylinder is considerably less than the ambient furnace temperature at the end of the heating period. Thus, in order to achieve the steady-state temperature condition at a selected target temperature $\left(100^{\circ} \mathrm{C}, 200{ }^{\circ} \mathrm{C}, 300\right.$ ${ }^{\circ} \mathrm{C}, 450{ }^{\circ} \mathrm{C}$, or $600^{\circ} \mathrm{C}$ ), it is necessary to use an ambient furnace temperature that is higher than the target temperature. Also, at steady state, the temperature gradient in the cylinder ranges from less than $6^{\circ} \mathrm{C}$ at a furnace ambient temperature of $100^{\circ} \mathrm{C}$ to more than $65^{\circ} \mathrm{C}$ at a furnace ambient temperature of $1000^{\circ} \mathrm{C}$. 
To validate these findings, a Mixture I specimen, instrumented with thermocouples, was heated to a target temperature of $450^{\circ} \mathrm{C}$ (core temperature) using an ambient heating rate of $5{ }^{\circ} \mathrm{C} / \mathrm{min}$. Figures 2.11 (a) and (b) show the temperature development in the cylinder and concrete surface-to-core temperature gradient due to heating, respectively. As shown in Figure 2.11 (a), after $5 \mathrm{~h}$ of heating, the specimen core attained a temperature of $450{ }^{\circ} \mathrm{C}$, with a surface-to-core thermal gradient of about $-6^{\circ} \mathrm{C}$ (the concrete core is hotter than the concrete surface at this point). This satisfies the criteria for the steady-state thermal condition as outlined in section 2.1.1 and validates that $5 \mathrm{~h}$ of heating at $5{ }^{\circ} \mathrm{C} / \mathrm{min}$ are required for steady-state conditions as found in the finite-element analysis. Also, as predicted by the finite element analysis, an ambient temperature of $500^{\circ} \mathrm{C}$ is required in order for the specimen to achieve steady-state target temperature of $450^{\circ} \mathrm{C}$. Based on both the analytical results and the measurement of temperature development in the specimen, a heating time $t$ of $5 \mathrm{~h}$ is selected as the exposure time to achieve steady-state conditions in this test program. 


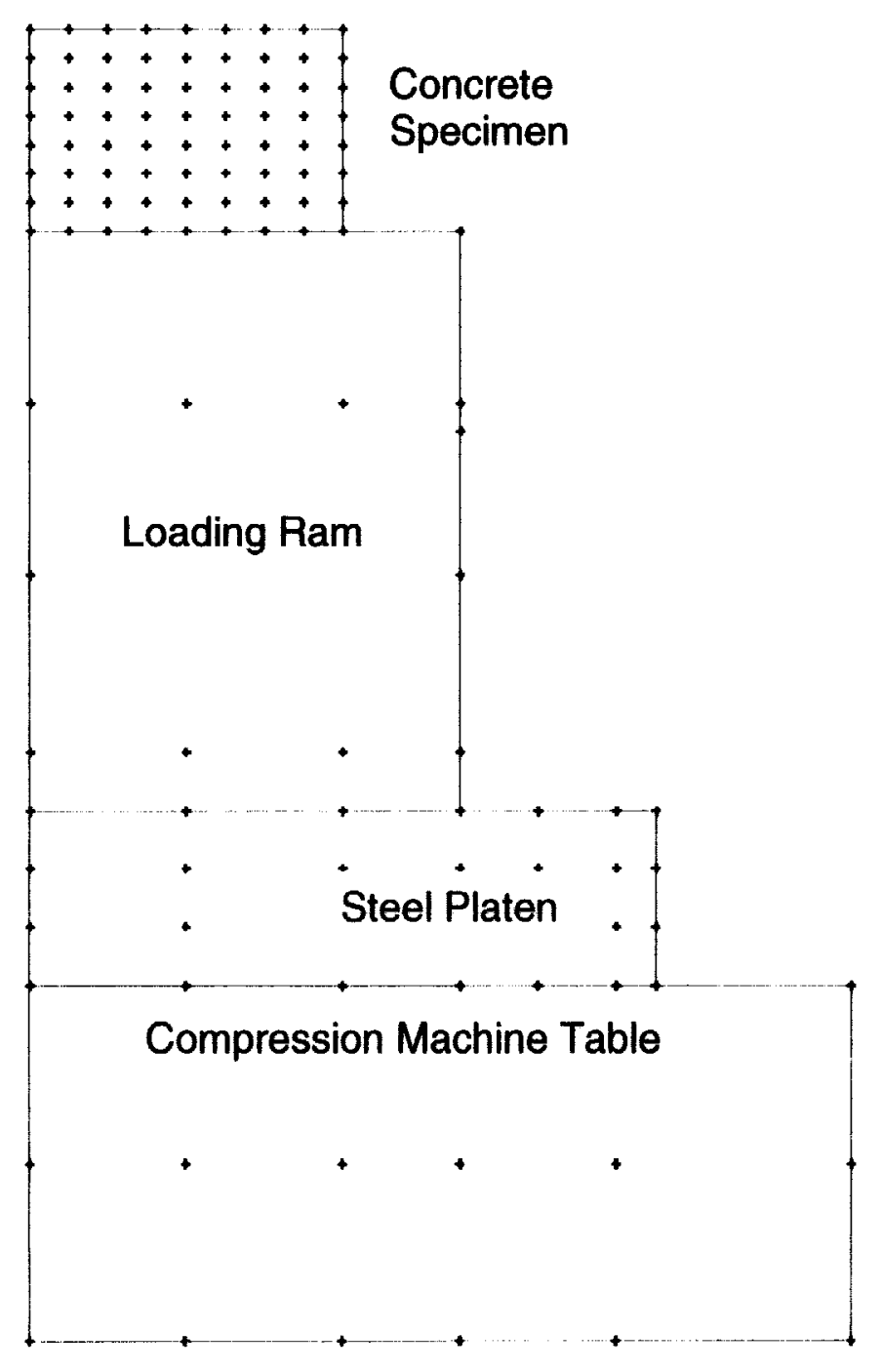

(a

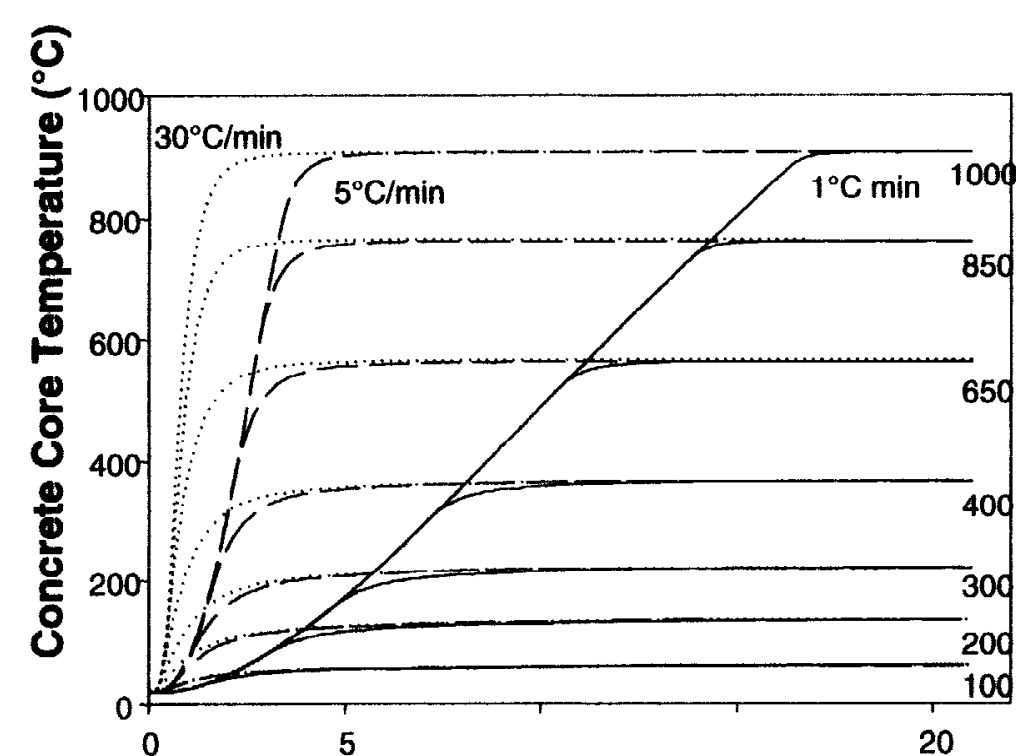

(b) Time,

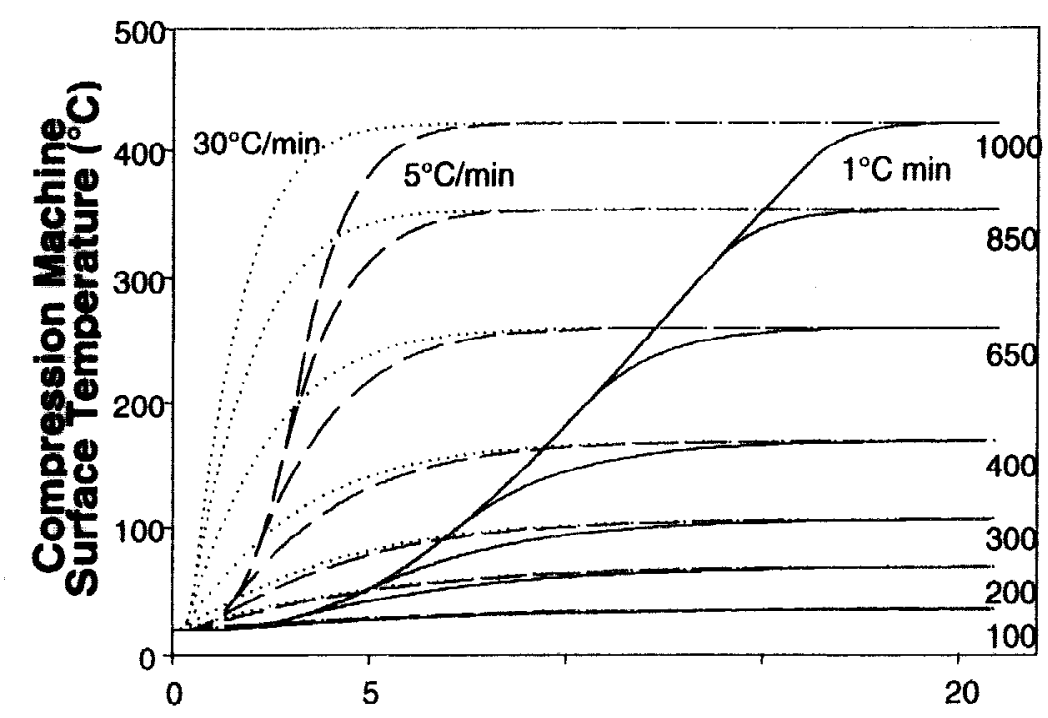

(c) Time,

Figure 2.9 Finite element modeling of heating of concrete cylinder 


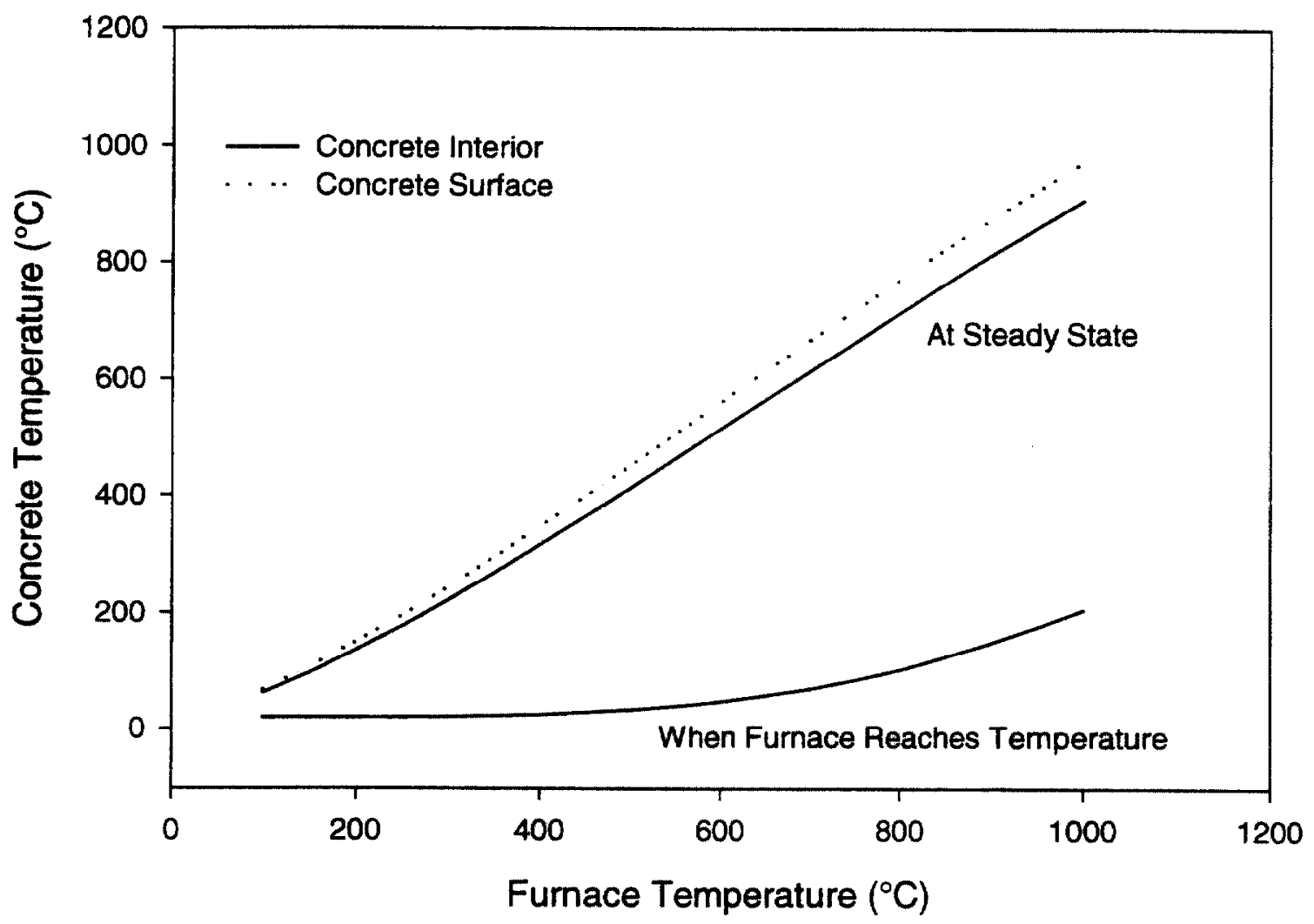

Figure 2.10 Calculated specimen temperature at steady-state condition as a function of ambient furnace temperature 


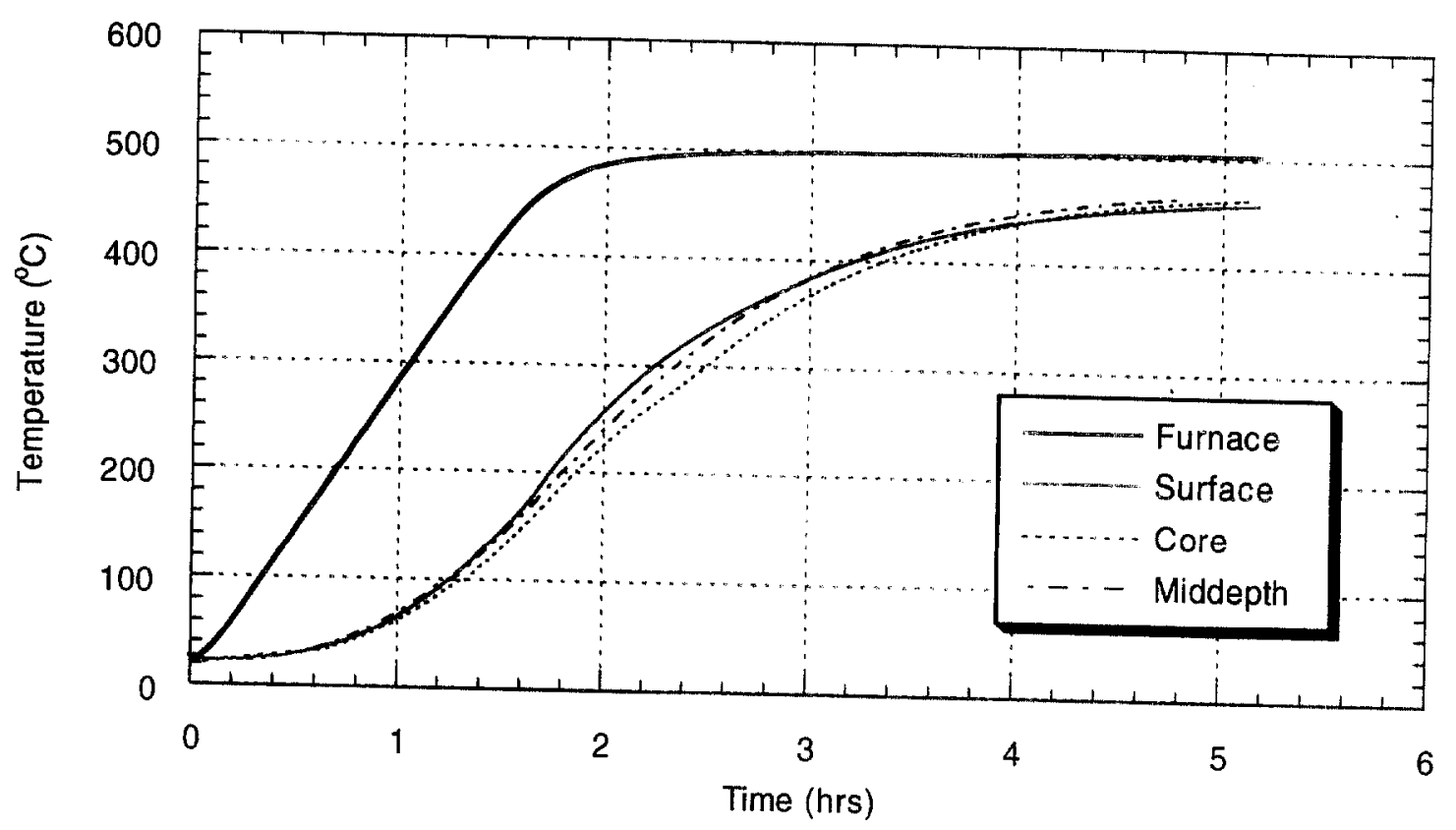

Figure 2.11 Temperature development in Mixture I cylinder, heated at $5^{\circ} \mathrm{C} / \mathrm{min}$

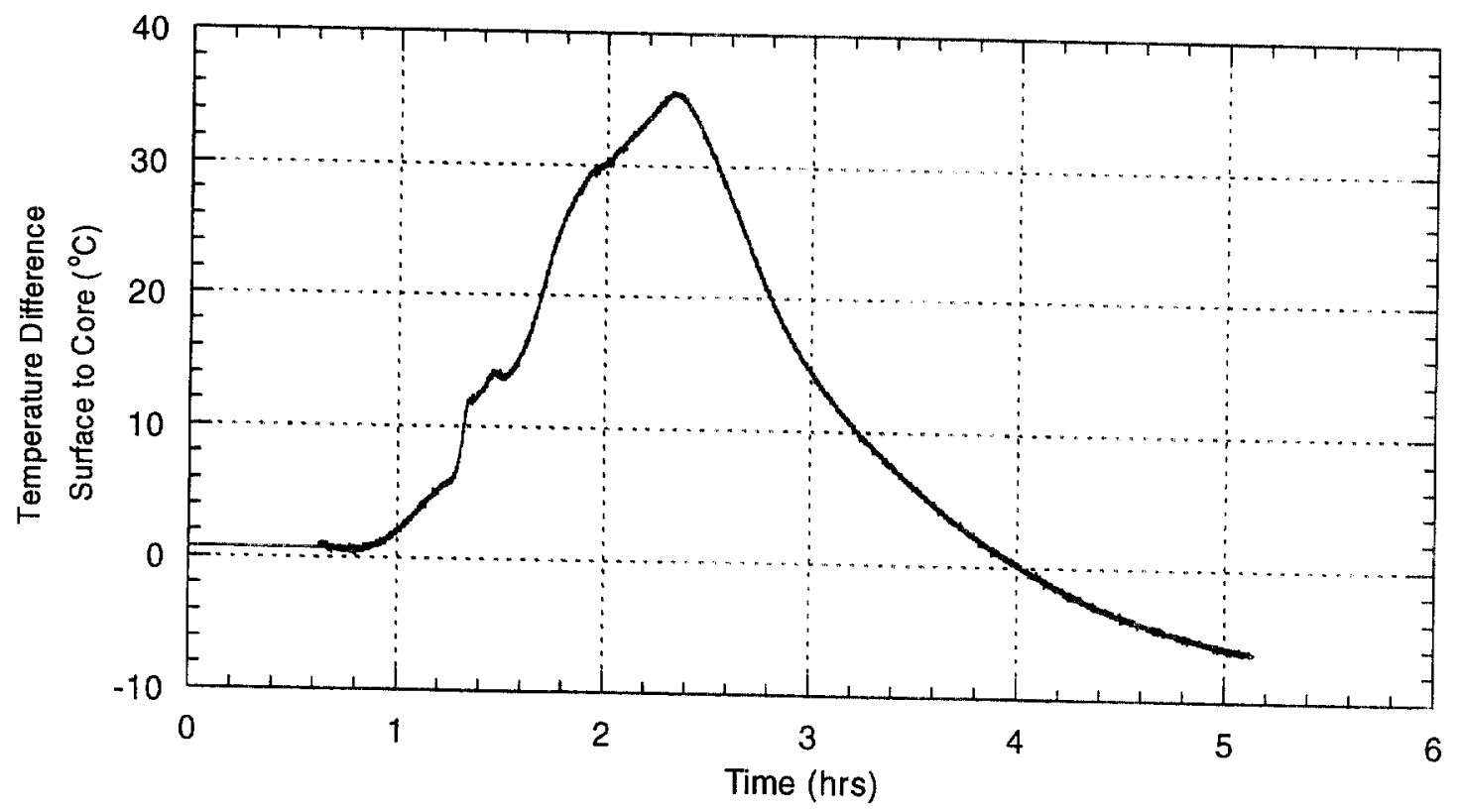

Figure 2.12 Temperature difference between surface and center of Mixture I cylinder, heated at $5^{\circ} \mathrm{C} / \mathrm{min}$ 


\section{EXPERIMENTAL RESULTS}

\subsection{Heating Characteristics}

\subsubsection{Temperature Development}

Figures 3.1 to 3.4 provide information on the heating characteristics of the four concrete mixtures in this test program. Specifically, Figures 3.1 (a) to 3.4 (a) show the temperature development within each cylinder when exposed to the ambient furnace temperature, which is shown as a thick solid line. Figures 3.1(b) to 3.4(b) show the temperature differences between the surfaces and centers of the cylinders, and the rates of temperature rise on the surfaces and centers. The rates of temperature rise on the surfaces and centers of the specimens were obtained by taking derivatives of the measured temperature at these locations with respect to time. These figures also provide an indication of the heat-induced moisture (vaporized capillary pore water and chemically bound water) transport in the specimens. The effects of heat-induced moisture transport produce perturbations in the temperature developments of each specimen. To aid in explaining the heat-induced perturbations in the temperature development of HSC, the reader is referred to Figures 3.1 (c) and (d), which depict the rate of temperature rises at the surface and center of a cylinder made of thermally "inert" material (Figure 3.1 (c)) and of a cylinder made of HSC (Figure 3.1 (d)). For the "inert" material, the rate of temperature rises at the surface and center of the cylinder will increase without interruption as the furnace temperature is being ramped up at a constant heating rate (Figure 3.1 (c)). Shortly after the furnace reaches the target (and holding) temperature, the rate of temperature rises on the surface and center of the inert material will reach their maximums and will decrease, also without interruption, as a function of time. For the concrete cylinder (Figure 3.1 (d)), which contains free and chemically bound water in its matrix, exposure to certain temperatures can cause the free and chemically bound water to vaporize and the vapor to migrate both outward (to lower pressure region) and inward (to cooler region inside the cylinder). The transformation of the concrete water from liquid to vapor phase at certain temperatures, and the resulting migration of vapor both in and outward, cause the rate of temperature rises at the surface and center of the concrete cylinder to fluctuate, or be "perturbed," as marked by vertical dashed lines on this figure. The heat-induced moisture migration is further explained in section 3.2.

Perturbations indicative of three major heat-induced transformations in cylinders of this test program are marked by three vertical dashed lines in Figures 3.1 to 3.4. The first perturbation coincides with a major drop in the rate of the temperature rise at the center of the cylinder. The second perturbation coincides with an increase and then sudden decrease in the rate of temperature rise at the surface of the specimen that results in a change in the slope of the temperature difference between the surface and center. The third perturbation coincides with an increase and then a decrease in the rate of temperature rise at the surface of the specimen. When the rates of temperature change 
at the surface and center are equal, the maximum temperature difference occurs between the surface and center of the specimen.

To better understand the effects of heating on the moisture transport within the cylinders, the temperature profile and thermal gradient of a mixture I specimen (Figure 3.1 (a) and (b)), heated to a target temperature of $450^{\circ} \mathrm{C}$ is examined. In Figure 3.1 (a), the thick solid line represents the ambient temperature inside the furnace. The thin solid line is the temperature measured on the concrete surface. The dash-dotted line is the temperature at a point inside the cylinder, $25 \mathrm{~mm}$ from the concrete surface (middepth). The dotted line is the temperature at the center of the cylinder, $51 \mathrm{~mm}$ from the surface. The dark solid line in Figure 3.1 (b) shows the temperature difference between the surface and center of the cylinder.

The first two vertical dashed lines from the left in Figure 3.1 (b) indicate the first two major perturbations in the rates of temperature rise on the surface and at center of the specimen. These occurred at $1 \mathrm{~h}: 15 \mathrm{~min}$ and $1 \mathrm{~h}: 40 \mathrm{~min}$ into heating. These coincide with concrete temperatures at the center of the cylinder of slightly above $100{ }^{\circ} \mathrm{C}$ and approximately $170^{\circ} \mathrm{C}$, as indicated by the two vertical dashed lines at the same times in Figure 3.1 (a). The perturbations in rates of temperature rise at the surface and at the center of the cylinder are believed to be due to the releases of free water and chemically bound water. At slightly above $100^{\circ} \mathrm{C}$, free water in the concrete begins to evaporate rapidly. A moisture front is driven by the heat toward the cooler center of the specimen, causing a decrease in the rate of temperature rise at the specimen center and thus an increase in the temperature difference between the cylinder's surface and center. When the center reaches temperature higher than $170^{\circ} \mathrm{C}$, significant chemically bound water is released. This caused a similar decrease in the rate of temperature rise at center, as marked by the second dashed line in Figures 3.1 (a) and (b).

The temperature difference between the specimen surface and center reaches a maximum of $36^{\circ} \mathrm{C}$ after $2 \mathrm{~h}: 20 \mathrm{~min}$ of heating, at a corresponding center temperature of $270^{\circ} \mathrm{C}$. This marks the third major perturbation in the rate of temperature rise at center of the specimen (third vertical dashed line from the left of Figures 3.1 (a) and (b)). When the rate of temperature rise of the surface and center are equal, the temperature difference between the center and surface reaches its maximum value. After this point, the rate of temperature rise on the concrete surface is lower than that of the center, causing the temperature difference to decrease as shown in Figure 3.1 (b). This trend continues until a true steady-state thermal condition develops after $4 \mathrm{~h}$ of heating, when the surface-to-center temperature difference is reduced to zero. After $5 \mathrm{~h}: 15 \mathrm{~min}$ of heating, the specimen center reaches the target temperature of $450^{\circ} \mathrm{C}$ and is about $6^{\circ} \mathrm{C}$ higher than the concrete surface.

Similar heating characteristics are also observed for mixture II specimen (see Figures 3.2 (a) and (b)). The three major perturbations in the rates of temperature rise on the surface and at center of mixture II specimens are also marked by three vertical dashed 
lines. As shown in Figures 3.2 (a) and (b), the perturbations occurred at approximately $1 \mathrm{~h}: 17 \mathrm{~min}, 1 \mathrm{hr}: 41 \mathrm{~min}$, and $2 \mathrm{~h}: 20 \mathrm{~min}$ into heating, which correspond to concrete temperatures at the center of the cylinder of about $100^{\circ} \mathrm{C}, 155^{\circ} \mathrm{C}$, and $235^{\circ} \mathrm{C}$, respectively.

Again, similar heating characteristics are observed for the mixture III specimen (see Figures 3.3 (a) and (b)). For this concrete mixture, the major heat-induced perturbations occurred at about $1 \mathrm{~h}: 16 \mathrm{~min}, 1 \mathrm{~h}: 43 \mathrm{~min}$, and $2 \mathrm{hr}$ : $32 \mathrm{~min}$, corresponding to concrete temperatures at the center of about $100^{\circ} \mathrm{C}, 150^{\circ} \mathrm{C}$, and $245^{\circ} \mathrm{C}$, respectively.

Finally, similar heating characteristics are also observed, in general, for the mixture IV specimen (see Figures 3.4 (a) and (b)), albeit the fluctuations in the rates of temperature rise on the surface and at center of this specimen are much more pronounced than for mixtures I, II and III. This is believed to be due to the higher water content in the mixture IV cylinder $(w / \mathrm{cm}=0.57)$. The perturbations occurred in mixture IV specimen at about $1 \mathrm{~h}: 16 \mathrm{~min}, 1 \mathrm{~h}: 45 \mathrm{~min}$, and $2 \mathrm{~h}: 20 \mathrm{~min}$, corresponding to temperatures at center of $80^{\circ} \mathrm{C}, 115^{\circ} \mathrm{C}$, and $190^{\circ} \mathrm{C}$, respectively. 


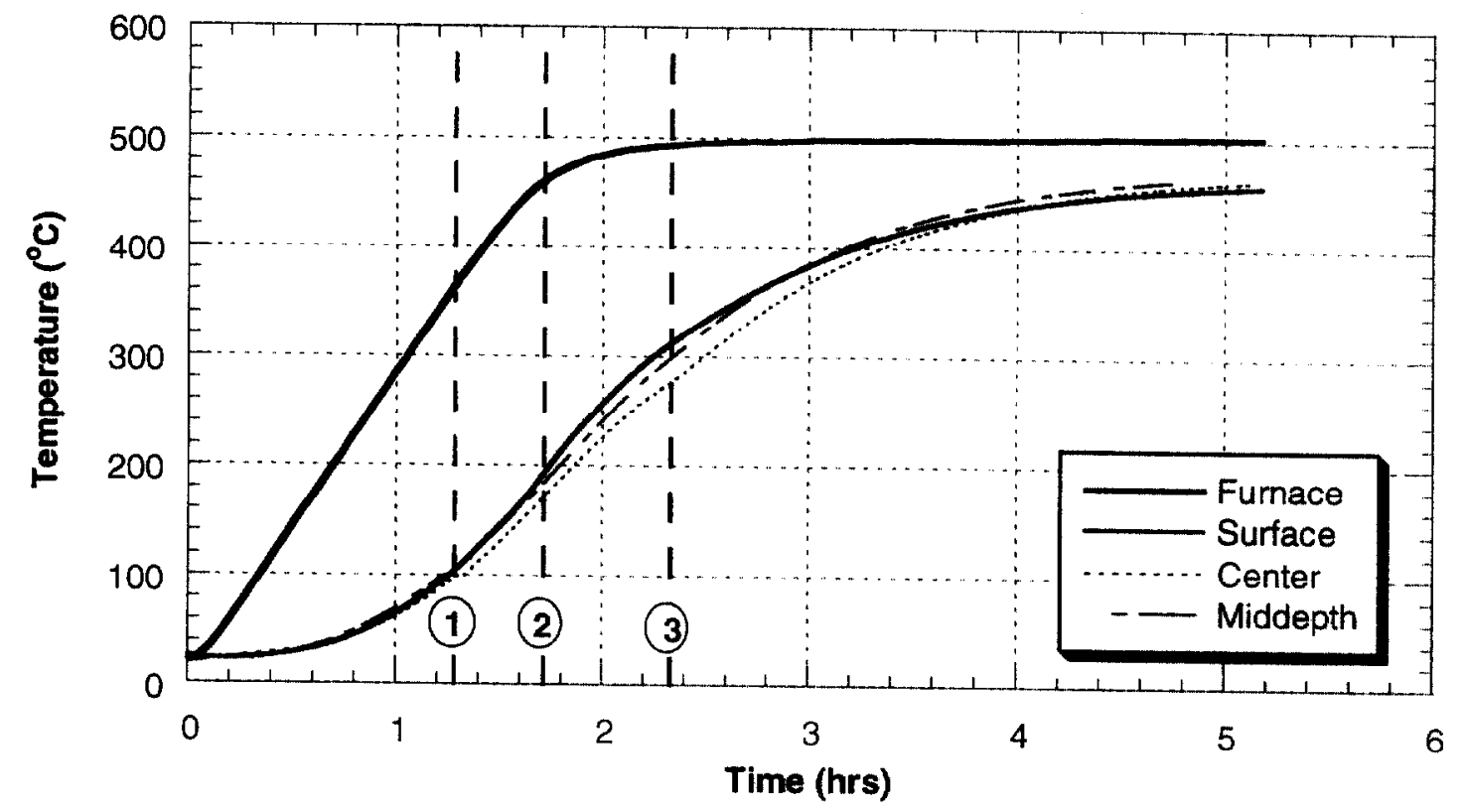

Figure 3.1(a) Temperature development in Mixture I cylinder, heated at $5^{\circ} \mathrm{C} / \mathrm{min}$

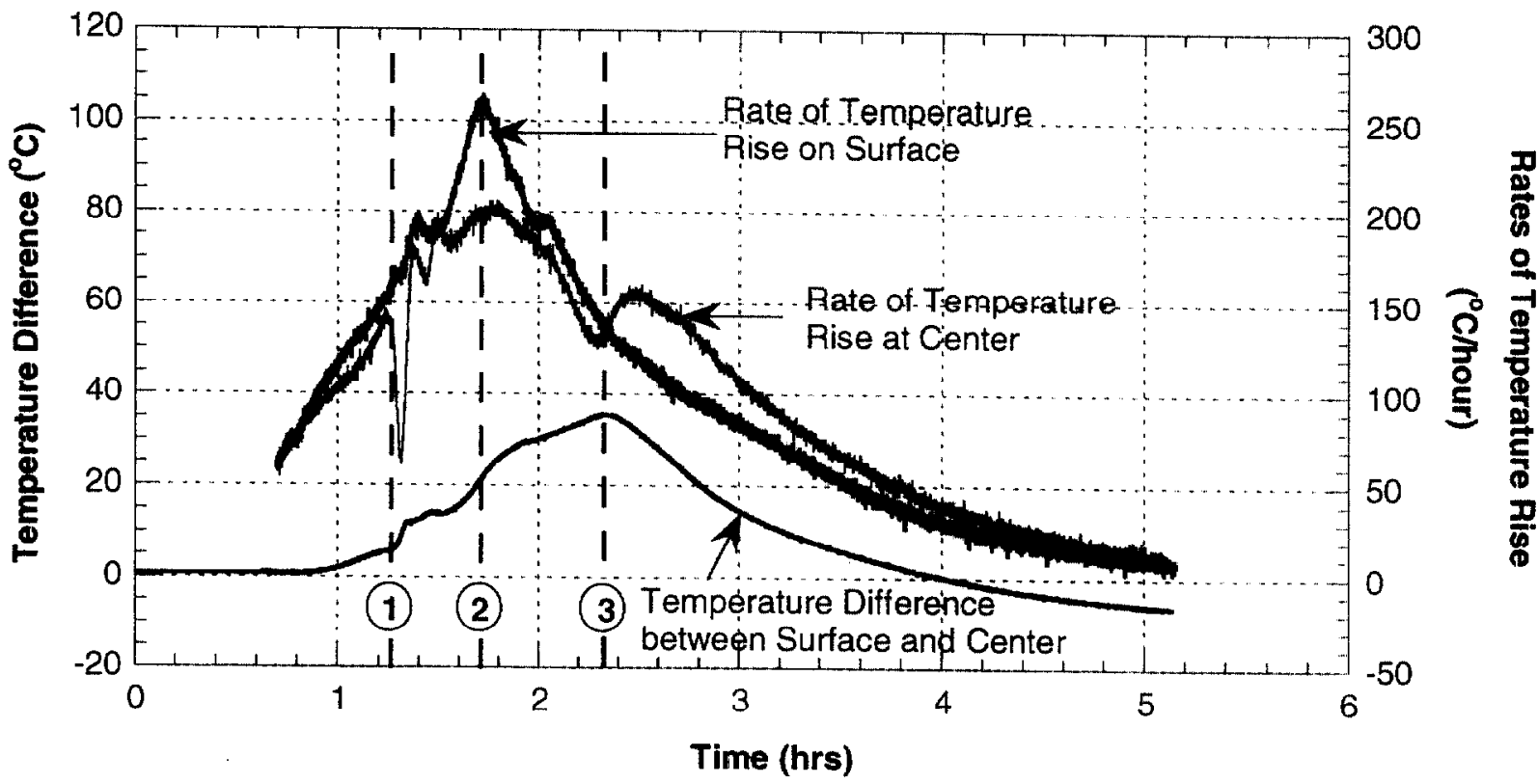

Figure 3.1(b) Temperature difference between surface and center of Mixture I cylinder, heated at $5^{\circ} \mathrm{C} / \mathrm{min}$ 


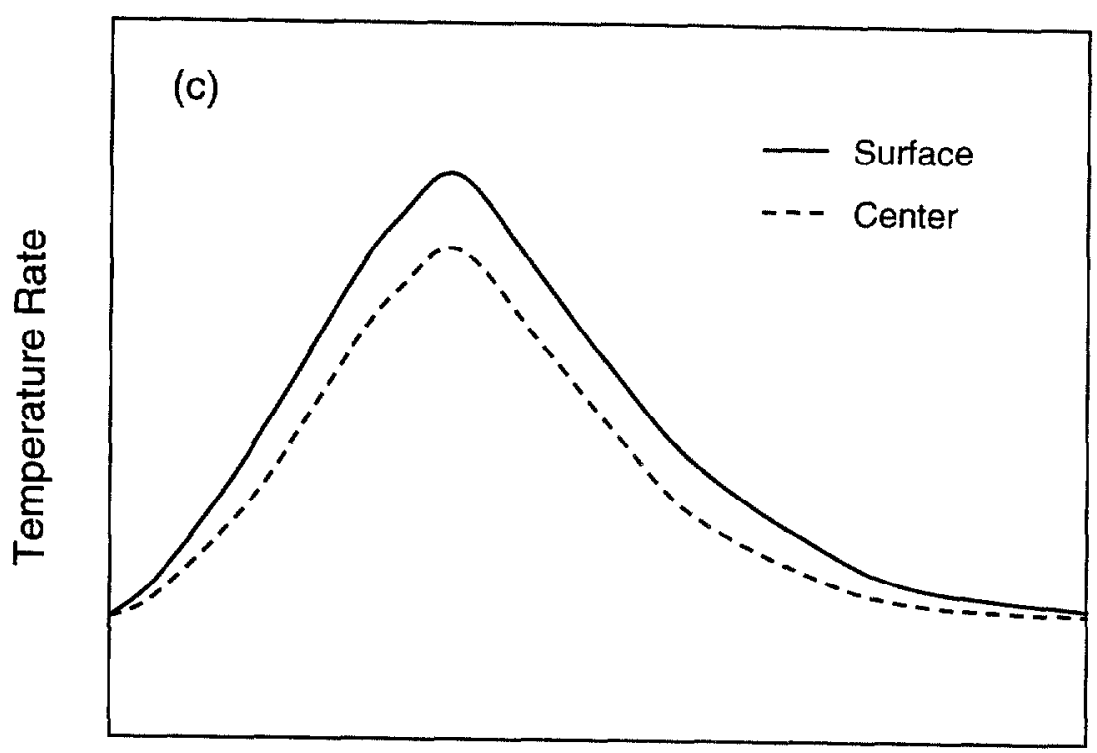

Time

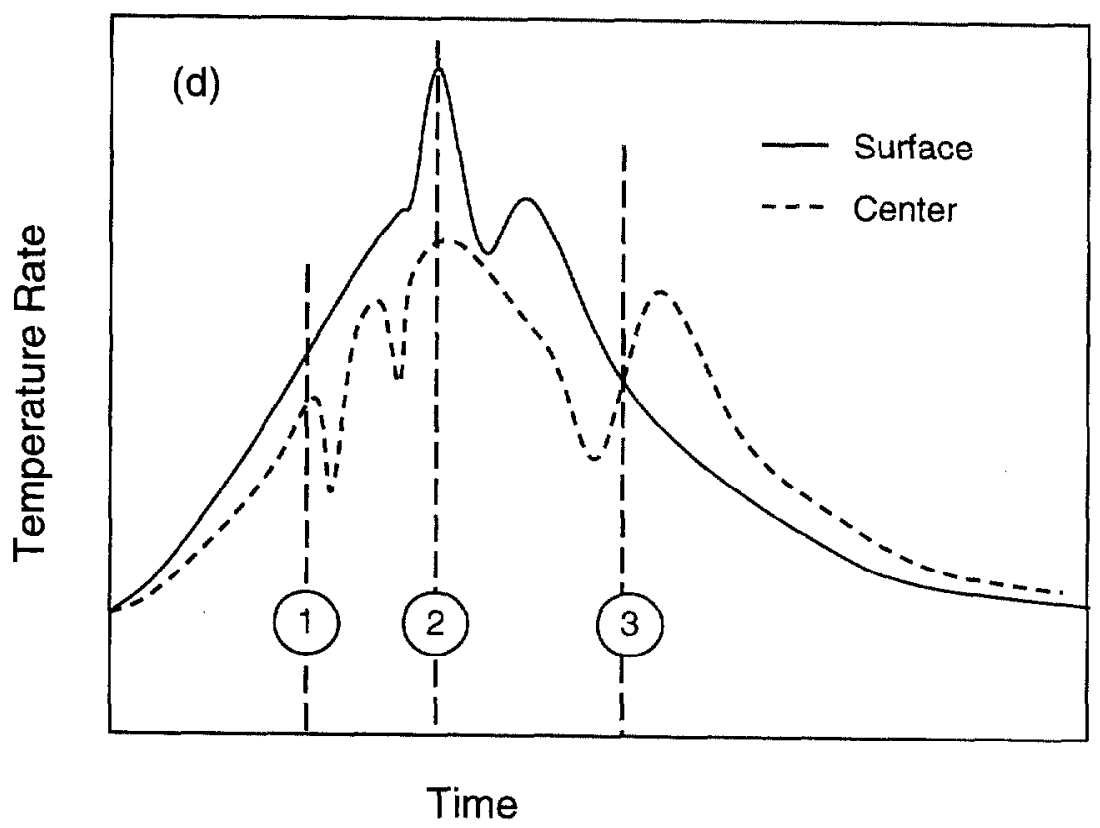

Figure 3.1 Schematics of rate of temperature rise at surface and center of cylinder: (c) in the absence of moisture-induced perturbations (d) with moisture-induced perturbations 


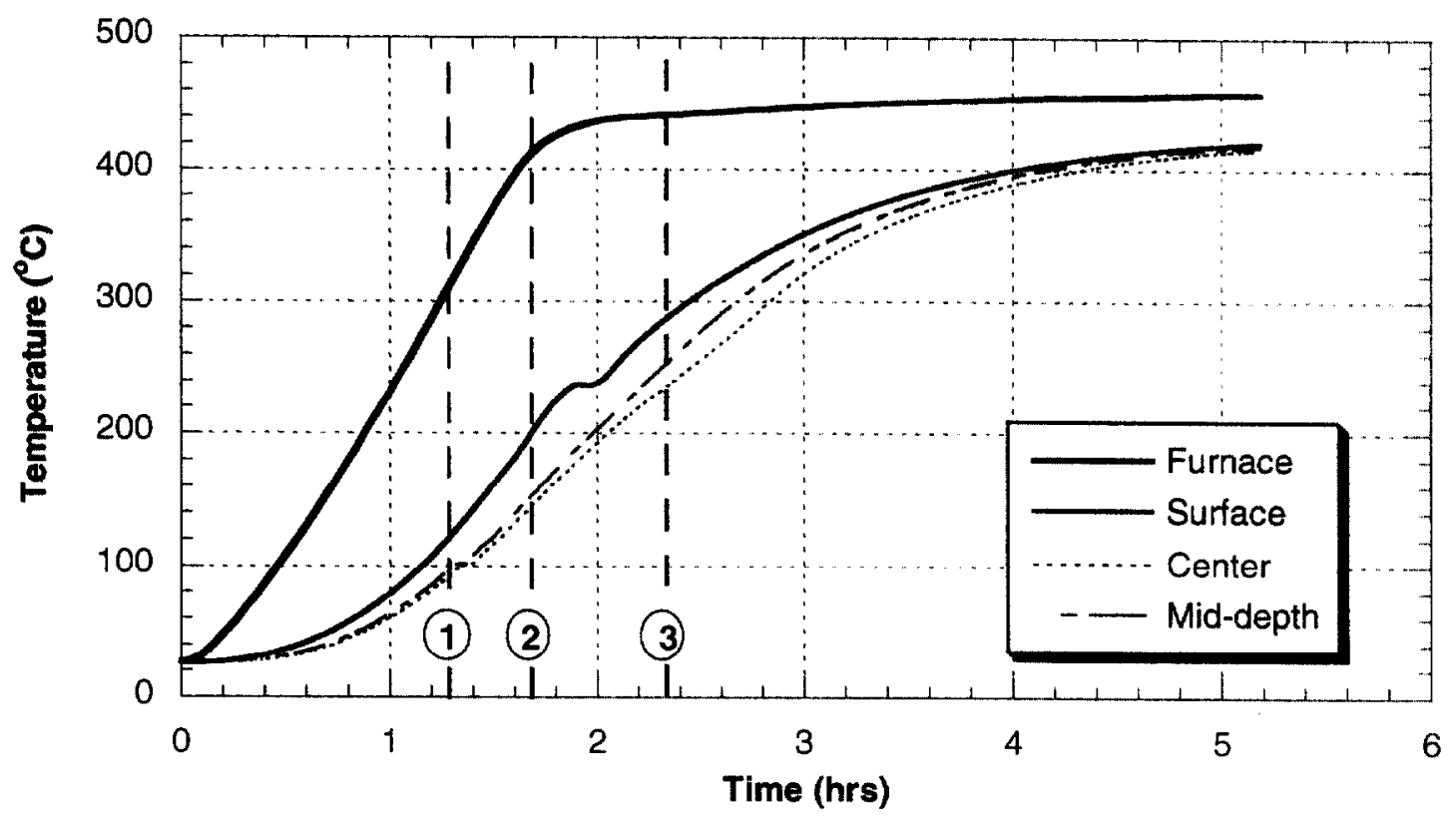

Figure 3.2(a) Temperature development in Mixture II cylinder, heated at $5^{\circ} \mathrm{C} / \mathrm{min}$

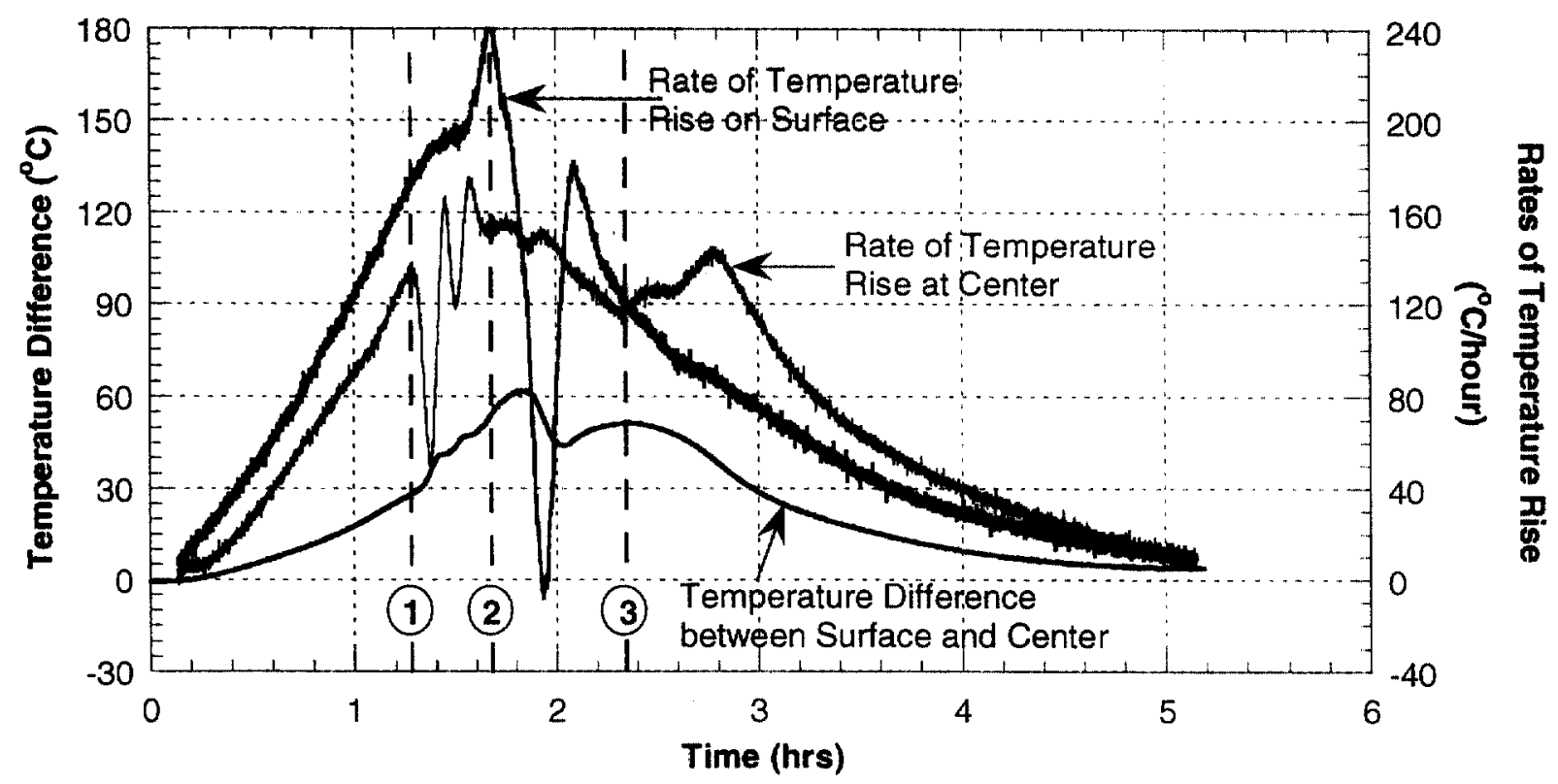

Figure 3.2 (b) Temperature difference between surface and center of Mixture II cylinder, heated at $5{ }^{\circ} \mathrm{C} / \mathrm{min}$ 


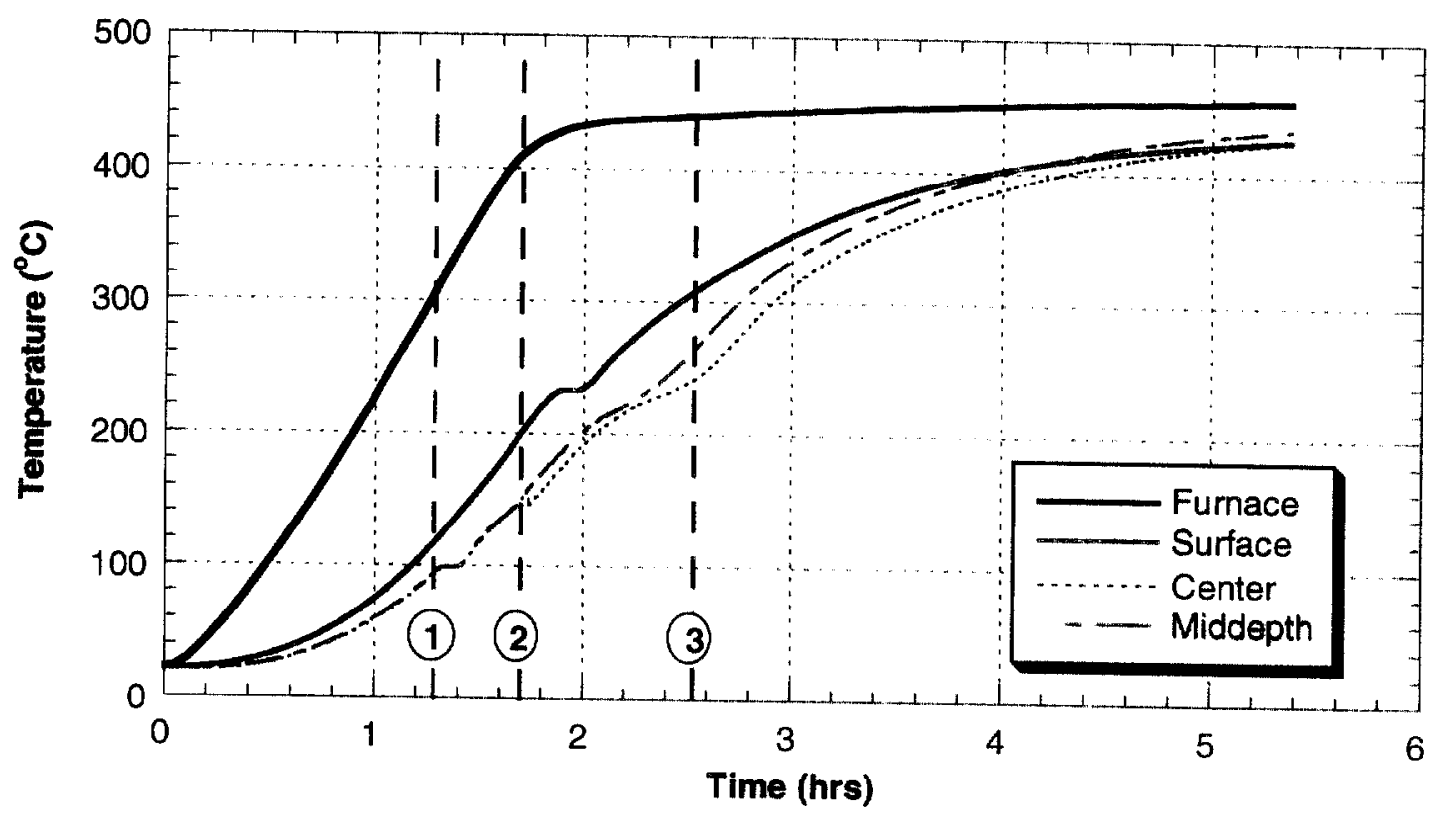

Figure 3.3(a) Temperature development in Mixture III cylinder, heated at $5^{\circ} \mathrm{C} / \mathrm{min}$

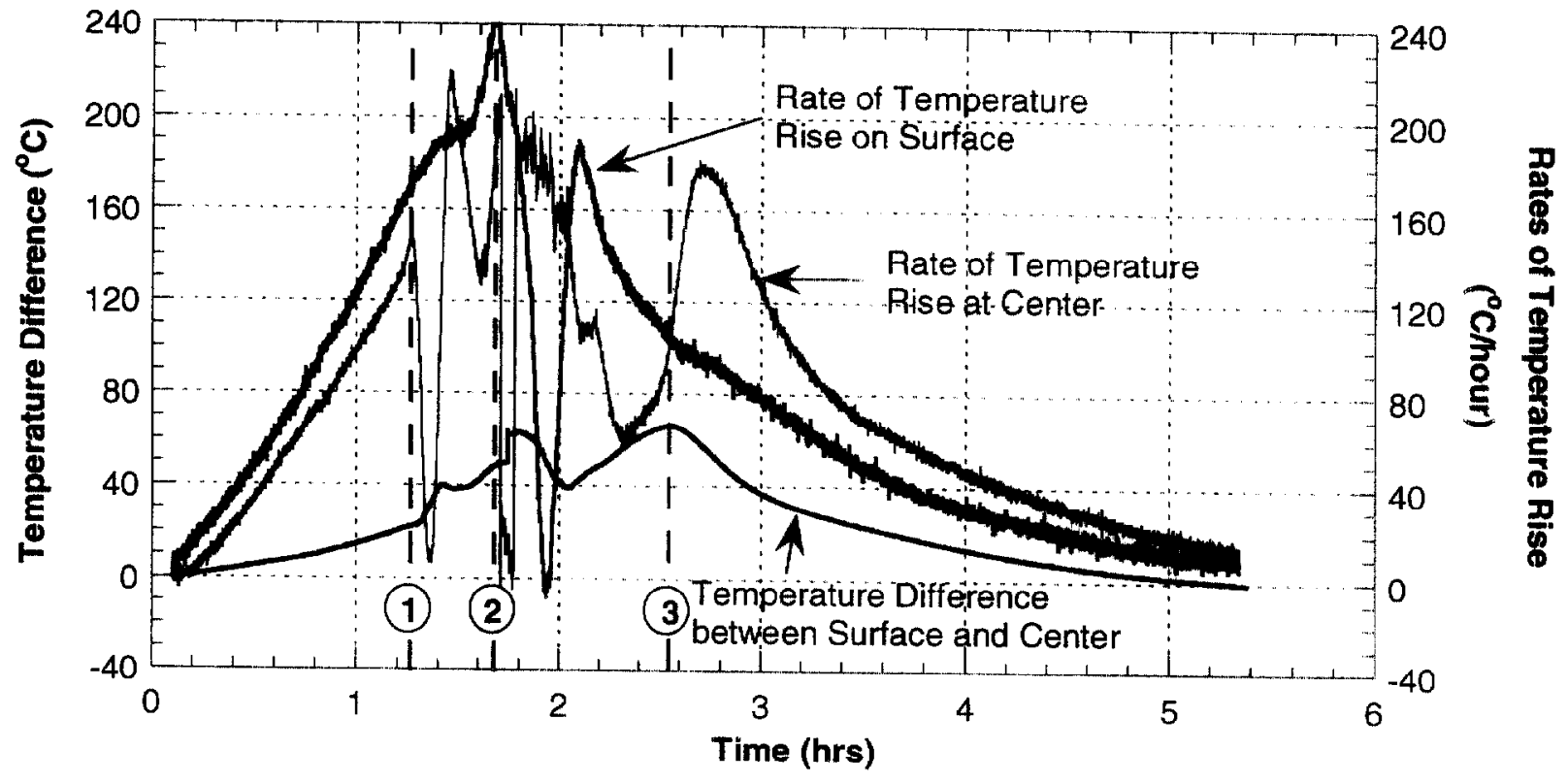

Figure 3.3(b) Temperature difference between surface and center of Mixture III cylinder, heated at $5^{\circ} \mathrm{C} / \mathrm{min}$ 


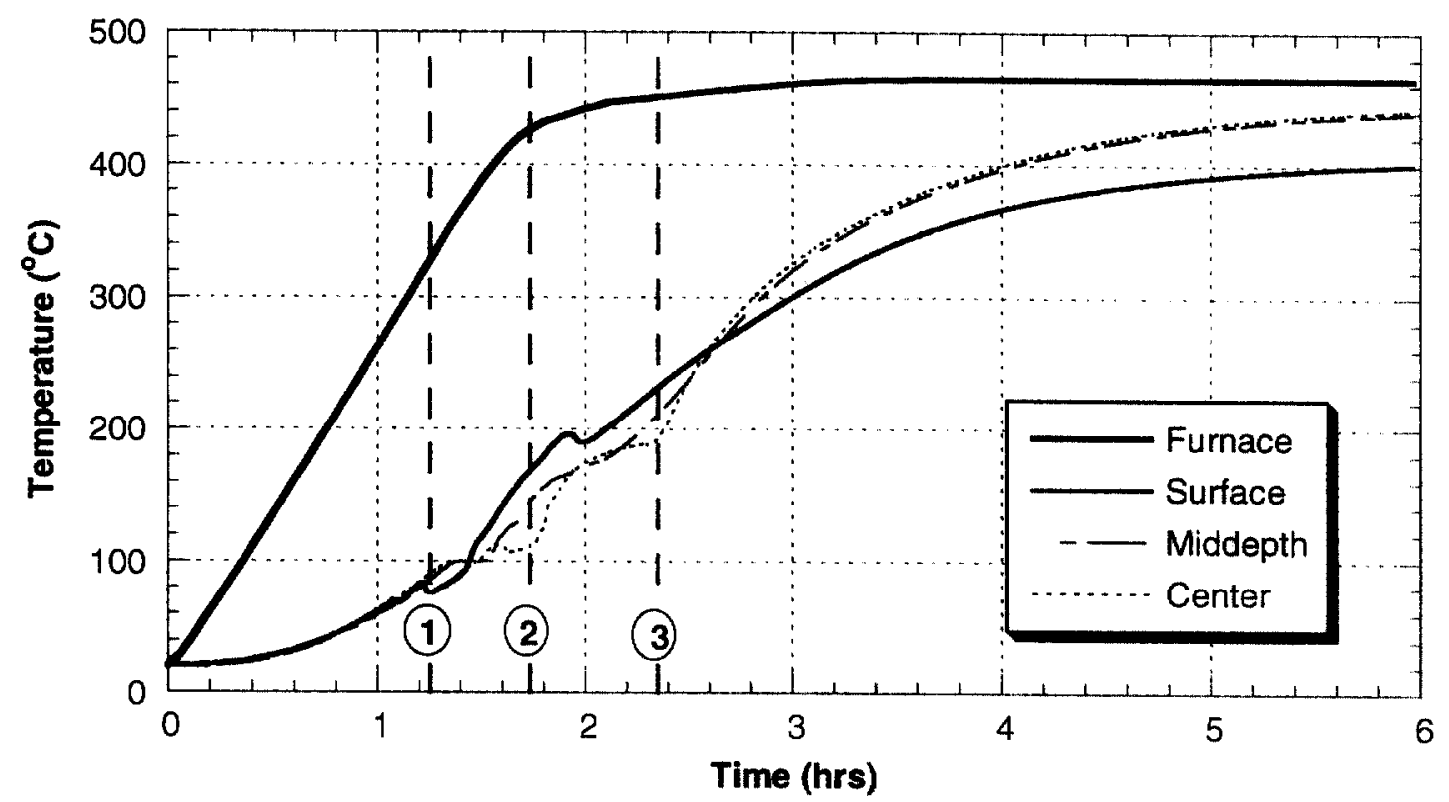

Figure 3.4(a) Temperature development in Mixture IV cylinder, heated at $5{ }^{\circ} \mathrm{C} / \mathrm{min}$

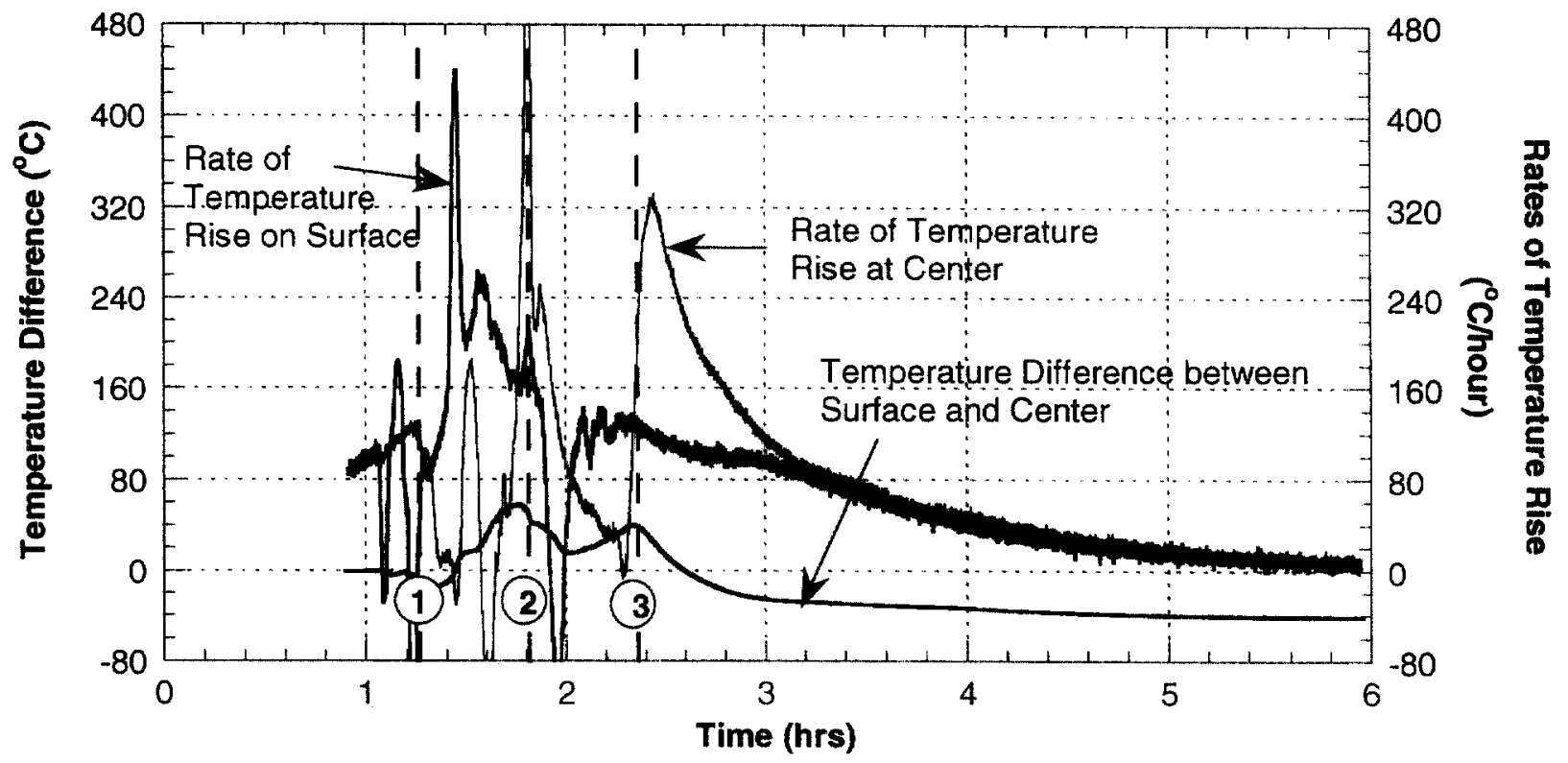

Figure 3.4(b) Temperature difference between surface and center of Mixture IV cylinder, heated at $5^{\circ} \mathrm{C} / \mathrm{min}$ 


\subsubsection{Mass Loss}

Heat-induced mass losses for all four concrete mixtures are shown in Figures 3.5 and 3.6. Figure 3.5 shows relative mass losses obtained from thermogravimetric analysis (TGA) of small ground concrete samples (approximately $100 \mathrm{mg}$ each) taken from the four concrete mixtures. Figure 3.6 shows relative mass losses obtained from heating full $(100 \times 200 \mathrm{~mm})$ cylinders at $5^{\circ} \mathrm{C} / \mathrm{min}$ to target temperatures of $100^{\circ} \mathrm{C}, 200^{\circ} \mathrm{C}, 300^{\circ} \mathrm{C}$, and $450^{\circ} \mathrm{C}$. The two vertical dashed lines in each of these figures indicate temperatures at which there were changes in rates of mass loss.

The TGA results show that, beginning at slightly above $100^{\circ} \mathrm{C}$ (first vertical dashed line in Figure 3.5), all four mixtures sustain similar amounts of relative mass loss. This temperature coincides with the changes in the rates of temperature rise between the surface and the center of the cylinder due to loss of free water as discussed in 3.1.1 (see Figures 3.1 to 3.4). A slower rate of heat-induced mass loss begins at about $215^{\circ} \mathrm{C}$ (second vertical dashed line in Figure 3.5) for all four concrete mixtures. While the mass loss rates were similar for the four mixtures, the amounts of relative mass loss differed. Mixtures III and IV ( $w / \mathrm{cm}=0.33$ and 0.57 , respectively), which contained no silica fume, sustained similar but larger loss than mixtures I and II $(w / c m=0.22$ and 0.33 ), which contained silica fume. The mass losses at this stage are due primarily to the release and evaporation of chemically bound water in the concrete samples.

Figure 3.6 shows average relative mass losses in full cylinders, heated at a rate of $5^{\circ} \mathrm{C} / \mathrm{min}$ and $5 \mathrm{~h}$ of exposure time. At each target temperature level, mass loss was measured for a group of at least three specimens and the results, along with the cocfficients of variation (CV), are listed in Table 3.3. The results show that relative mass losses in mixture III and IV specimens follow the same two stages that begin at slightly above $100^{\circ} \mathrm{C}$ and $200^{\circ} \mathrm{C}$ as observed in the TGA measurements, with the mixture IV specimens sustaining the highest amount of relative mass loss. However, the changes in rate of mass loss for mixtures I and II at above $200^{\circ} \mathrm{C}$ are less apparent, with the mixture I specimen sustaining no change in rate of mass loss up to $300^{\circ} \mathrm{C}$. Mass loss data for mixture I specimens at $450^{\circ} \mathrm{C}$ are not available due to explosive spalling of all three specimens while being heated to that target temperature. More detailed discussion concerning the explosive spalling of this group of specimens is given in the next section.

Recall that the initial moisture contents (IMC) for the four concrete mixtures ranged between $5.0 \%$ for mixture I and $7.3 \%$ for mixture IV (see Table 2.6). Initial moisture contents represent the amount of free water in the hardened paste and within aggregate particles and were obtained by drying small concrete samples (400-day samples) at $105^{\circ} \mathrm{C}$ until the difference in mass losses between successive measurements was negligible $(\leq 0.1 \%)$. The ranges of free water losses in all four concrete mixtures are represented by the horizontal band in Figures 3.5 and 3.6 (at normalized masses of 0.93 
and 0.95). The TGA results, shown in Figure 3.5, indicate that all four mixtures sustained significant loss of free water and chemically-bound water at about $215^{\circ} \mathrm{C}$ (marked by the second vertical dashed line). However, the results of heating full-size specimens, shown in Figure 3.6, indicate that while specimens of mixtures II, III, and IV appear to have lost most of this free water at $215^{\circ} \mathrm{C}$, the free water in mixture I specimens was not completely lost at this temperature (only $4 \%$ mass loss). These differences in mass loss between the TGA samples and the heated cylinders indicate that, while mixture II, III and IV cylinders have little problem losing water at high temperatures, mixture I cylinders have a more restrictive water loss process and could thus develop significant internal pressures (leading to spalling).

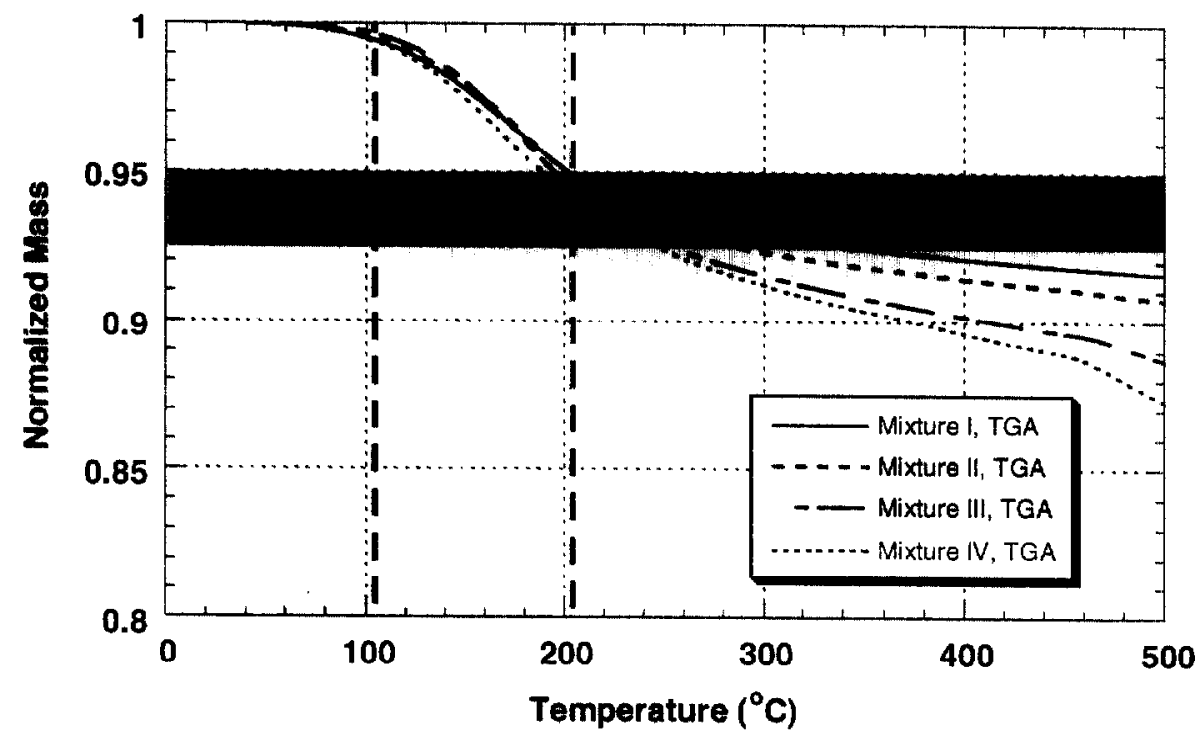

Figure 3.5 Mass losses from TGA

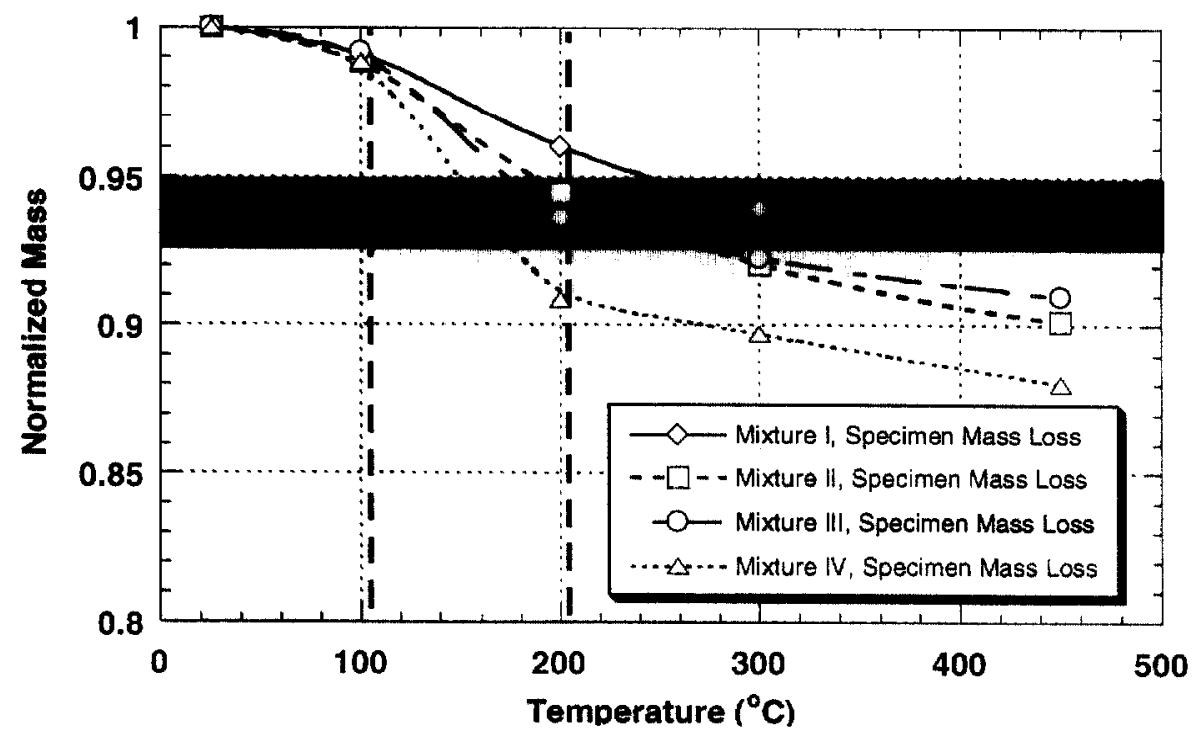

Figure 3.6 Mass losses from heating of full cylinders, shading represents initial free water moisture content of concrete mixtures 


\subsection{Spalling Characteristics}

Figure 3.7 (a) depicts the sequence of steps leading to heat-induced explosive spalling in moist HSC [31]. When subjected to heating, heat flow into HSC will result in an increase in the temperature of the pore water (free water). When the pore water, and later chemically-bound water (hydrated water), reach a high enough temperature, they will begin to vaporize. This vaporization causes an increase in pore pressure. As pore pressure increases, a pressure gradient forms between the zone of vaporization and lower pressure regions deeper inside the concrete and at the exterior surface of the concrete. Vapor migrates along the pressure gradient both outward, and escapes to the atmosphere, and inward to the lower temperature region where it condenses and adds to the liquid pore water already present. This vapor migration causes a temporary decrease in the rates of temperature rise at regions inside the concrete and on the concrete surface. As heating continues, accumulation of pore water builds up in the cooler regions until a completely saturated front is formed. Once this saturated front, or "moisture clog," is formed, vapor is severely impeded from migrating inward in the concrete. Instead it has to migrate through the dry region to escape to the atmosphere. If the rate of heating is sufficiently high, vapor in concrete with low permeability such as HSC will not be able to escape fast enough to keep internal pore pressures from rising inside the concrete. Spalling occurs when the combination of pore pressure and thermal stresses exceeds tensile strength of the concrete.
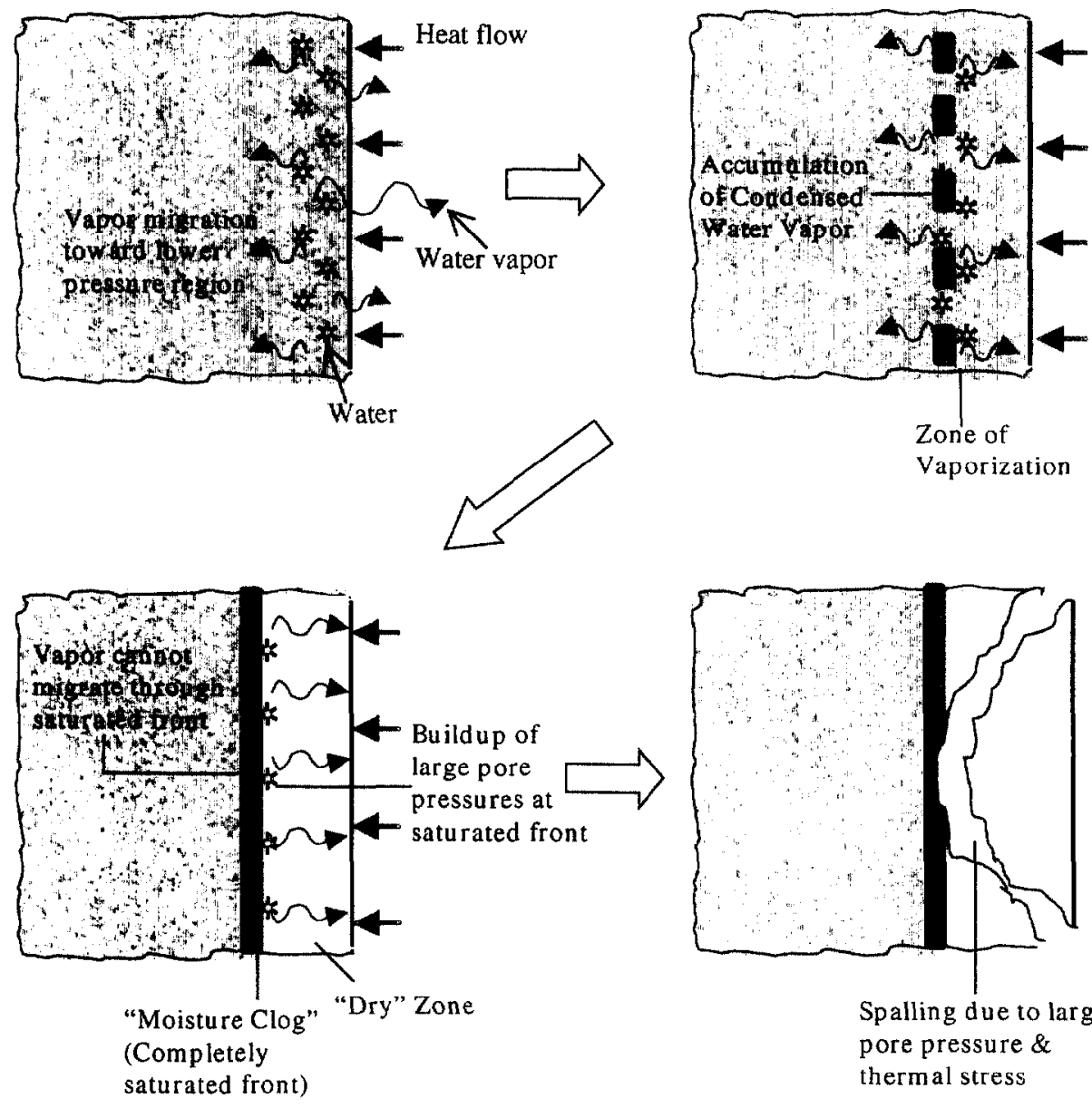

Figure 3.7(a) Sequence of steps leading to fire induced spalling (reproduced after Consolazio, McVay, and Rish [31]) 
Table 2.7 shows the test matrix and the incidences of explosive spalling failure in this test program. Explosive spalling is characterized by the sudden disintegration of the test specimens into fine fragments during heating. This disintegration is accompanied by a sharp loud bang and the instantaneous release of a sufficient amount of energy which projects the small concrete fragments at high velocity in all directions.

Reconstruction of the exploded specimens shows that the largest remaining piece in all cases is the concrete core, which measured approximately $70 \mathrm{~mm}$ at maximum width and $120 \mathrm{~mm}$ at maximum length. This core is surrounded by an approximately $20 \mathrm{~mm}$ thick $(3 / 4$ in) concrete outer shell along the length of the cylinder. The depth of approximately $20 \mathrm{~mm}$ ( $3 / 4$ in) appears to be the location of the primary fracture surface. Figure 3.7 shows the fragments of an exploded specimen and a rendering of the fracture formation based on reconstruction using these fragments.

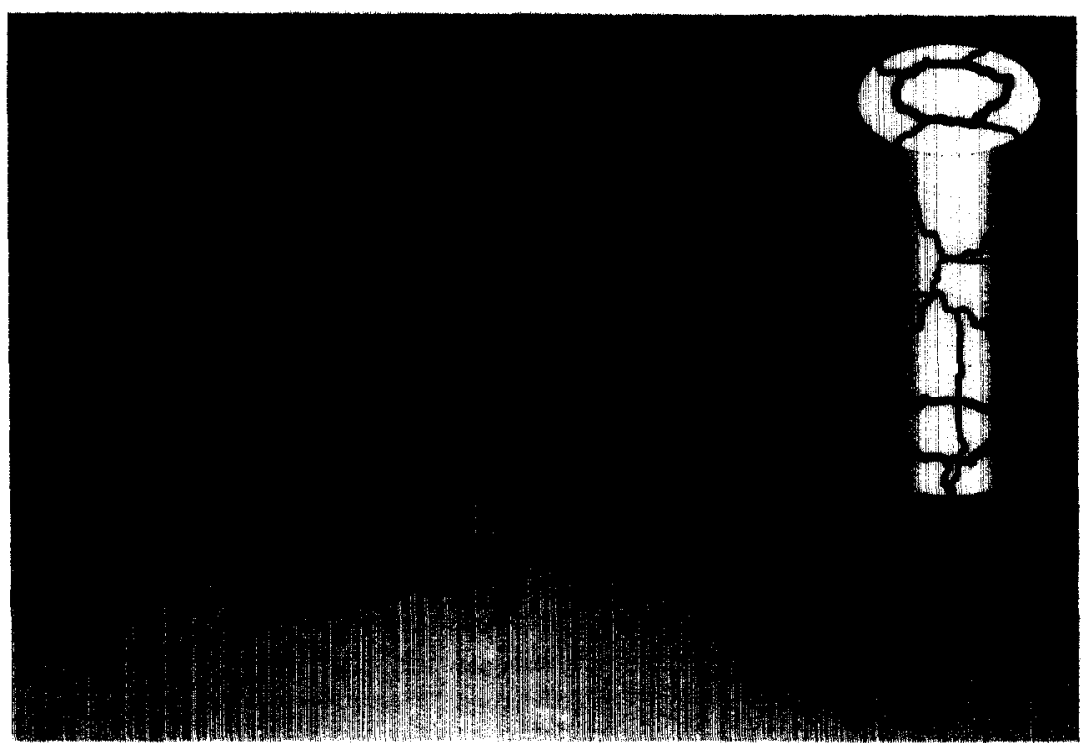

Figure 3.7 (b) Remnants of an exploded cylinder and rendering of the fracture formation

As shown in Table 2.7, a minimum of three specimens were tested for each test combination. For the stressed tests, explosive spalling occurred in all mixtures II and III's specimens $(w / \mathrm{cm}=0.33)$ that were being heated to the target temperature of $600{ }^{\circ} \mathrm{C}$. While mixtures I and IV's specimens ( $w / \mathrm{cm}=0.22$ and 0.57 , respectively) did not experience any explosive spalling throughout the entire temperature range.

For the unstressed tests, explosive spalling occurred in all mixture I's specimens and in one of four mixture II's specimens being heated to $450{ }^{\circ} \mathrm{C}$, while no spalling was observed in mixtures III and IV up to this temperature level. All specimens in mixture II and III that were being heated to $600{ }^{\circ} \mathrm{C}$ also failed due to explosive spalling. Mixture I was not tested at $600{ }^{\circ} \mathrm{C}$ due to the consistent spalling failure observed at the lower target temperature of $450^{\circ} \mathrm{C}$. Again, as in the stressed tests, mixture IV specimens did not experience any spalling failure throughout the entire temperature range. 


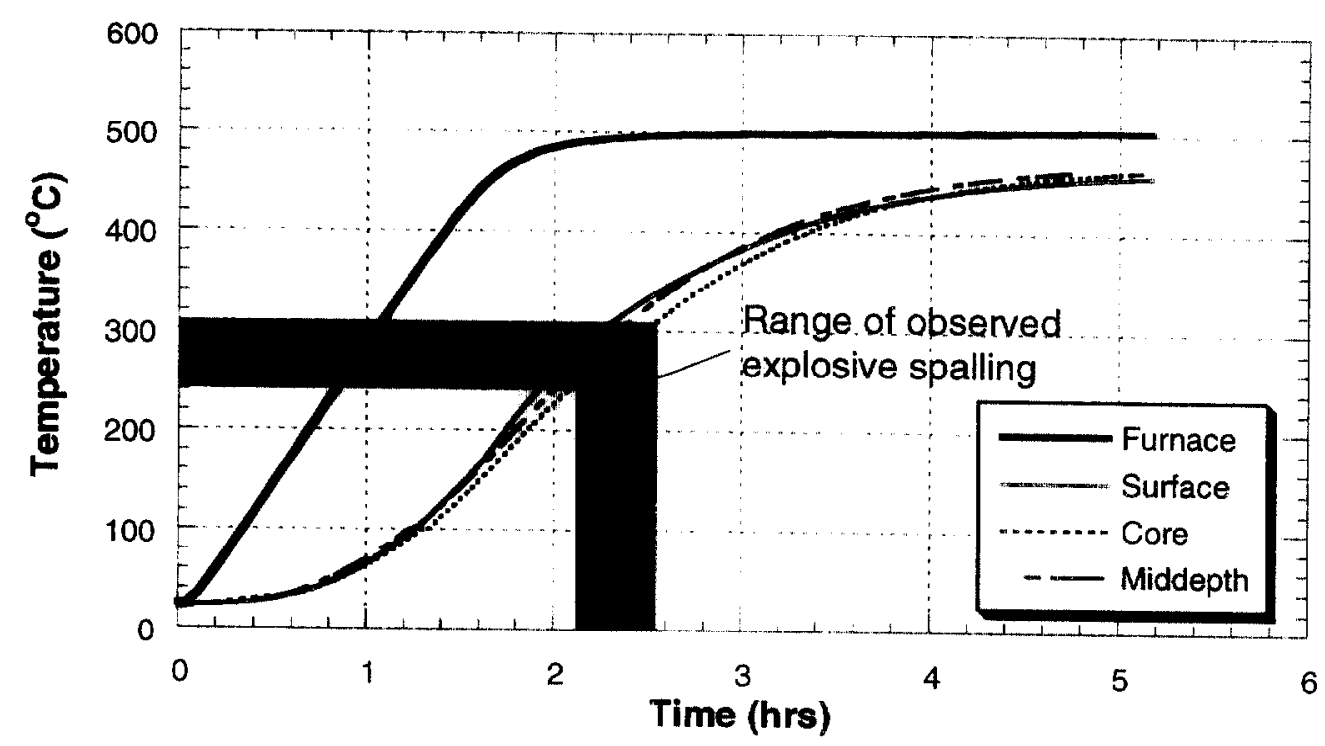

Figure 3.8 Core temperature and time ranges of observed explosive spalling in mixture I specimens

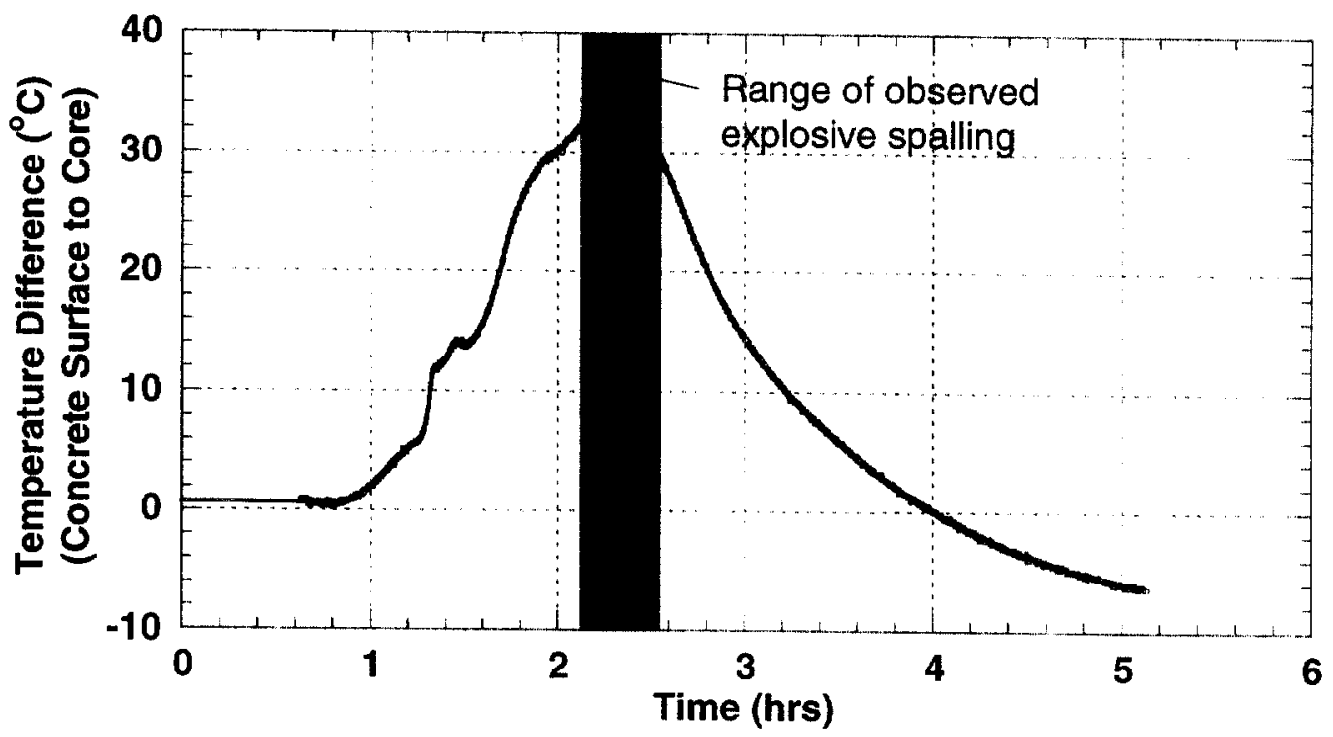

Figure 3.9 Range of temperature difference when explosive spalling occurred

For the unstressed residual property tests, the highest target temperature was $450{ }^{\circ} \mathrm{C}$, not $600^{\circ} \mathrm{C}$ as in the case of the stressed and unstressed tests. Also, unlike the stressed and unstressed tests where each specimen of the same test group was heated 
individually, the entire group of specimens being heated to a given temperature was heated together in the unstressed residual property tests. Explosive spalling occurred in five specimens, four of mixture I concrete and one of mixture II. One of the four exploded mixture I specimens belongs to a group of five specimens being heated to a target temperature of $300^{\circ} \mathrm{C}$ (specimen RS-I-300-2 in Table 3.3, see convention in section 3.3.1). The specimen's core temperature when explosive spalling occurred was estimated to be $240^{\circ} \mathrm{C}$. The other three exploded mixture I specimens are from the group being heated to $450^{\circ} \mathrm{C}$ (specimens RS-I-450-1 to 3). These specimens exploded successively, beginning at an estimated core temperature of $240^{\circ} \mathrm{C}$ and ending at 280 ${ }^{\circ} \mathrm{C}$. The exploded mixture II specimen (RS-II-300-4) belongs to the group of specimens being heated to $300^{\circ} \mathrm{C}$. This specimen exploded at an estimated core temperature of $260^{\circ} \mathrm{C}$.

The concrete temperature range of $240^{\circ} \mathrm{C}$ to $280^{\circ} \mathrm{C}$ in which explosive spalling occurred in mixture I specimens is superposed over the plots of temperature history (Figure 3.1 (a)) and temperature difference (Figure 3.1 (b)) for mixture I concrete and shown in Figures 3.8 and 3.9. As can be seen in Figure 3.9, the temperature range in which explosive spalling occurred coincides with the time of high thermal gradient between the specimen surface and core. This suggests that, while internal pore pressure may be the primary cause for the explosive spalling of the specimens as evidenced by the high velocity with which the concrete fragments were projected at failure, the buildup of thermally induced strain energy was also large at this time, and thus thermal stress might have a secondary role in this failure. 
Table 2.7 Test Matrix

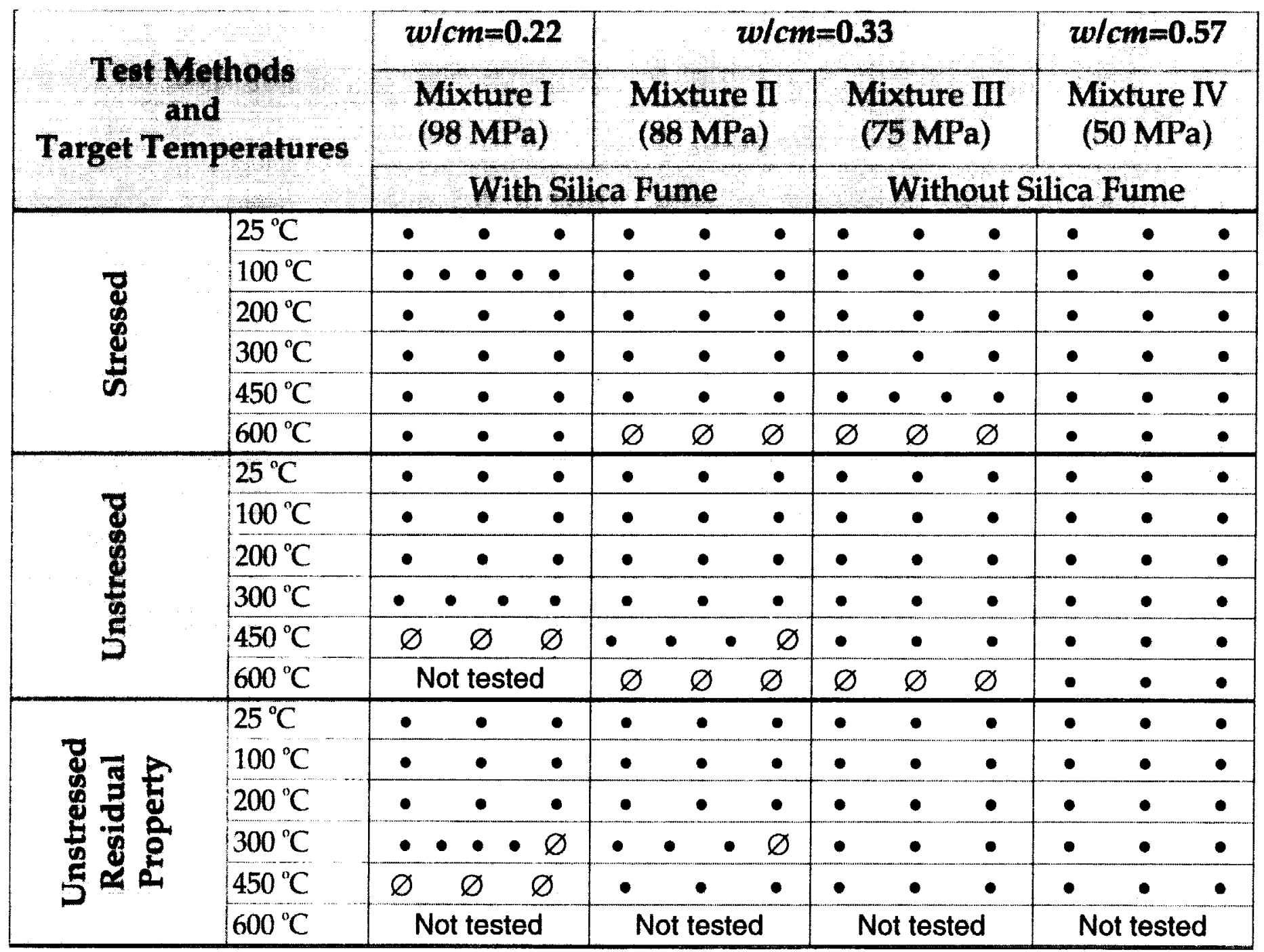

- Test specimen that failed in uniaxial compression

$\varnothing$ Test specimen that failed by explosive spalling 


\title{
3.3 Mechanical Properties
}

This section presents the results of tests to measure compressive strength and modulus of elasticity. The results are grouped according to the type of test. Individual test specimens are identified using the following convention:

\author{
Test Method - Concrete Mixture - Target Temperature - Specimen Number \\ (ST: Stressed Test) \\ (I, II, III, or IV) \\ $\left(25^{\circ} \mathrm{C}\right.$ to $\left.600{ }^{\circ} \mathrm{C}\right)$ \\ $(1,2,3, \ldots)$ \\ (UN: Unstressed Test) \\ (RS: Unstressed Residual Property Test)
}

\subsubsection{Results of Stressed Tests}

Results of the stressed tests are summarized in Table 3.1. At each target temperature, at least three specimens were tested. The measured ultimate and normalized compressive strengths with respect to temperatures are shown in Figure 3.10 (a) and (b). The measured ultimate and normalized static Young's modulii of elasticity with respect to temperatures are shown in Figures 3.11 (a) and (b). All stressed test specimens were restrained by a compressive preload of $0.4 \mathrm{f}_{23}{ }^{\circ} \mathrm{C}$ that was maintained for the entire duration of heat exposure and is shown in column 3 of Table 3.1. Prior to heating, the specimens' masses, dimensions, and longitudinal resonant frequencies were measured and used to calculate dynamic Young's modulus of elasticity in accordance with ASTM C215-91 Standard Test Method for Fundamental Transverse, Longitudinal and Torsional Frequencies of Concrete Specimens. These measurements are listed in Table A.1 of Appendix A. The calculated dynamic Young's modulus of elasticity at room temperature is listed in column 4 of Table 3.1. The standard deviation (SD) and the coefficient of variation (CV) for the dynamic elastic modulus are shown in column 5 . Since under the stressed test condition, the specimens were tested hot while maintained under a constant preload, it was not possible to obtain the dynamic Young's modulus of elasticity at elevated temperatures. Thus, the modulus of elasticity at elevated temperature was calculated from the strain measurement obtained from the furnacemounted compresssometer described in section 2.5.2, in accordance with ASTM C46994 Standard Test Method for Static Modulus of Elasticity and Poisson's Ratio of Concrete in Compression. The static elastic modulus of each specimen is listed in Column 6 of Table 3.1. As shown in this column, the static modulus of elasticity at elevated temperatures was not measured for all the specimens. This is due to the difficulty involved in setting up the furnace-mounted compressometer and keeping it from being disturbed during the setup and heating processes. It was found that the furnace-mounted compressometer was very sensitive to any disturbances such as closing the furnace door, testing machine vibration, and prolonged exposure to high temperatures. Column 7 lists the SD and CV of the measured static modulii of elasticity for each target temperature. The measured compressive strengths, SD and CV of the measured strengths at each target temperature are listed in columns 8 and 9. Column 10 lists the percentage strength loss relative to the average room temperature strength, and column 
11 lists the average strength loss. Finally, incidences of explosive spalling failure and the time and estimated concrete temperature at which explosive spalling occurred are noted in column 12.

The symbols in Figures 3.10 (a) and (b) represent the individual test result at each target temperature. The lines in Figures 3.10 (a) and (b) connect the means of ultimate and normalized compressive strengths for each HSC mixture. Strength data for mixtures II and III at $600{ }^{\circ} \mathrm{C}$ are not available due to explosive spalling of all specimens of these two mixtures while being heated to this temperature. As shown in Figures 3.10 (a) and (b), under the stressed test condition, compressive strength of the four HSC mixtures varied similarly with increasing temperature. Between room temperature and $100^{\circ} \mathrm{C}$, all four mixtures had a strength reduction of between $25 \%$ to $33 \%$. This is followed by a minor strength recovery between $100^{\circ} \mathrm{C}$ to $300^{\circ} \mathrm{C}$. In the range of $200^{\circ} \mathrm{C}$ to $450{ }^{\circ} \mathrm{C}$, however, there is no statistically significant difference in the strength reduction of the four mixtures. At $600^{\circ} \mathrm{C}$ there is significant additional strength reduction.

When the within group variability is taken into account, the following differences in strength reduction are noted:

- At $100^{\circ} \mathrm{C}$, mixture $I$ has a smaller strength reduction than the other mixtures, and there is no difference between mixtures II, III, and IV.

- At $200{ }^{\circ} \mathrm{C}, 300^{\circ} \mathrm{C}$, and $450{ }^{\circ} \mathrm{C}$ there is no difference between the four mixtures.

- At $600^{\circ} \mathrm{C}$, mixture I has a smaller strength loss than mixture IV.

- Mixtures II and III are more susceptible to explosive spalling.

Figures 3.11 (a) and (b) show the decrease in static Young's modulus of elasticity for the four HSC mixtures under the stressed test condition. In contrast to strength loss, there is a general trend of progressive loss of modulus of elasticity with increasing temperature. Since data at elevated temperatures were incomplete, it is not possible to conduct a rigorous analysis for statistically significant differences among the four mixtures. The incomplete data, however, indicate no difference among the mixtures. 
Table 3.1 Summary of Stressed Test Results

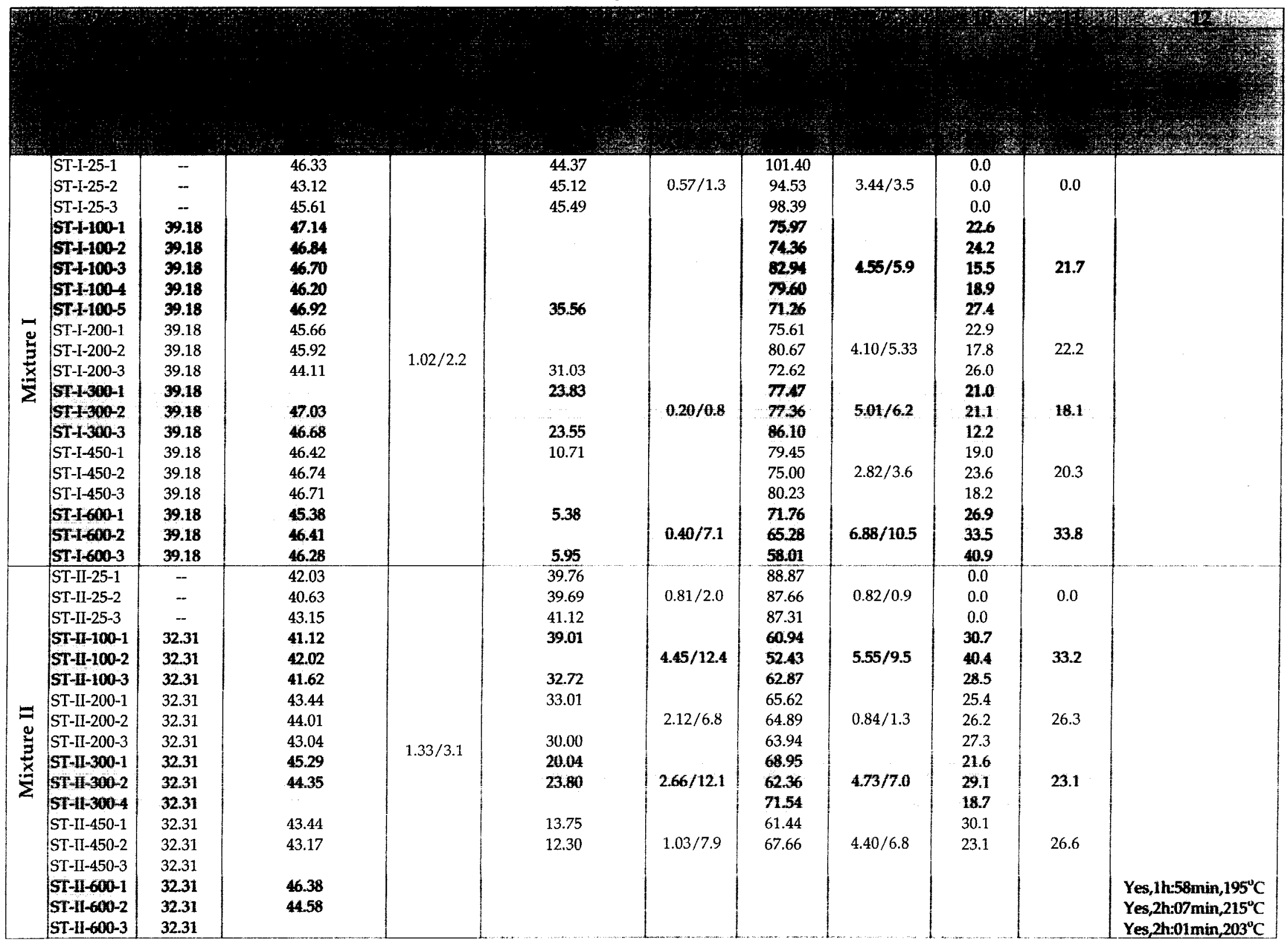


Table 3.1 Summary of Stressed Test Results (continued)

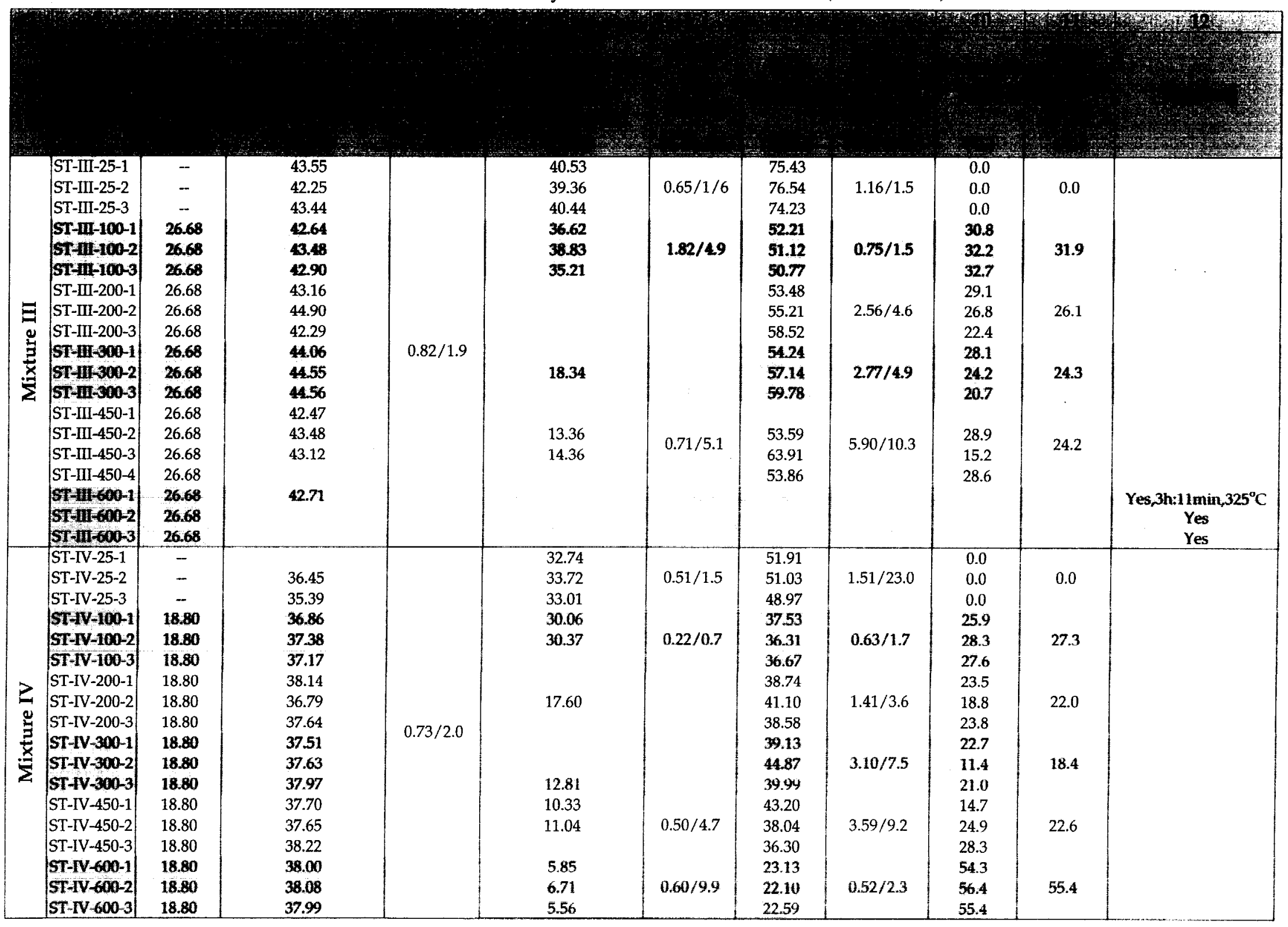




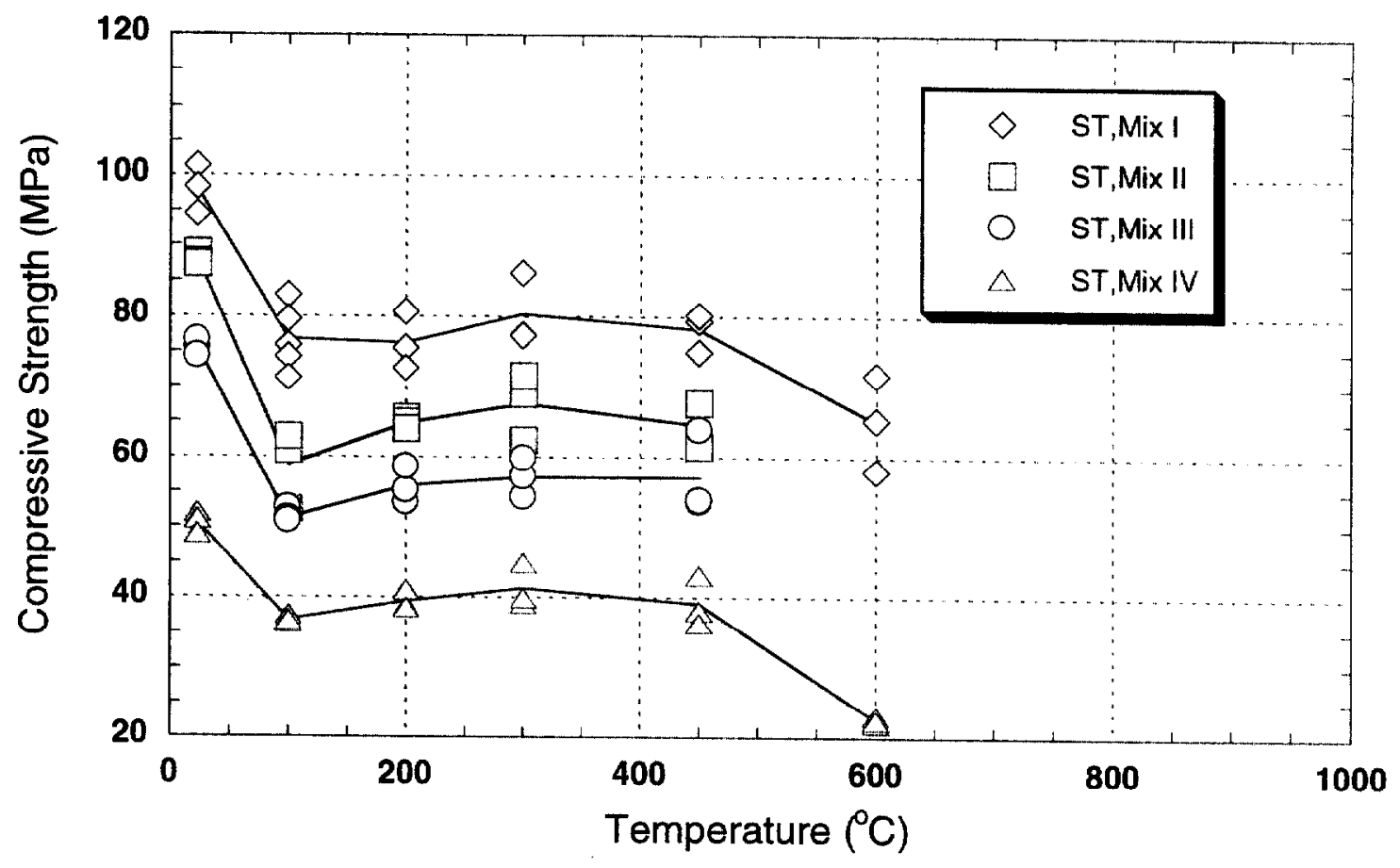

Figure 3.10(a) Compressive strengths as function of target temperature under stressed test

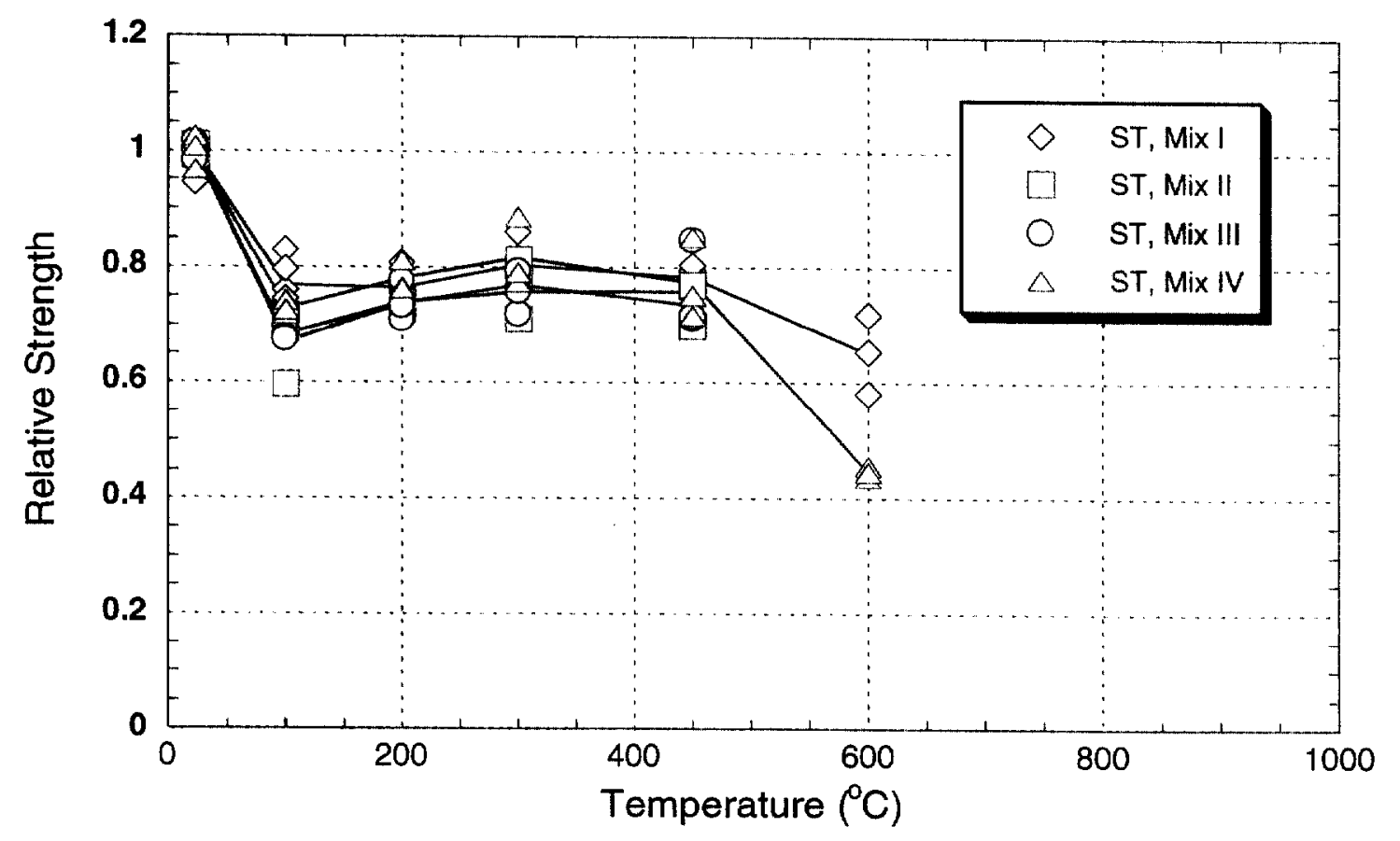

Figure 3.10(b) Relative compressive strengths as function of target temperature under stressed test 


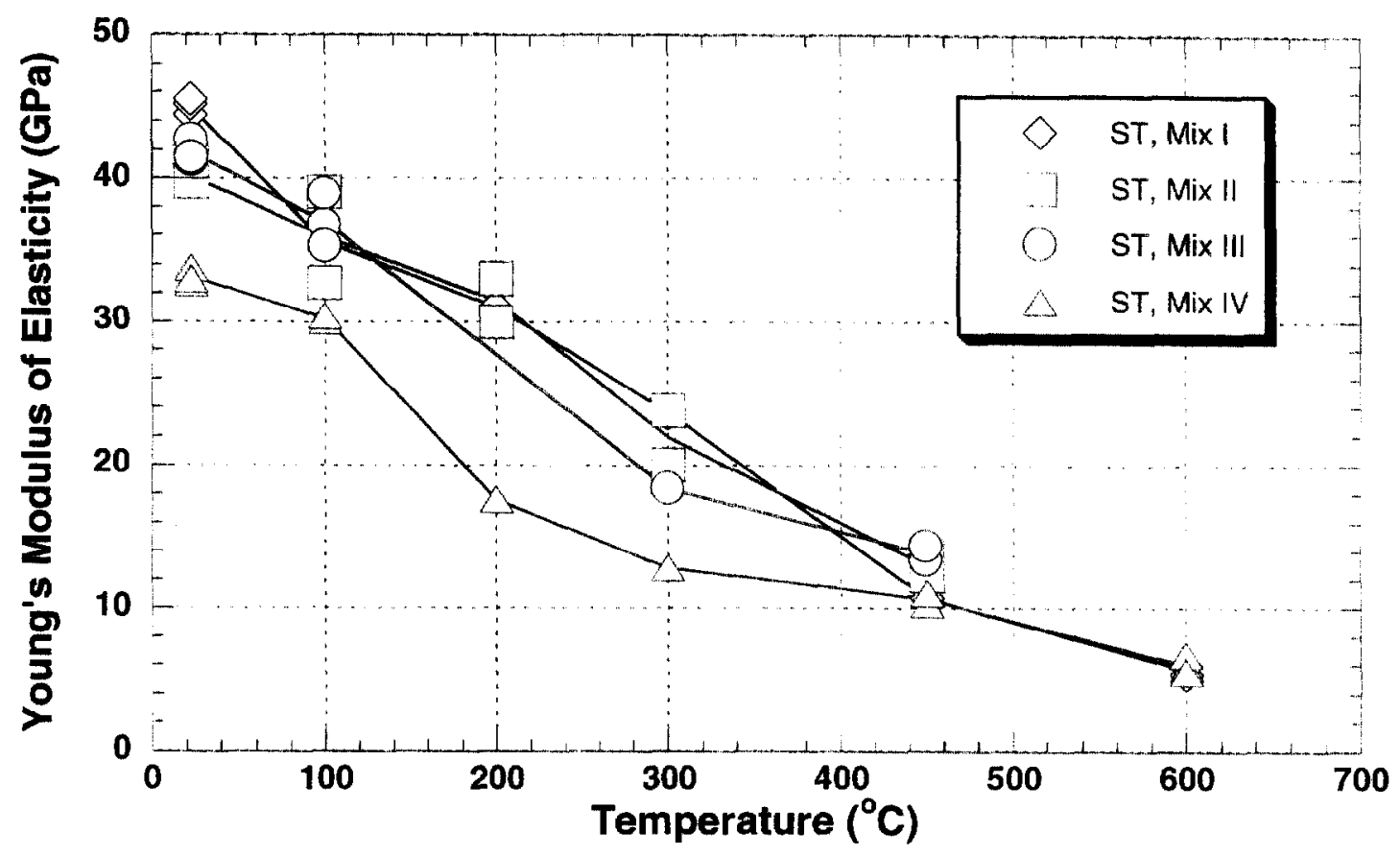

Figure 3.11(a) Young's modulus of elasticity as function of target temperature under stressed test

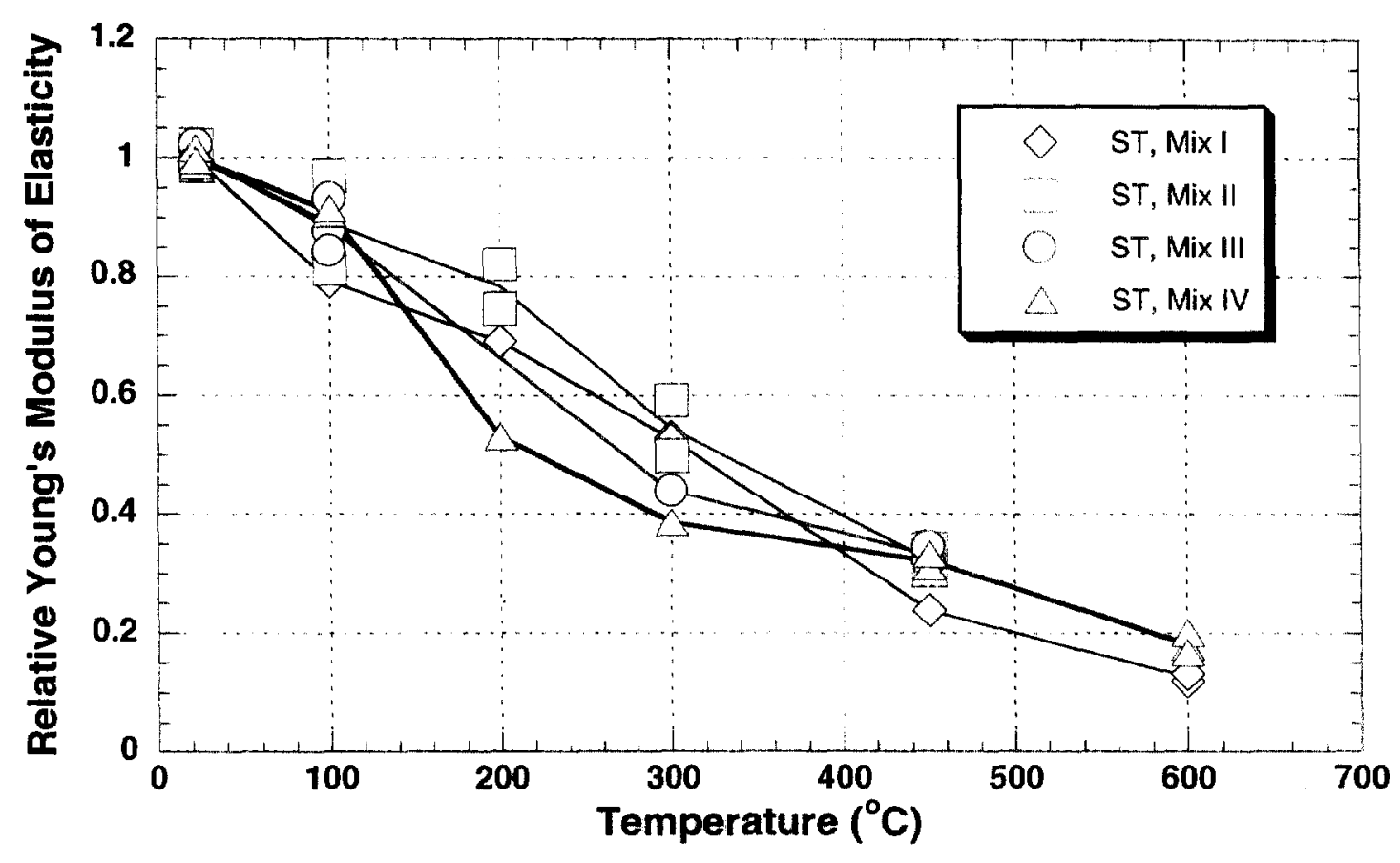

Figure 3.11(b) Relative Young's modulus of elasticity as function of target temperature under unstressed test 


\subsubsection{Results of Unstressed Tests}

Results of the unstressed tests are summarized in Table 3.2. The measured ultimate and normalized compressive strengths with respect to temperature are shown in Figures 3.12 (a) and (b). The measured ultimate and normalized static Young's modulii of elasticity with respect to temperature are shown in Figures 3.13 (a) and (b).

Measurements of masses, dimensions, and longitudinal frequencies of the cylinders for calculating the initial dynamic Young's modulus of elasticity are listed in Table A.2 of Appendix A. Similar to the stressed tests, unstressed test specimens were tested hot and thus measurements of mass, dimensions, and longitudinal resonant frequencies at elevated temperatures which are necessary for calculating dynamic Young's modulus of elasticity at elevated temperatures were not available. Thus, modulus of elasticity at elevated temperature is based on the strain measurement obtained from the furnacemounted compressometer. The static modulus of elasticity of each specimen is listed in column 5 of Table 3.2. Again, data for static modulus are incomplete due to the difficulty involving the use of the compressometer.

The symbols in Figures 3.12 (a) and (b) represent the measured ultimate and normalized compressive strengths for each test specimen, and the lines represent the mean values for each mixture. As shown in these figures and in Table 2.7, because of explosive spalling, strength data are not available for mixture I above $300^{\circ} \mathrm{C}$ nor for mixtures II and III above $450^{\circ} \mathrm{C}$. As can be seen on these figures, the compressive strengthtemperature relationships for the four HSC mixtures were similar to those observed for the stressed tests. Between $25^{\circ} \mathrm{C}$ to $100^{\circ} \mathrm{C}$, all mixtures had significant strength losses, ranging between $26 \%$ for mixture IV and $35 \%$ for mixture $\Pi$. These relative strength losses are slightly higher than those observed for the stressed tests at the same temperature. As temperature increases from $100^{\circ} \mathrm{C}$ to $300^{\circ} \mathrm{C}$, there is some strength recovery, and the range of relative strength losses is between $18 \%$ and $26 \%$ of the room temperature strengths. Analysis of variance showed that the higher mean strengths at $300^{\circ} \mathrm{C}$ are statistically significant. Whereas differences in the mean strengths at $100^{\circ} \mathrm{C}$, $200^{\circ} \mathrm{C}$, and $450^{\circ} \mathrm{C}$ were not statistically significant. Above $300^{\circ} \mathrm{C}$ and $450{ }^{\circ} \mathrm{C}$, there are further strength losses for mixtures II, III, and IV, and the occurrences of explosive spalling in mixture I. At $600^{\circ} \mathrm{C}$, there are strength data only for mixture IV, which has a total strength loss of $70 \%$. Strength data for mixtures I, II, and III at $600{ }^{\circ} \mathrm{C}$ were not available due to explosive spalling.

The four mixtures had similar relative strength losses when heated up to $300^{\circ} \mathrm{C}$. However, in terms of explosive spalling potential, mixture I showed the highest degree of susceptibility, because the entire group of specimens exploded while being heated to $450^{\circ} \mathrm{C}$ (see Table 2.7). Mixture II appeared to be slightly less susceptible, as explosive spalling occurred in one out of four specimens while being heated to $450^{\circ} \mathrm{C}$, and the entire group of specimens exploded while being heated to $600^{\circ} \mathrm{C}$. Mixture III also appeared to be slightly less susceptible to explosive spalling compared with mixtures I 
and II, because no mixture III specimens exploded at $450^{\circ} \mathrm{C}$ but the entire group exploded while being heated to $600^{\circ} \mathrm{C}$. As in the stressed tests, explosive spalling did not occur in any of the mixture IV specimens.

Figures 3.13 (a) and (b) show the decrease in static Young's modulus of elasticity for the four mixtures under the unstressed test condition. The static Young's modulus of elasticity decreased progressively with increased temperatures, and the magnitudes of the losses in relative values were similar to those in the stressed tests.

In general, the reduction in relative value of elastic modulus was independent of the mixture. The only exception was for heating to $200^{\circ} \mathrm{C}$, for which mixture IV had a slightly greater reduction. 
Table 3.2 Summary of Unstressed Test Results

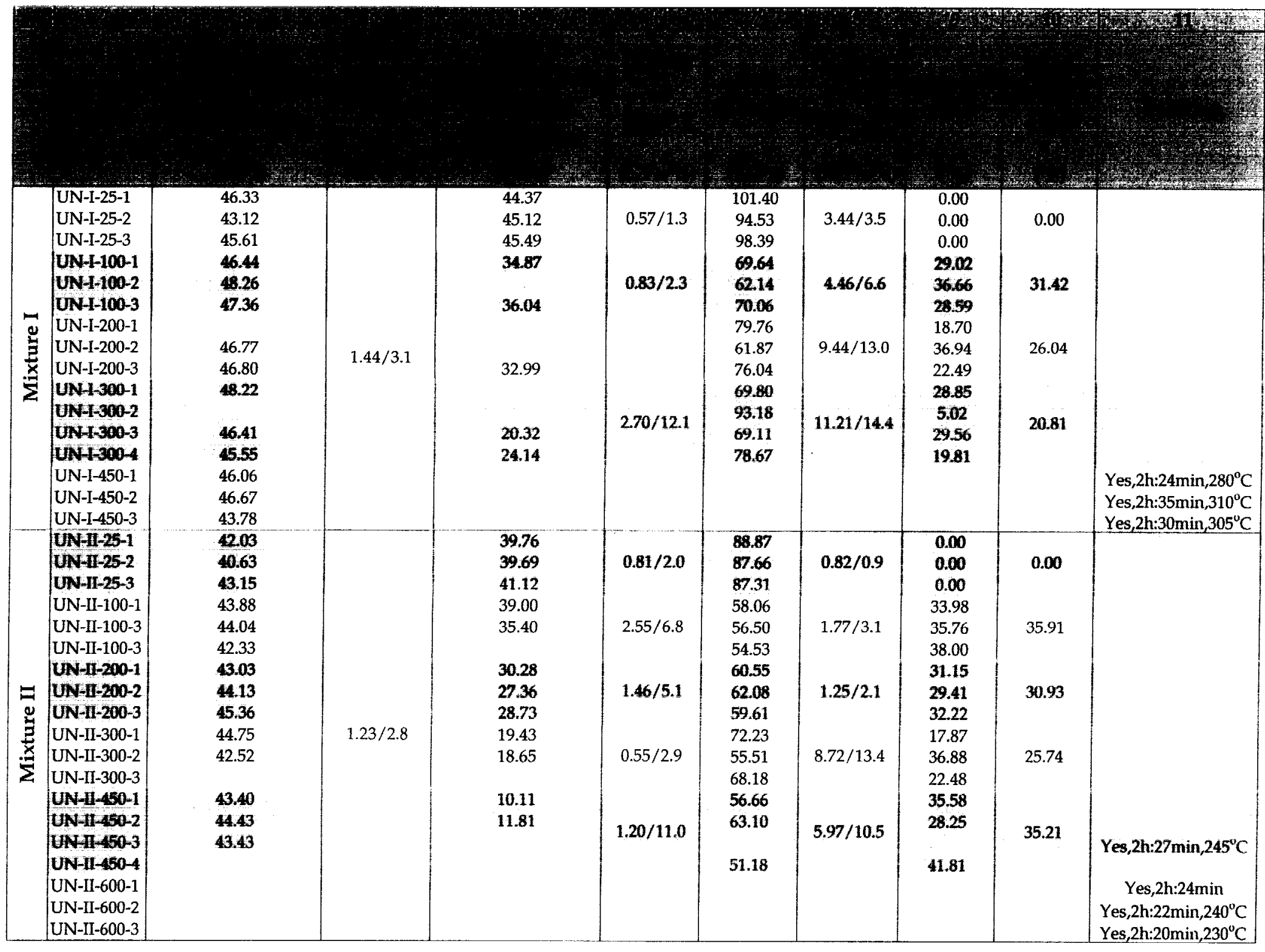




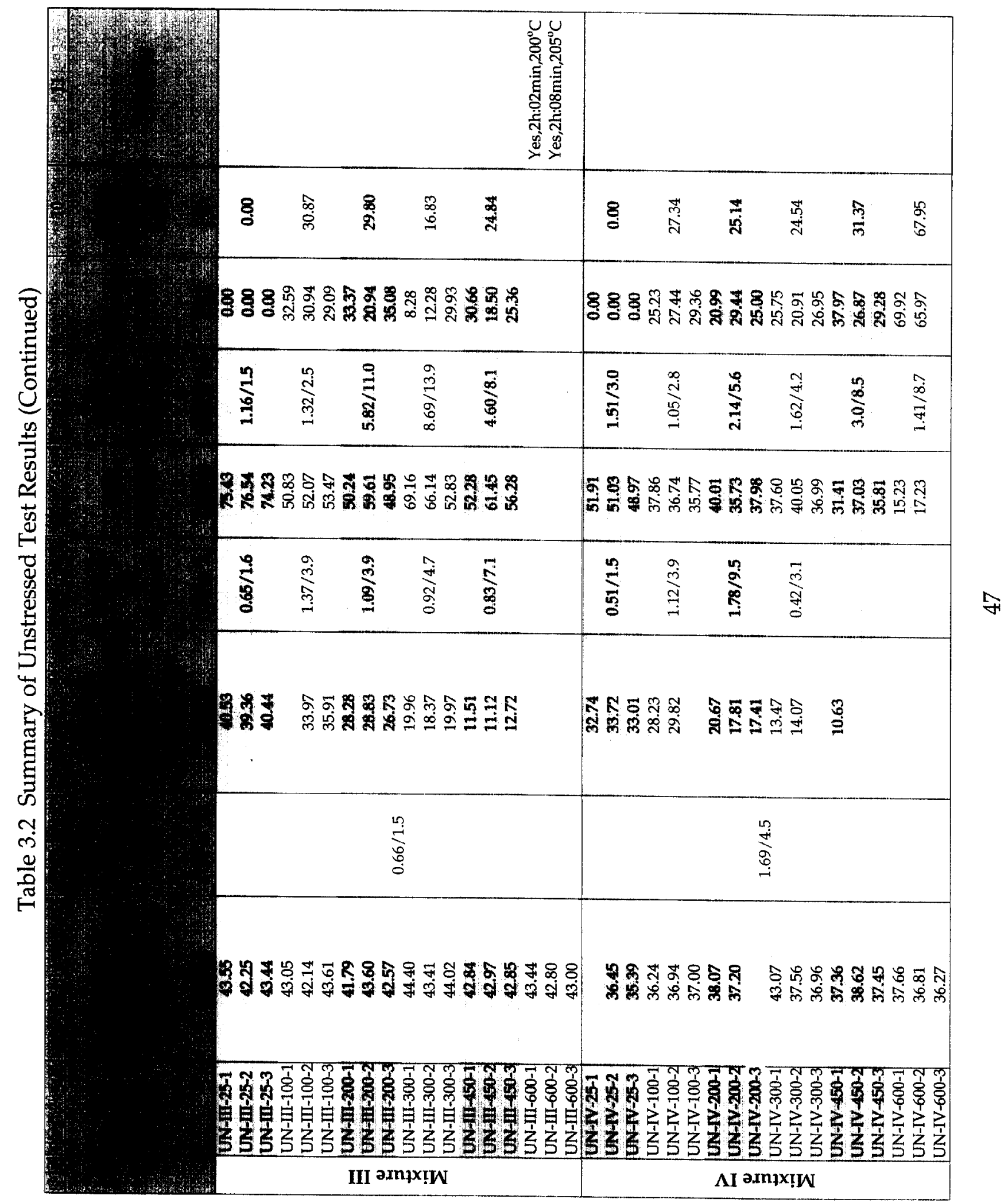




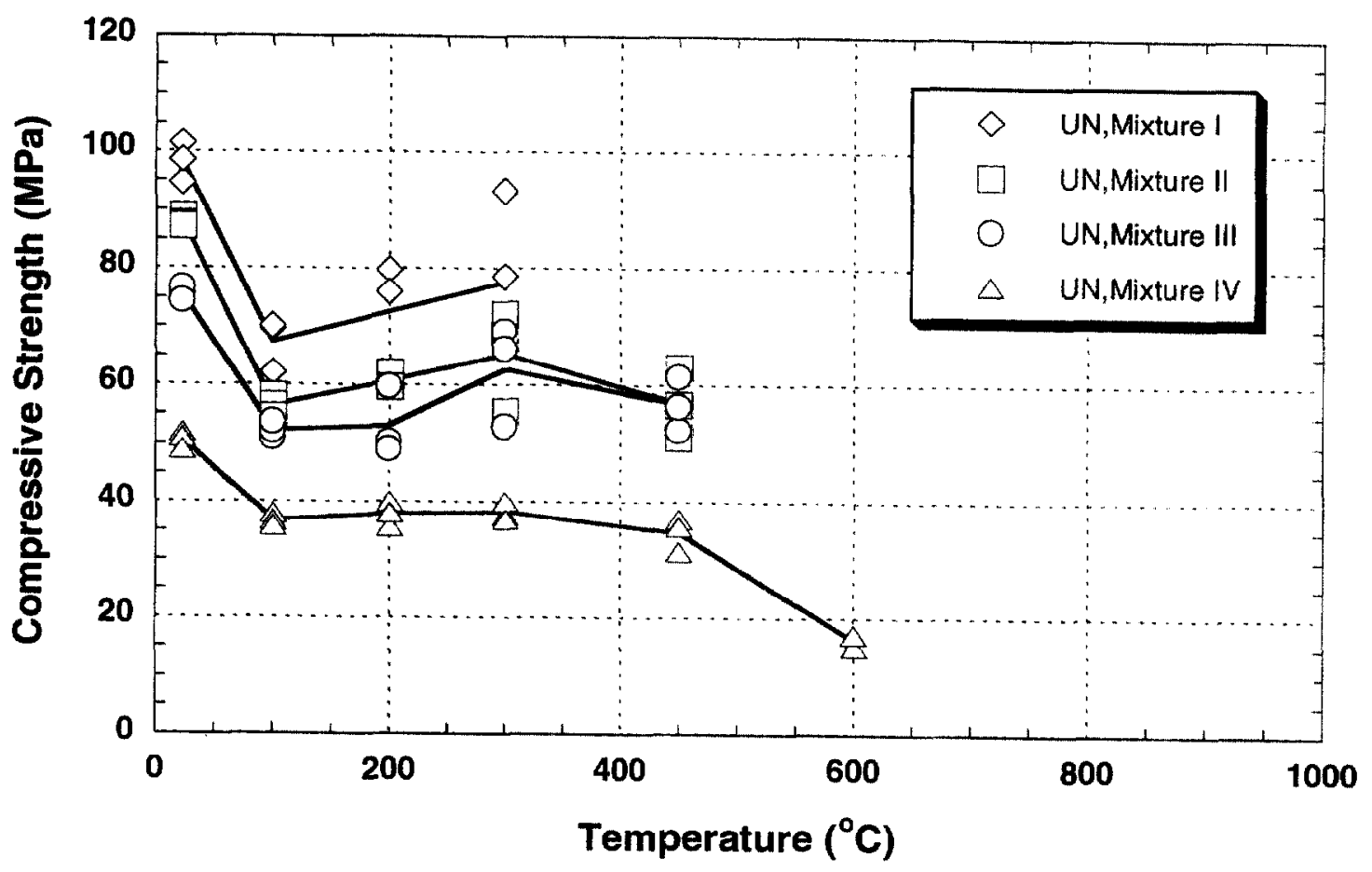

Figure 3.12(a) Compressive strengths as function of target temperature under unstressed test

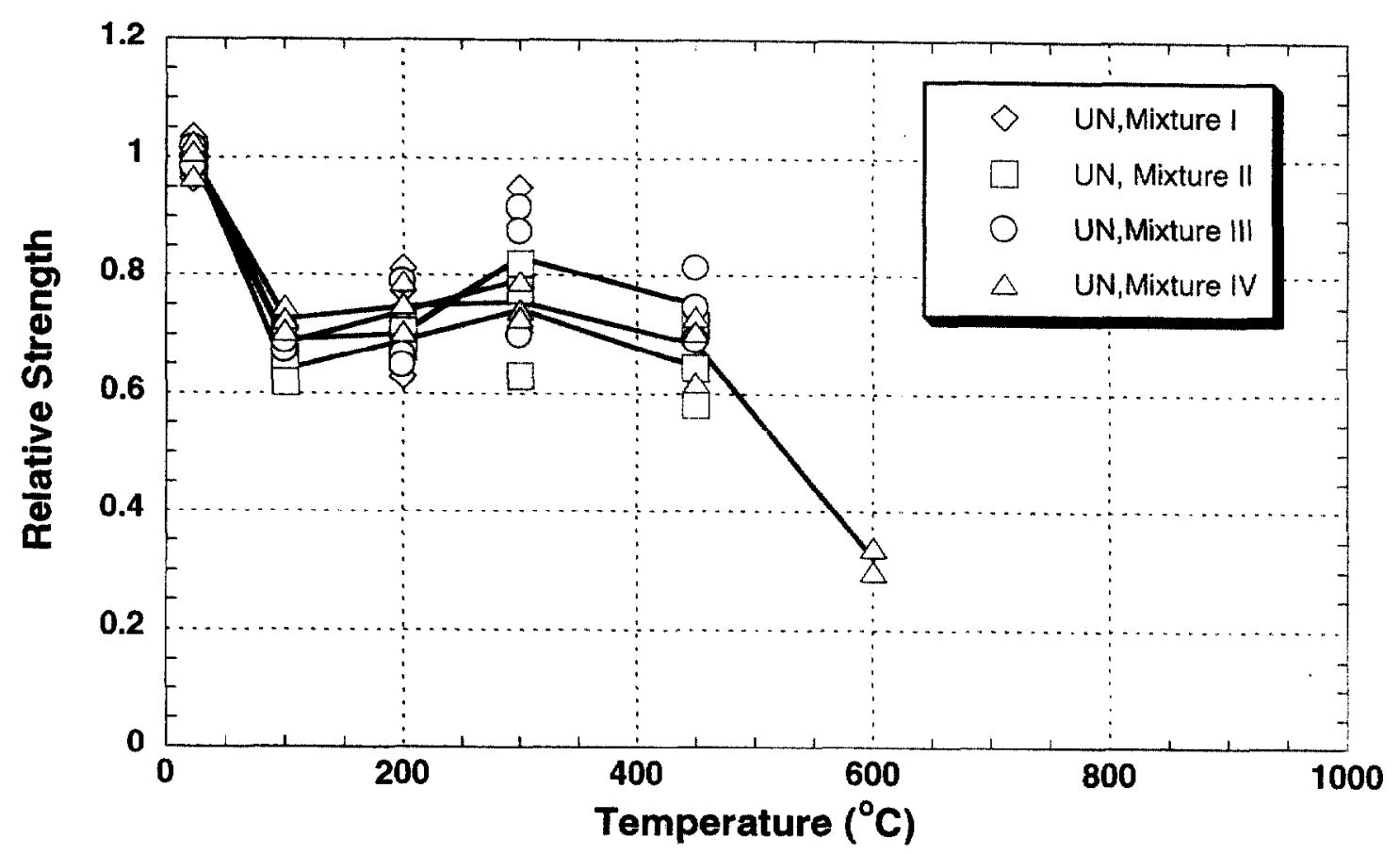

Figure 3.12(b) Relative compressive strengths as function of target temperature under unstressed test 


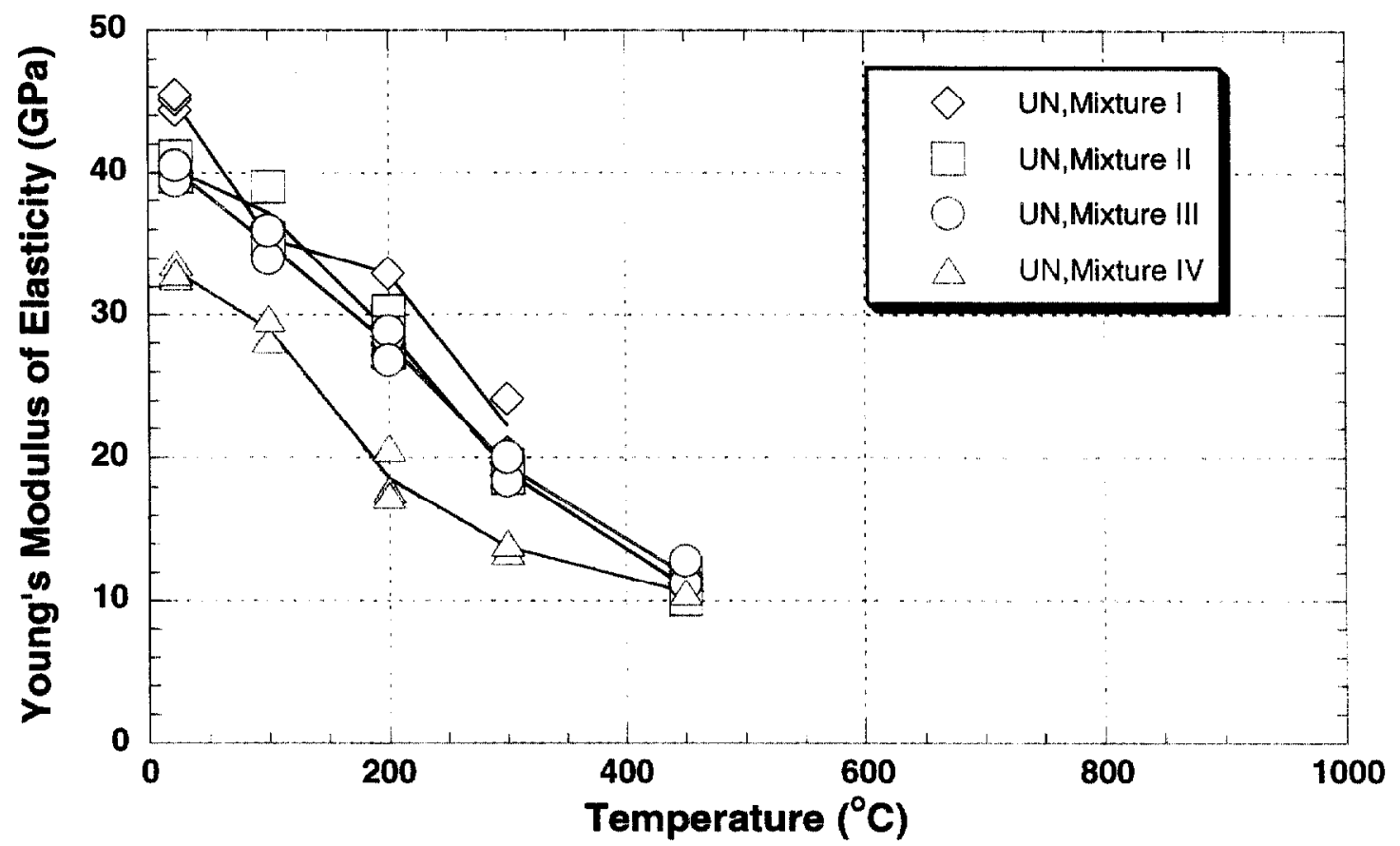

Figure 3.13(a) Young's modulus of elasticity as function of target temperature under unstressed test

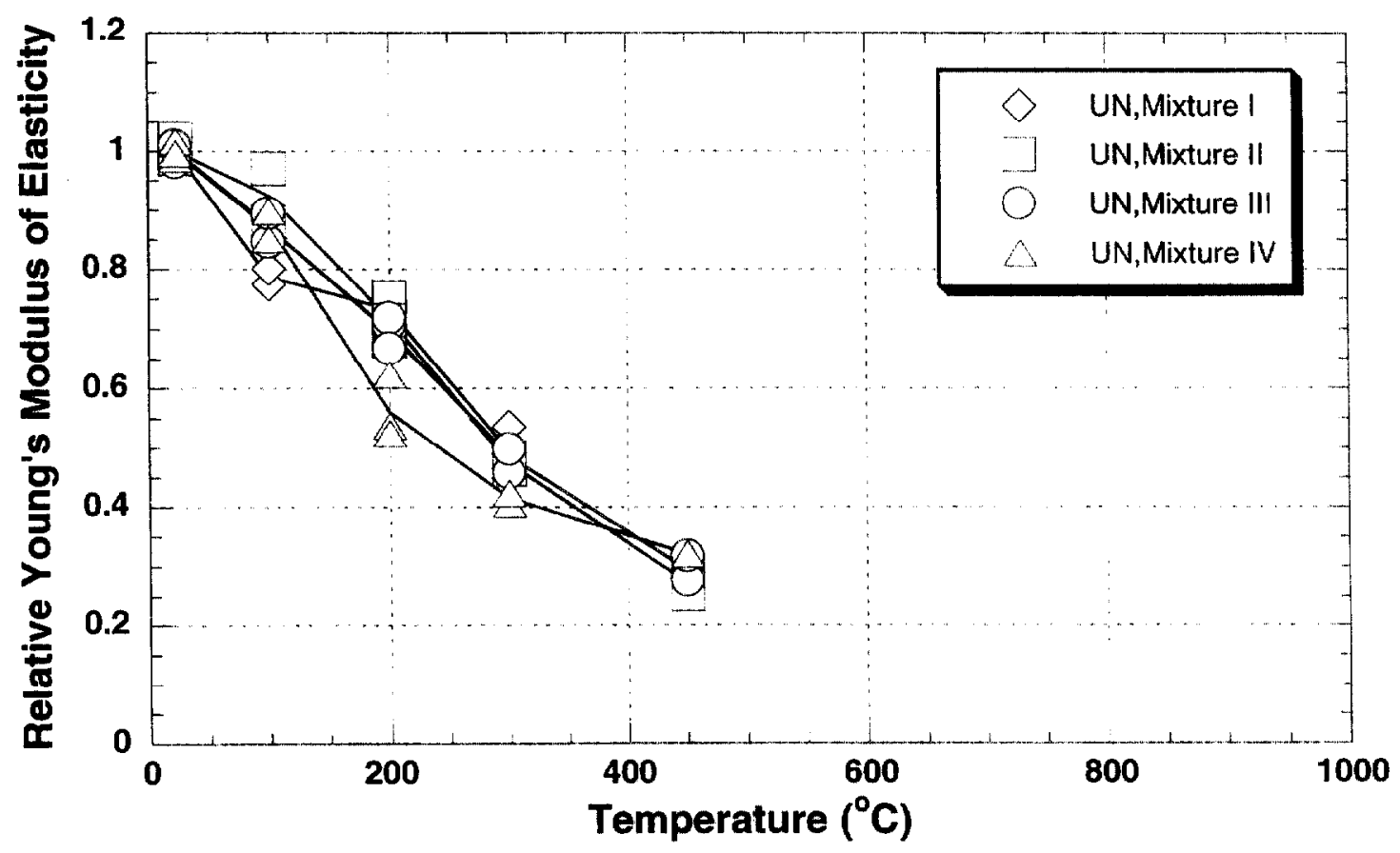

Figure 3.13(b) Relative Young's modulus of elasticity as function of target temperature under unstressed test 


\subsubsection{Results of Unstressed Residual Property Tests}

Compressive strengths and modulii of elasticity of original $\left(25^{\circ} \mathrm{C}\right)$ and heated specimens, obtained under the unstressed residual property test method, are listed in Table 3.3 and plotted with respect to the target exposure temperatures in Figures 3.14 and 3.15. Also listed in Table 3.3 are residual strengths of heated specimens, normalized with respect to the means of room temperature strengths, and the coefficients of variation (CV) and standard deviation (SD) for each group of specimens. As shown, the $\mathrm{CV}$ for compressive strength measurements varies from $0.9 \%$ to $6.6 \%$, with an average value of $3.8 \%$.

Plotted in Figures 3.14 and 3.15 are both the individual test data (symbols) at each temperature level and the means (lines) of these test data. As shown in Figure 3.14 (a) and (b), compressive strengths of mixtures III and IV concretes, which had $w / \mathrm{cm}$ ratios of 0.33 and 0.57 respectively and contained no silica fume, varied similarly with increasing temperature. The strength-temperature relationships in these two mixtures can be characterized by an initial strength reduction of between $25 \%$ to $30 \%$ at $100{ }^{\circ} \mathrm{C}$. This is followed by a fairly constant residual relative strength between $100{ }^{\circ} \mathrm{C}$ to $300{ }^{\circ} \mathrm{C}$. Mixture IV has slightly higher residual relative strength at $200^{\circ} \mathrm{C}$, while mixture III has similar strengths at the three temperatures. Further reduction in compressive strength resumes at temperatures above $300^{\circ} \mathrm{C}$. Exposure to $450{ }^{\circ} \mathrm{C}$ caused a $50 \%$ compressive strength loss in mixtures III and IV.

The silica fume containing concretes, mixtures I $(w / \mathrm{cm}=0.22)$ and II $(w / \mathrm{cm}=0.33)$, had a similar strength reduction of between 10 to $15 \%$ at $100{ }^{\circ} \mathrm{C}$. At temperatures above $100^{\circ} \mathrm{C}$, the strength of mixture II continued to drop - almost linearly - with increasing temperature, while mixture I had a higher strength at $200^{\circ} \mathrm{C}$. Between $200^{\circ} \mathrm{C}$ and 300 ${ }^{\circ} \mathrm{C}$, the relative strength of both mixtures decreased following a similar trend as that of mixture II. At $300^{\circ} \mathrm{C}$, however, mixture I sustained only about $13 \%$ strength loss, while mixture II had about $30 \%$ loss. At $450^{\circ} \mathrm{C}$, mixture II sustained a similar strength loss, about $50 \%$, as for mixtures III and IV. Strength data for mixture I at $450{ }^{\circ} \mathrm{C}$ were not available due to explosive spalling of the entire group of specimens while being heated to this temperature.

An analysis of variance was performed on the relative strength values listed in Table 3.3. Because no results were available for mixture $\mathrm{I}$ at $450^{\circ} \mathrm{C}$, the analysis excludes the data for $450^{\circ} \mathrm{C}$. The ANOVA indicated that the effect concrete mixture was statistically significant, but the interaction effect of temperature and mixture was also statistically significant. The latter result means that the effect of concrete mixture depends on the exposure temperature. The following summarizes the residual strengths of the four mixtures as a function of exposure temperature: 
- For exposure to $100^{\circ} \mathrm{C}$, there was less loss in relative strength for mixtures I and II compared with mixtures III and IV.

- For exposure to $200^{\circ} \mathrm{C}$ and $300^{\circ} \mathrm{C}$, mixture I suffered less relative strength loss than mixtures II, III, and IV.

- For exposure to $450^{\circ} \mathrm{C}$, mixtures II, III, and IV suffered similar loss in relative strength.

Overall, for exposure temperatures of $100^{\circ} \mathrm{C}, 200^{\circ} \mathrm{C}$, and $300^{\circ} \mathrm{C}$, mixture I (lowest $w / \mathrm{cm}$ ) had the highest residual relative strength, mixtures II and III had similar residual relative strengths, and mixture IV tended to have the lowest residual strength. Thus there appears to be a relationship between $w / \mathrm{cm}$ and the residual strength after exposure to elevated temperature.

The residual dynamic Young's modulus of elasticity, calculated for each specimen by normalizing the elastic modulus after heating by the value measured before heating, are also listed in Table 3.3. Also listed in Table 3.3 are the CV for the residual dynamic Young's modulus of elasticity, which ranges from $0.8 \%$ to $11.4 \%$.

Figures 3.15 (a) and (b) show the variation of residual dynamic Young's modulus of elasticity of four concrete mixtures in this test program with increasing temperatures. The symbols in these figures represent individual test data, and the lines represent the means. The dynamic Young's modulus of elasticity of the four mixtures of concrete decreased similarly with increasing temperature. Between room temperature $\left(25^{\circ} \mathrm{C}\right)$ and $300^{\circ} \mathrm{C}$, dynamic Young's modulus of elasticity for all mixtures decreased by more than $50 \%$. Between $300^{\circ} \mathrm{C}$ to $450^{\circ} \mathrm{C}$, the rate of modulus reduction decreased.

Mixtures II and III, which have the same $w / \mathrm{cm}$ ratio of 0.33 and somewhat similar roomtemperature compressive strengths (81 $\mathrm{MPa}$ and $72 \mathrm{MPa}$, respectively), display almost identical residual dynamic Young' modulus of elasticity. The reduction in elastic modulus of mixtures II and III concretes are consistently less than (5 to 10$) \%$ that of mixture IV, which has a $w / \mathrm{cm}$ of 0.57 and a room-temperature compressive strength of $47 \mathrm{MPa}$. The reduction in dynamic modulus of elasticity for mixture I concrete $(w / \mathrm{cm}=0.22,98 \mathrm{MPa})$ is less consistent within the range of temperatures examined and varied between those of mixture IV and mixtures II and III. 

Table 3.3 Summary of Residual Property Test Results

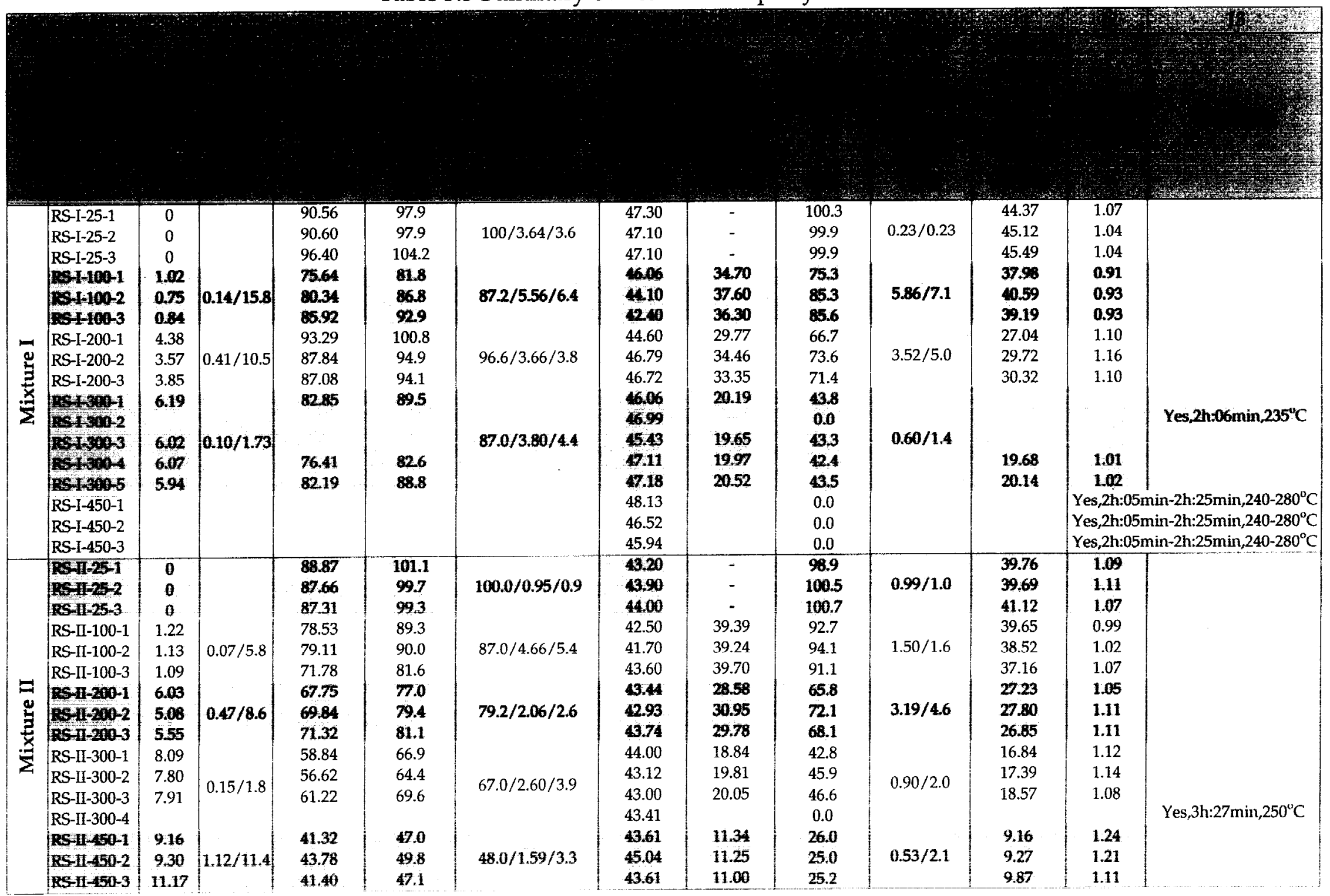


Table 3.3 Summary of Residual Property Test Results (continued)

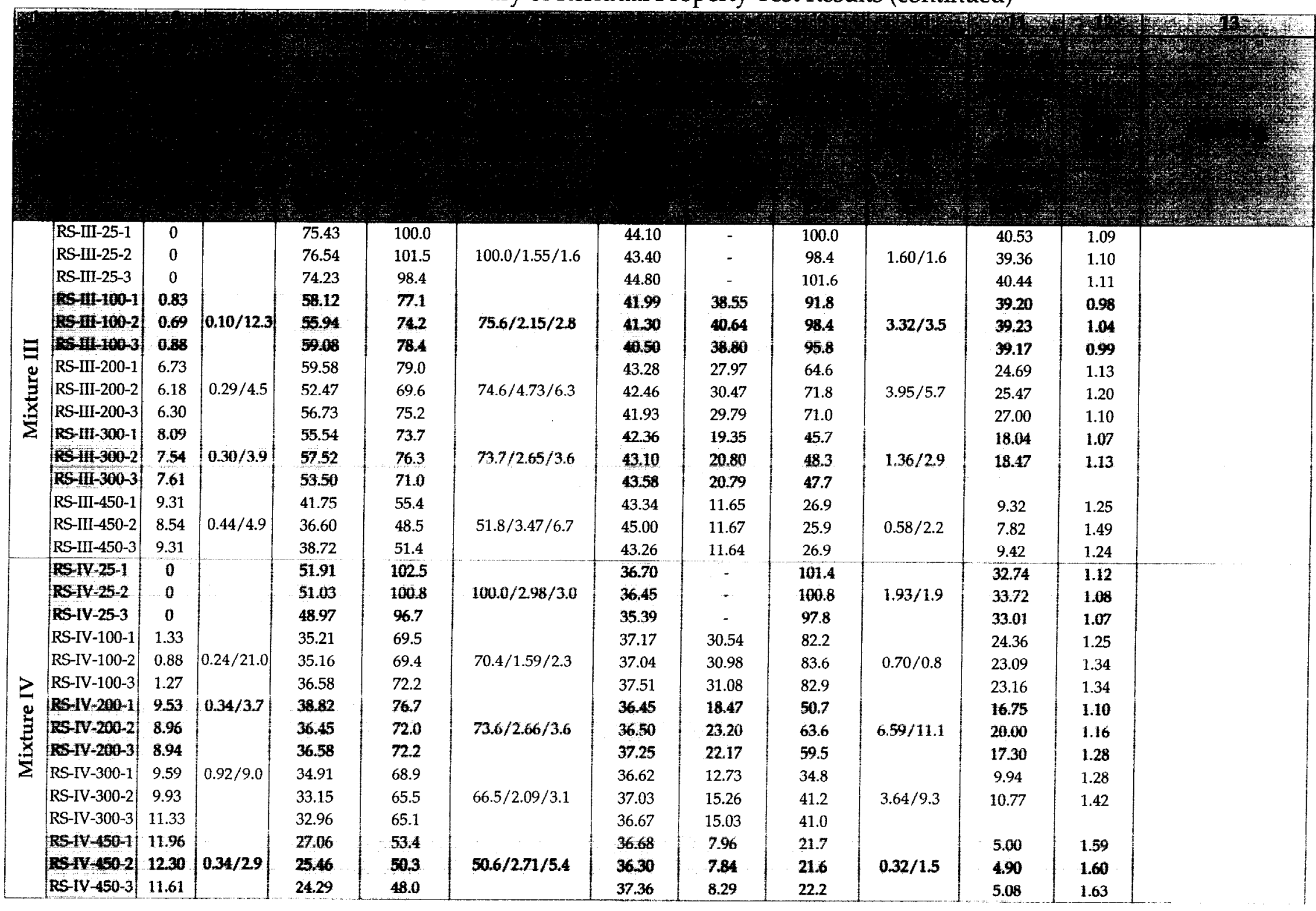




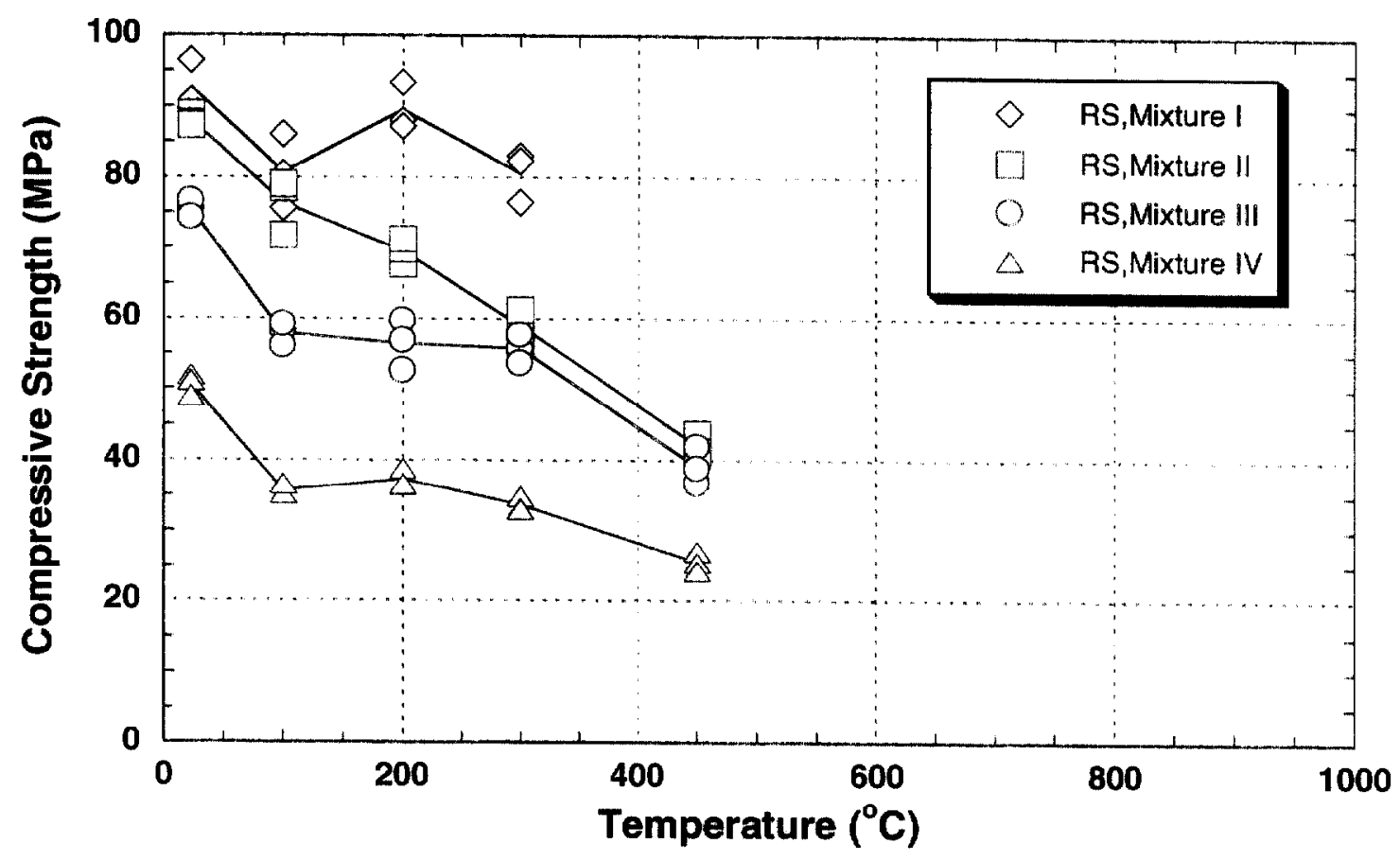

Figure 3.14(a) Compressive strengths as function of target temperature under unstressed residual property test

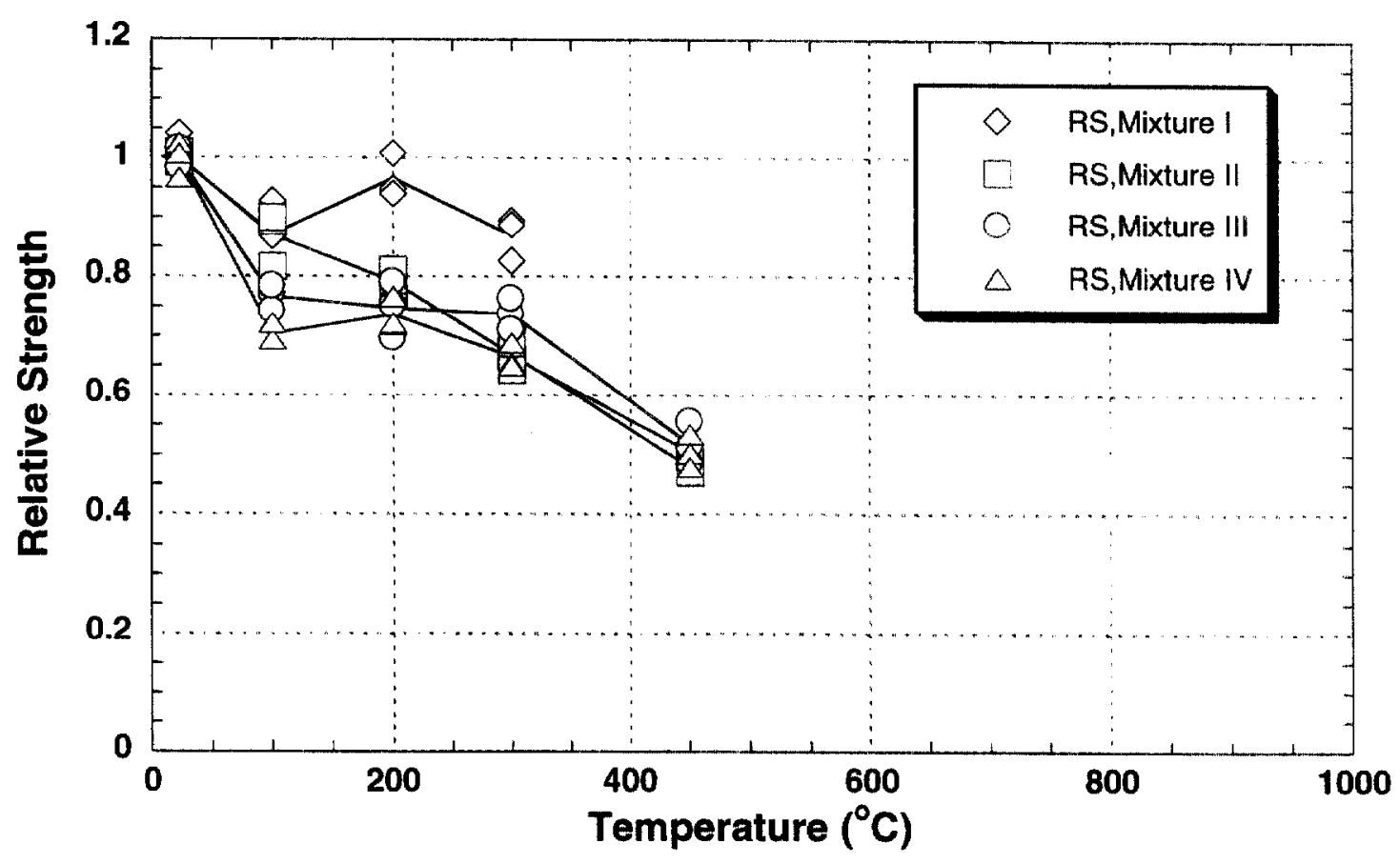

Figure 3.14(b) Relative compressive strengths as function of target temperature under unstressed residual property test 


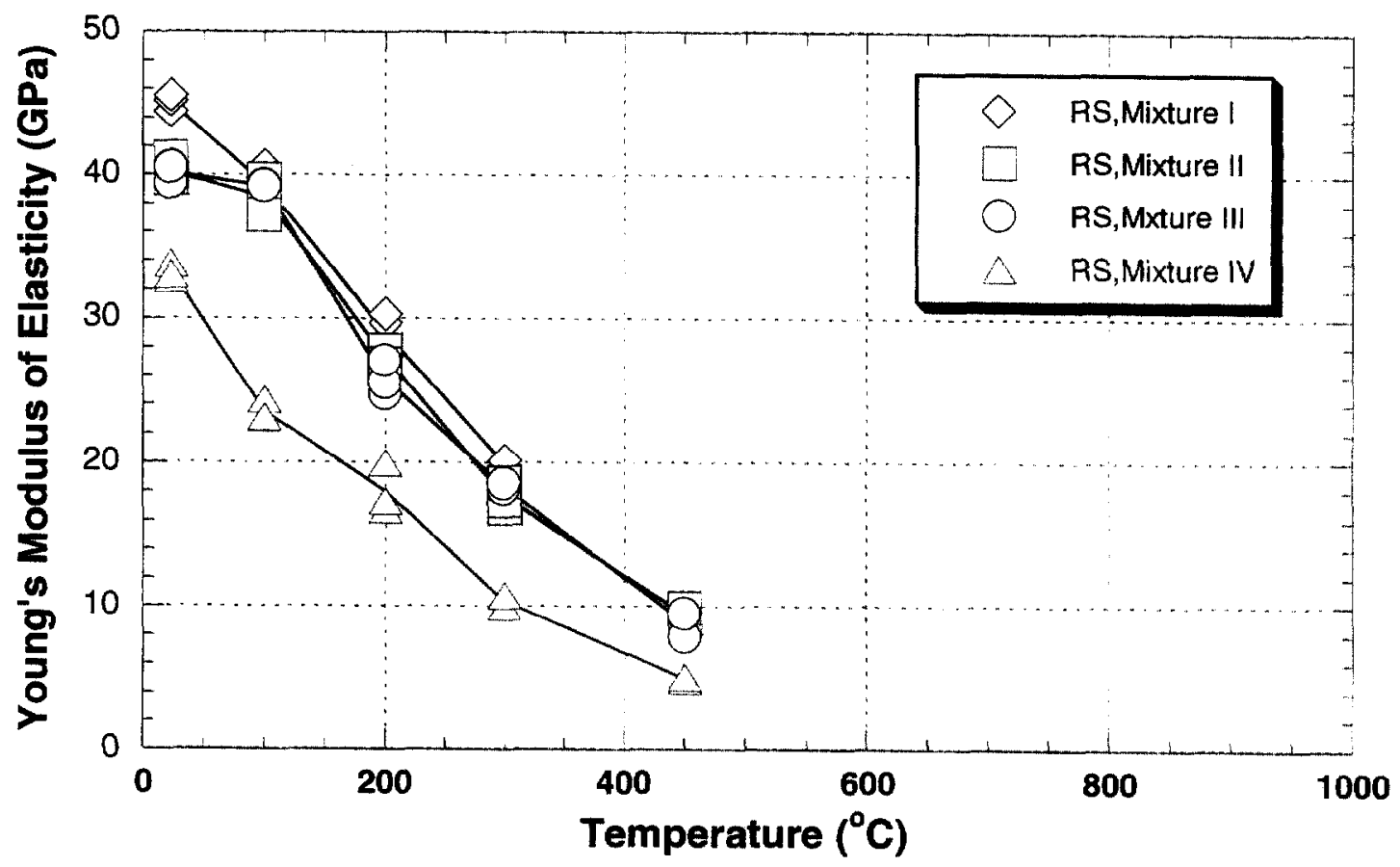

Figure 3.15(a) Young's modulus of elasticity as function of target temperature under unstressed residual property test

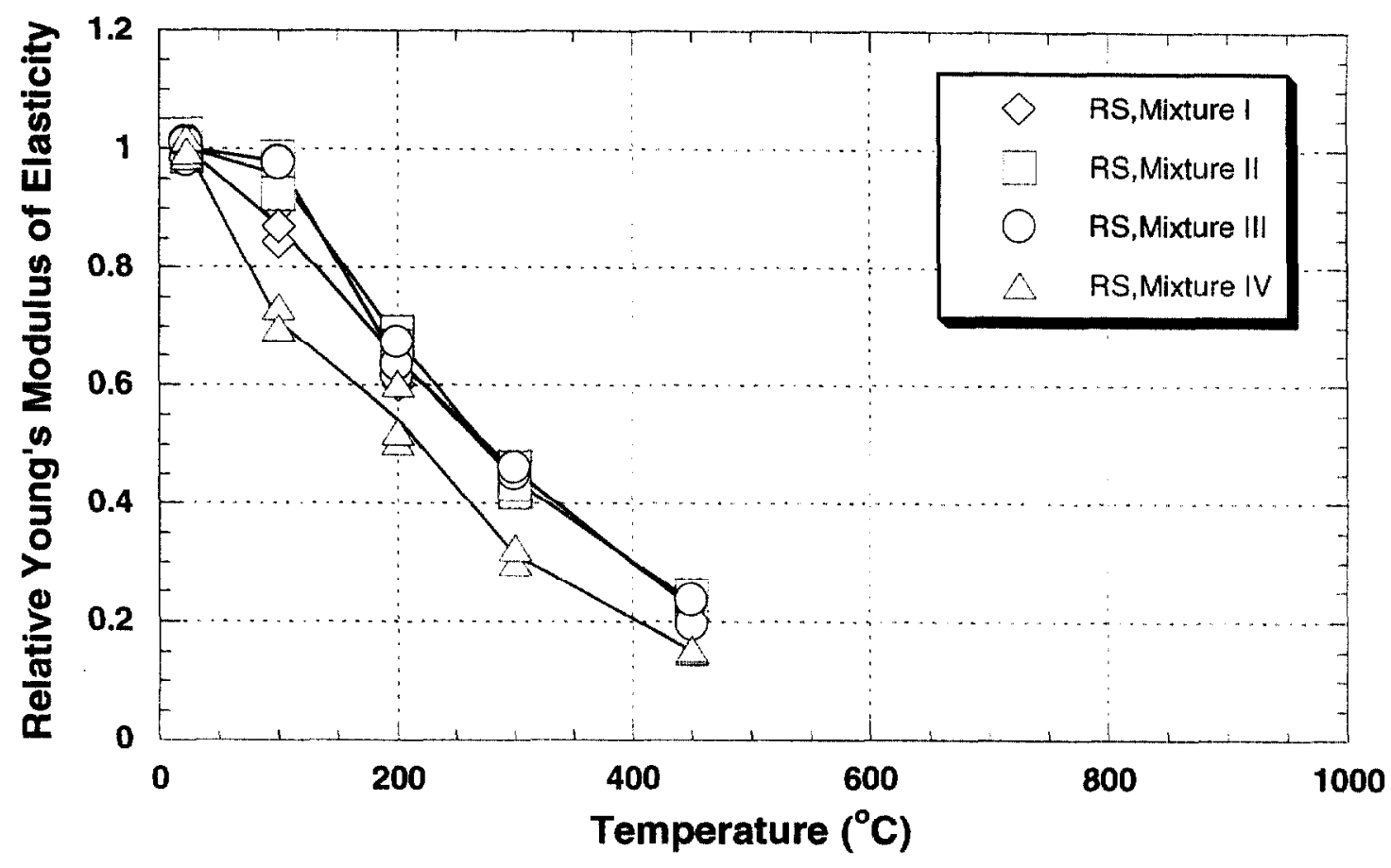

Figure 3.15(b) Relative Young's modulus of elasticity as function of target temperature under unstressed residual property test 



\subsection{EFFECTS OF TEST METHODS, $w / \mathrm{cm}$, and SILICA FUME}

The previous sections examined the relationships between exposure temperature and reductions in mechanical properties. This section examines the effects of test method, $w / \mathrm{cm}$, and silica fume on the observed loss of compressive strength. The individual relative strength values reported in Tables 3.1,3.2, and 3.3 were grouped together and analysis of variance (ANOVA) was used to establish whether these factors had statistically significant effects on strength loss. Because specimens in the unstressed residual property test were not heated to $600^{\circ} \mathrm{C}$ and because of the large number of explosive failures of specimens that were being heated to $600^{\circ} \mathrm{C}$ for the other two test methods, there are few test results for this exposure temperature. Hence, the test results for $600{ }^{\circ} \mathrm{C}$ exposure were excluded from the ANOVA.

Table 3.4 shows the results of the ANOVA for the combined data. The main factors that were included in the analysis were as follows:

- Temperature

- Test method

- $w / \mathrm{cm}$

- Presence of silica fume

In addition to the main factors, two-factor interactions were also included. The last column in Table 3.4 shows the significance level associated with the effects of the main factors and two-factor interactions. Any effect with a significance level less than 0.05 was judged to be statistically significant.

\subsubsection{Effect of test methods}

Figure 3.16 shows the individual relative strength values group according to test method. Overall, the following mean strengths were obtained for the three test methods for heating to $100^{\circ} \mathrm{C}, 200^{\circ} \mathrm{C}, 300^{\circ} \mathrm{C}$, and $450^{\circ} \mathrm{C}$ :

- Unstressed tests: average relative strength $=0.724$

- Stressed tests: average relative strength $=0.759$

- Residual property tests: average relative strength $=0.726$ 
Table 3.4 Analysis of variance table of relative strength for exposure to $100{ }^{\circ} \mathrm{C}, 200^{\circ} \mathrm{C}$, $300{ }^{\circ} \mathrm{C}$, and $450{ }^{\circ} \mathrm{C}$

\begin{tabular}{|c|c|c|c|c|c|}
\hline Source & df & $\begin{array}{l}\text { Sums of } \\
\text { Squares }\end{array}$ & Mean Square & F-ratio & Prob. \\
\hline Constant & 1 & 75.9976 & 75.9976 & 25856 & $\leq 0.0001$ \\
\hline Temp & 3 & 0.119456 & 0.0398186 & 13.547 & $\leq 0.0001$ \\
\hline MAla & 2 & 0.0437902 & 0.0218951 & 7.449 & 00099 \\
\hline Teplp & 6 & 0.347662 & 0.0579437 & 19.713 & 50.0001 \\
\hline$w / \mathrm{wm}^{2} \mathrm{~s}$ & 2 & 0.0904909 & 0.0452455 & 15.393 & S619601 \\
\hline Temp*w/cm & 6 & 0.0128836 & 0.00214726 & 0.73053 & 0.6260 \\
\hline Method*w/cm & 4 & 0.0405632 & 0.0101408 & 3.45 & 0.0107 \\
\hline SF & 1 & 0.00726885 & 0.00726885 & 2.473 & 0.1187 \\
\hline Temp*SF & 3 & 0.0186072 & 0.00620241 & 2.1102 & 0.1031 \\
\hline Method*SF & 2 & 0.0180484 & 0.0090242 & 3.0702 & 0.0504 \\
\hline Error & 110 & 0.323325 & 0.00293932 & & \\
\hline Total & 139 & 1.35138 & & & \\
\hline
\end{tabular}

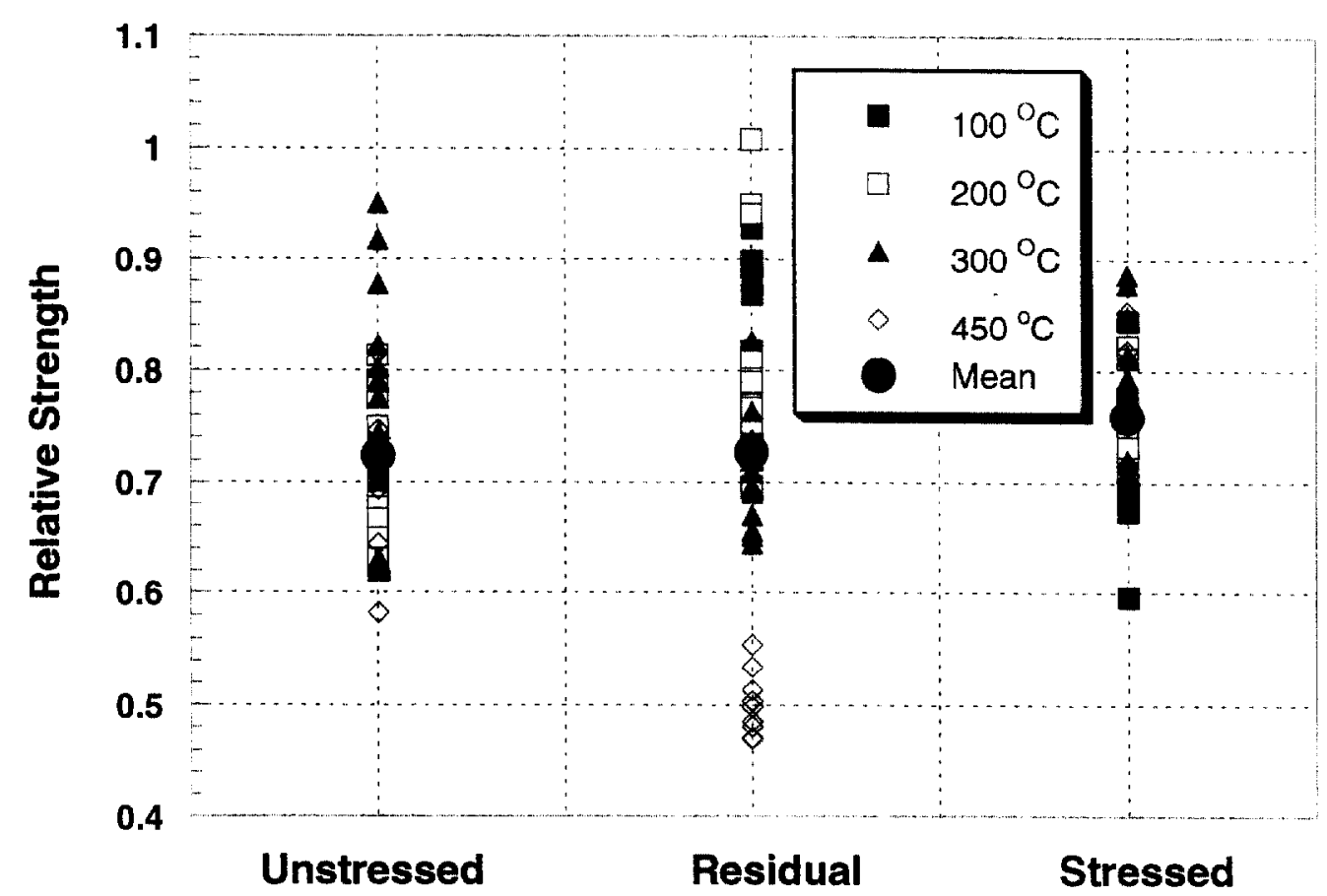

Figure 3.16 Relative strength versus test method for exposure temperatures of $100{ }^{\circ} \mathrm{C}, 200^{\circ} \mathrm{C}, 300^{\circ} \mathrm{C}$, and $450{ }^{\circ} \mathrm{C}$ 
Table 3.4 shows that the test method has a statistically significant effect on the relative strength. Overall, it was found that the stressed test produced the smallest strength loss, and there was no statistically significant difference between the relative strength losses obtained from the unstressed and residual property tests. Table 3.4, however, shows that there were two statistically significant two-factor interactions that involve test method: temperature*method and $\operatorname{method}^{*} w / \mathrm{cm}$. These interactions mean that the effect of test method depends on the exposure temperature and the $w / \mathrm{cm}$. Thus, while the stressed test produced the smallest strength loss on average, this did not apply to all exposure temperatures and values of $w / \mathrm{cm}$. Table 3.5 shows the average relative strength values for the different test methods grouped according exposure temperatures (the standard error, S.E., is the standard deviation, S.D., divided by the square root of the number of individual results). ANOVA was carried out within each temperature group, and the following summarizes the results:

- For exposure to $100^{\circ} \mathrm{C}$ and $200^{\circ} \mathrm{C}$, the residual property test method resulted in the smallest strength loss, and there was no statistically significant difference in the strength loss obtained with the other two test methods.

- For exposure to $300^{\circ} \mathrm{C}$, there were no statistically significant differences among the strength losses measured by the three methods.

- For exposure to $450^{\circ} \mathrm{C}$, the greatest loss was measured in the residual property test method, and there was no statistically significant difference in the strength loss measured by the other two methods.

Table 3.5 Summary of relative strength values as a function of exposure temperature and test method

\begin{tabular}{|c|l|c|c|c|c|}
\hline Temperature & Method & $\mathbf{n}$ & Average & S.D. & S.E. \\
\hline \multirow{3}{*}{$100{ }^{\circ} \mathrm{C}$} & Unstressed & 12 & 0.686 & 0.0399 & 0.0115 \\
\cline { 2 - 6 } & Residual & 12 & 0.803 & 0.0815 & 0.0235 \\
\cline { 2 - 6 } & Stressed & 14 & 0.725 & 0.0617 & 0.0165 \\
\hline \multirow{3}{*}{$200^{\circ} \mathrm{C}$} & Unstressed & 12 & 0.720 & 0.0614 & 0.0177 \\
\cline { 2 - 6 } & Residual & 12 & 0.810 & 0.1010 & 0.0292 \\
\cline { 2 - 6 } & Stressed & 12 & 0.758 & 0.0336 & 0.0097 \\
\hline \multirow{3}{*}{$300^{\circ} \mathrm{C}$} & Unstressed & 13 & 0.781 & 0.0923 & 0.0256 \\
\cline { 2 - 6 } & Residual & 12 & 0.735 & 0.0898 & 0.02596 \\
\cline { 2 - 6 } & Stressed & 12 & 0.790 & 0.0525 & 0.0152 \\
\hline \multirow{3}{*}{$450^{\circ} \mathrm{C}$} & Unstressed & 9 & 0.695 & 0.0707 & 0.0236 \\
\cline { 2 - 6 } & Residual & 9 & 0.501 & 0.0288 & 0.00966 \\
\cline { 2 - 6 } & Stressed & 11 & 0.769 & 0.0563 & 0.0170 \\
\hline
\end{tabular}


In a similar way, Table 3.6 shows the average values of relative strength for the different test methods grouped according to $w / \mathrm{cm}$. ANOVA was carried out within each $w / \mathrm{cm}$ group, and the following results were obtained:

- For $w / c m=0.22$, the smallest strength loss occurred in the residual property test method, and there was no difference between the results for the other two methods.

- For $w / \mathrm{cm}=0.33$, there were no statistically significant differences among the three methods

- For $\mathrm{w} / \mathrm{cm}=0.57$, the smallest loss was obtained with the stressed test and the greatest loss was obtained with the residual property test.

In summary, the results of these tests show that the test method has a statistically significant effect of the measured strength loss due to high-temperature exposure. The strength loss measured by a given test method, however, appears to depend on the exposure temperature and concrete mixture. For the lowest $w / \mathrm{cm}(0.22)$ and lower exposure temperature $\left(100^{\circ} \mathrm{C}\right.$ and $\left.200^{\circ} \mathrm{C}\right)$, the strength loss measured by the residual property test was the smallest. On the other hand, for higher exposure temperature (450 ${ }^{\circ} \mathrm{C}$ ) and $w / \mathrm{cm}(0.57)$, the strength loss was the highest in the residual property test.

Table 3.6 Relative strength as a function of $w / \mathrm{cm}$ and test method

\begin{tabular}{|c|l|c|c|c|c|}
\hline $\boldsymbol{w} / \mathrm{cm}$ & Method & $\mathbf{n}$ & Mean & S.D. & S.E. \\
\hline \multirow{4}{*}{0.22} & Unstressed & 10 & 0.744 & 0.0950 & 0.0300 \\
\cline { 2 - 6 } & Residual & 9 & 0.903 & 0.0613 & 0.0204 \\
\cline { 2 - 6 } & Stressed & 14 & 0.793 & 0.0413 & 0.0110 \\
\hline \multirow{4}{*}{0.33} & Unstressed & 24 & 0.712 & 0.0828 & 0.0169 \\
\cline { 2 - 6 } & Residual & 24 & 0.697 & 0.1318 & 0.0269 \\
\cline { 2 - 6 } & Stressed & 23 & 0.730 & 0.0530 & 0.0111 \\
\hline \multirow{4}{*}{0.57} & Unstressed & 12 & 0.729 & 0.0446 & 0.0129 \\
\cline { 2 - 6 } & Residual & 12 & 0.653 & 0.0946 & 0.0273 \\
\cline { 2 - 6 } & Stressed & 12 & 0.774 & 0.0533 & 0.0154 \\
\hline
\end{tabular}

The test method also appears to influence the tendency for explosive spalling, but no statistical analysis was applied to this observation. As was mentioned in Section 3.2, the presence of stress while the specimens were being heated seems to reduce the tendency for explosive spalling. This is clearly seen in the behavior of the mixture I specimens (see Table 2.7). None of the cylinders from mixture I experienced explosive spalling for the stressed tests. This is clearly an area for additional study. 


\subsubsection{Effect of $w / \mathrm{cm}$}

Table 3.4 shows that the factor $w / \mathrm{cm}$ had a statistically significant effect on the relative strength loss due to high temperature exposure. Figure 3.17 shows the individual relative strength values grouped according to $w / \mathrm{cm}$. Overall, the following mean strengths were obtained for the three values of $w / \mathrm{cm}$ :

- $w / \mathrm{cm}=0.22$ : average relative strength $=0.808$

- $w / \mathrm{cm}=0.33$ : average relative strength $=0.713$

- $w / \mathrm{cm}=0.57$ : average relative strength $=0.719$

The statistical analysis indicated that, overall, mixture $\mathrm{I}(w / \mathrm{cm}=0.22)$ had the lowest strength loss, and there was no statistically significant difference between strength loss for $w / \mathrm{cm}=0.33$ and 0.57 . As shown in Table 3.4, however, there was a statistically significant two-factor effect involving $w / \mathrm{cm}$ and test method. Thus the effect of $w / \mathrm{cm}$ was not the same for each test method. Table 3.7 shows the average relative strengths previously shown in Table 3.6, but regrouped according to test method. The results of separate ANOVA for each test method indicated the following:

- For the unstressed test, there were no statistically significant differences due to $w / \mathrm{cm}$.

- For the residual property test, the strength loss for each $w / \mathrm{cm}$ was different. The smallest loss was for $w / c m=0.22$, and the largest loss was for $w / c m=0.57$.

- For the stressed test, the strength loss for $w / \mathrm{cm}=0.22$ was less than for $w / \mathrm{cm}=$ 0.33 . 


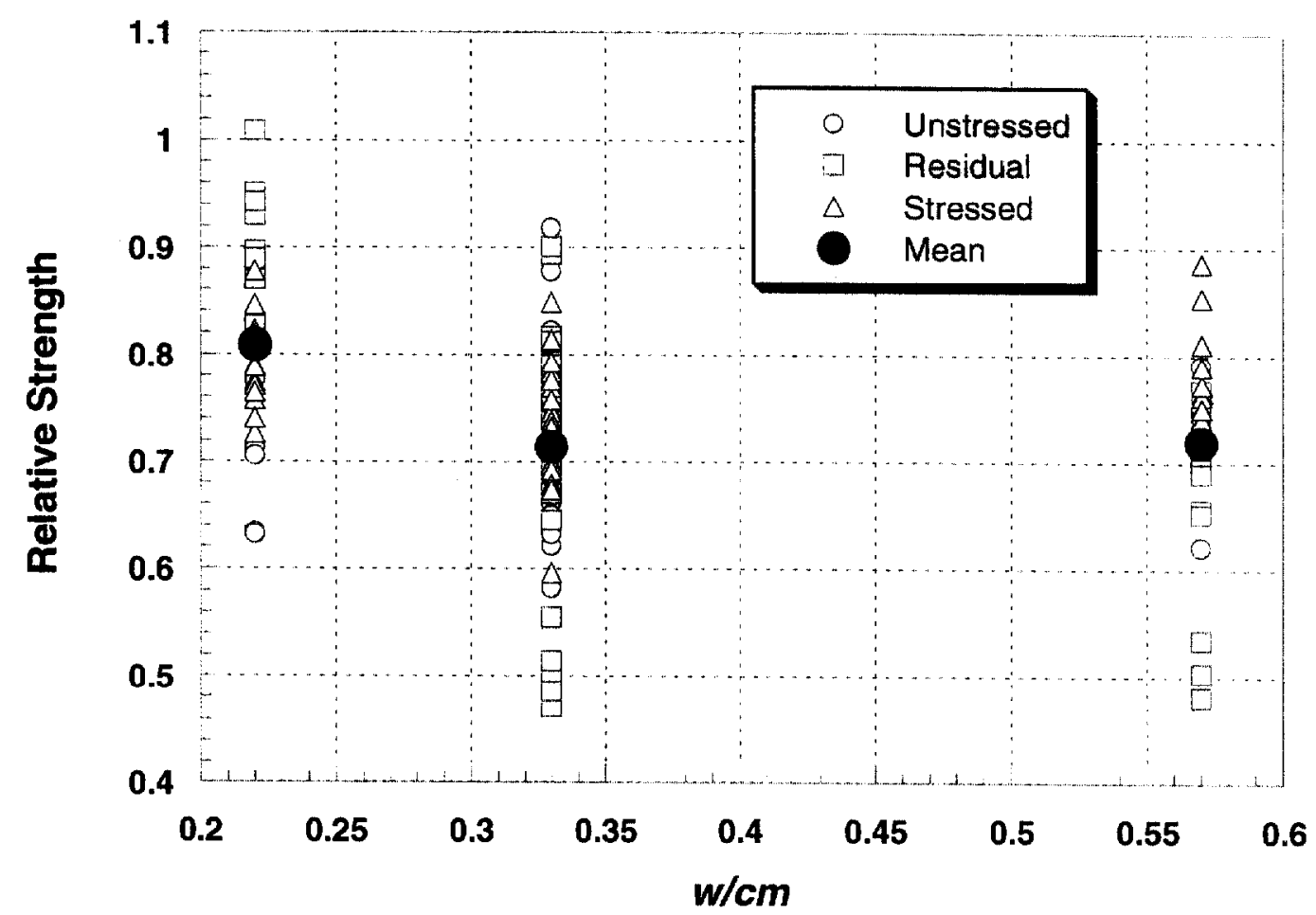

Figure 3.17 Relative strength versus $w / \mathrm{cm}$ for exposure temperatures of 100 ${ }^{\circ} \mathrm{C}, 200{ }^{\circ} \mathrm{C}, 300{ }^{\circ} \mathrm{C}$, and $450{ }^{\circ} \mathrm{C}$

In summary, the analysis showed that the effect of $w / \mathrm{cm}$ on strength loss during hightemperature exposure depends on the test method. For the mixtures used in this study, it appears that the strength loss was the smallest for mixture I with the lowest $w / \mathrm{cm}$. This conclusion, however, did not apply to unstressed test, for which $w / \mathrm{cm}$ had no statistically significant effect on the strength loss. It should be mentioned that the scatter of the individual test results plays an important role in the ANOVA, and may explain why some differences between average results were not found to be statistically significant.

As shown in Table 2.7, the $w / \mathrm{cm}$ has an effect on the potential for explosive spalling during high-temperature exposure. It is clear that mixture IV, with $w / \mathrm{cm}=0.57$, was immune to explosive spalling under the test conditions used in this study. From the comparison of incidences of explosive spalling during heating under unstressed conditions, Mixtures II and III $(w / c m=0.33)$ had a lower spalling tendency than mixture I $(w / c m=0.22)$. This relationship between $w / \mathrm{cm}$ and propensity for explosive spalling is consistent with the notion that explosive spalling is related to the resistance to water vapor transport. As the $w / \mathrm{cm}$ is reduced, capillary porosity is reduced and water vapor transport is more restricted, leading to higher internal vapor pressure. 
Table 3.7 Average relative strength as a function of test method and $w / \mathrm{cm}$

\begin{tabular}{|c|c|c|c|c|c|}
\hline Method & w/cm & Count & Mean & S.D. & S.E. \\
\hline \multirow{4}{*}{ Unstressed } & 0.22 & 10 & 0.744 & 0.0950 & 0.0300 \\
\cline { 2 - 6 } & 0.33 & 24 & 0.712 & 0.0828 & 0.0169 \\
\cline { 2 - 6 } & 0.57 & 12 & 0.729 & 0.0446 & 0.0129 \\
\hline \multirow{4}{*}{ Residual } & 0.22 & 9 & 0.903 & 0.0613 & 0.0204 \\
\cline { 2 - 6 } & 0.33 & 24 & 0.697 & 0.1318 & 0.0269 \\
\cline { 2 - 6 } & 0.57 & 12 & 0.653 & 0.0946 & 0.0273 \\
\hline \multirow{3}{*}{ Stressed } & 0.22 & 14 & 0.793 & 0.0412 & 0.0110 \\
\cline { 2 - 6 } & 0.33 & 23 & 0.730 & 0.0530 & 0.0111 \\
\cline { 2 - 6 } & 0.57 & 12 & 0.774 & 0.0533 & 0.0154 \\
\hline
\end{tabular}

\subsubsection{Effect of silica fume}

Table 3.4 indicates that the presence of silica fume did not have a statistically significant effect on the strength loss due to exposure to elevated temperatures of $100^{\circ} \mathrm{C}, 200^{\circ} \mathrm{C}$, $300^{\circ} \mathrm{C}$, and $450^{\circ} \mathrm{C}$. The two-factor effect test method*silica fume had a significance level of 0.0504 , which means that the effect of silica fume depended somewhat on the test method. Further analysis of the data revealed that for the unstressed tests, mixtures III and IV without silica fume had less strength loss than mixtures I and II with silica fume. For the other two test methods, the presence of silica fume had no effect on strength loss.

As shown in Table 2.7, mixture II had two more incidences of explosive spalling than mixture III, however, it is not apparent whether this difference is significant. Thus there is no clear evidence that the presence of silica fume by itself affects the tendency for explosive spalling. 


\section{COMPARISON OF NIST TEST RESULTS WITH OTHERS AND CODES}

\subsection{Comparison with others test results}

The experimental data from this study were compared with data obtained from other studies. While it is recognized that differences in the heating conditions (i.e., exposure time, heating rate), type of aggregate, specimen shape and size, specimen curing condition and so forth, used in different test programs could result in measurements that are not directly compatible, it is necessary to compare the NIST results with those of others based only on the test methods since there are insufficient data to be normalized with respect to all the applicable variables.

\subsubsection{Stressed Tests}

Figure 4.1 shows the normalized compressive strength versus temperature relationships of HSC (solid lines) and NSC (dashed lines) obtained in NIST and other test programs under the stressed test method. The range of NIST test results is shaded for convenience. As is shown in this figure, there is only a limited amount of data for this test condition. This is probably due to the difficulty in applying and maintaining a constant preload on a test specimen while it is being heated simultaneously. HSC stressed test data include results of NIST measurements for four HSC mixtures (thick solid lines with symbols), measurements by Castillo and Durrani [4] (red thin solid line), and measurements by Khoury and Algar [21] (blue thin solid line). NSC data include results of tests by Abrams [1] on specimens with two types of aggregatecarbonate dolomitic sand and gravel from Elgin, Illinois and siliceous sand and gravel from Eau Claire, Wisconsin (dashed lines). The followings are some key parameters of these test programs.

- NIST:

$\mathrm{f}_{230 \mathrm{c}}=50 \mathrm{MPa}$ to $100 \mathrm{MPa}, w / \mathrm{cm}=0.22$ to 0.57 , preload $=0.4 \mathrm{f}_{230 \mathrm{C}}$ heating rate $=5^{\circ} \mathrm{C} / \mathrm{min}, 100 \mathrm{~mm} \times 200 \mathrm{~mm}$ cylinders.

- Castillo and Durrani: $\mathrm{f}_{230 \mathrm{c}}=89 \mathrm{MPa}, w / \mathrm{cm}=0.33$, preload $=0.4 \mathrm{f}_{230 \mathrm{c},}$, heating rate $=7$

${ }^{\circ} \mathrm{C} / \mathrm{min}$ to $8{ }^{\circ} \mathrm{C} / \mathrm{min}, 51 \mathrm{~mm} \times 102 \mathrm{~mm}$ cylinders.

- Khoury and Algar: $\mathrm{f}_{230 \mathrm{c}}=85 \mathrm{MPa}, w / \mathrm{cm}=0.32$, preload $=0.2 \mathrm{f}_{230 \mathrm{C}}$, heating rate $=$ $2^{\circ} \mathrm{C} / \mathrm{min}, 60 \mathrm{~mm} \times 180 \mathrm{~mm}$ cylinders.

- Abrams: $\mathrm{f}_{230 \mathrm{C}}=23 \mathrm{MPa}$ to $45 \mathrm{MPa}, w / \mathrm{cm}=$ unknown, preload $=0.4 \mathrm{f}_{230 \mathrm{C}^{\prime}}$ heating rate $=$ unknown, $75 \mathrm{~mm} \times 150 \mathrm{~mm}$ cylinders.

As shown in Figure 4.1, the NIST test results indicate that HSC will sustain a strength reduction of between $25 \%$ to $35 \%$ of its room-temperature compressive strength when heated to $100^{\circ} \mathrm{C}$. This is consistent with measurements by Castillo and Durrani [4] and Khoury and Algar [21]. At this temperature, measurements by Abrams [1] indicate a slight strength gain for siliceous NSC and no effect on strength for calcareous NSC. 
Between $100^{\circ} \mathrm{C}$ to $300^{\circ} \mathrm{C}$, the NIST test results indicate a slight strength recovery for the four HSC mixtures used in this test program, with the measured strength reductions ranging from $18 \%$ to $27 \%$. This is also similar to measurements by Castillo and Durrani [4]. A much more significant strength recovery was recorded by Khoury and Algar [21], which showed a strength loss of only $7 \%$ at $300{ }^{\circ} \mathrm{C}$ (from $27 \%$ at $100^{\circ} \mathrm{C}$ ). For NSC, measurements by Abrams [1] indicate a slight strength gain at $300^{\circ} \mathrm{C}$.

Between $300^{\circ} \mathrm{C}$ and $450^{\circ} \mathrm{C}$, NIST test data showed only a minor strength loss between $300^{\circ} \mathrm{C}$ and $450^{\circ} \mathrm{C}$. Khoury and Algar's data, however, indicated a more significant strength reduction between these two temperature levels, while Castillo's data actually showed a strength recovery between $300^{\circ} \mathrm{C}$ and $400^{\circ} \mathrm{C}$ that resulted in a $20 \%$ strength increase over the room-temperature strength. Data for NSC showed a strength at $450^{\circ} \mathrm{C}$ that is similar to the room-temperature strength.

Between $450^{\circ} \mathrm{C}$ and $600^{\circ} \mathrm{C}$, NIST test data showed an increased rate of strength reduction for specimens of mixtures I and IV, and consistent explosive spalling failure

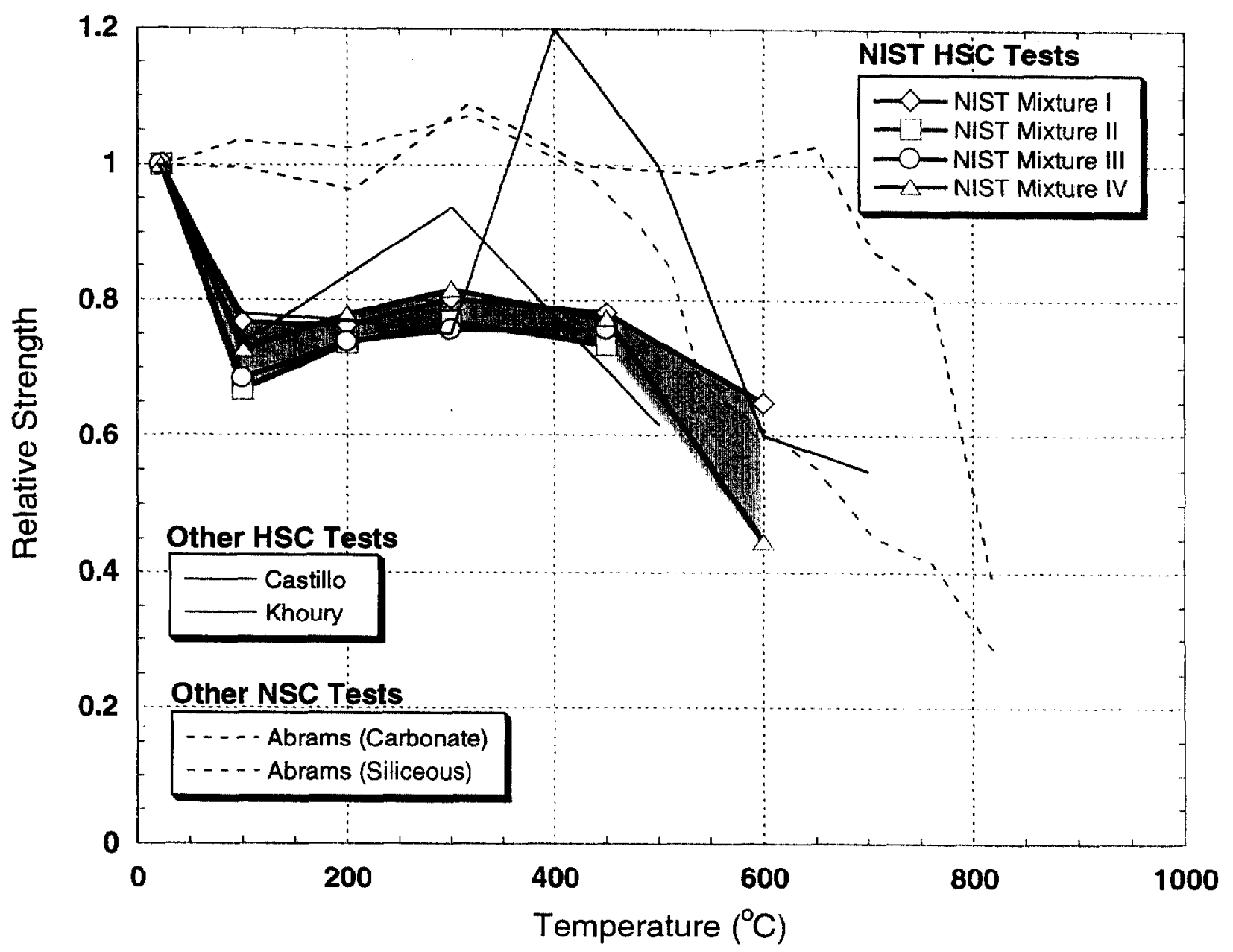

Figure 4.1 NIST Stressed Test Results Compared with Others 
for specimens of mixtures II and III while being heated to the target temperature of 600 ${ }^{\circ} \mathrm{C}$. In mixture II specimens, explosive spalling occurred in all three specimens when the measured temperatures at the center of the specimens were between $195^{\circ} \mathrm{C}$ and 215 ${ }^{\circ} \mathrm{C}$ (see Table 3.1). Explosive spalling also occurred to all mixture III specimens, with a measured temperature of $325^{\circ} \mathrm{C}$ at the center of one of the specimens. Test data by Khoury al $\backslash$ nd Algar [21] indicated continued strength reduction at the same rate during the temperature range of $300^{\circ} \mathrm{C}$ to $500^{\circ} \mathrm{C}$, with no mention of explosive spalling. Tests by Castillo and Durrani [4] indicated a sharp strength loss between $400^{\circ} \mathrm{C}$ and $600^{\circ} \mathrm{C}$, but the measured relative strength at $600^{\circ} \mathrm{C}$ fell within the range of the NIST results. Castillo and Durrani reported explosive spalling in about one third of the specimens being heated to $700{ }^{\circ} \mathrm{C}$, with a reported spalling temperature range of $320^{\circ} \mathrm{C}$ to $360^{\circ} \mathrm{C}$. It was not certain if this temperature range referred to the ambient temperature inside the furnace, or temperatures at points on the specimens surface or center. For NSC, siliceous specimens showed a progressive loss of strength starting from $400{ }^{\circ} \mathrm{C}$, while calcareous specimens did not sustain any strength loss until exposure to temperatures higher than $650^{\circ} \mathrm{C}$.

\subsubsection{Unstressed Tests}

Figure 4.2 shows the normalized compressive strength versus temperature relationships of HSC (solid lines) and NSC (dashed lines) under the unstressed test condition obtained in the NIST tests and in studies conducted by Castillo and Durrani [4], Hammer [17], Diederichs et al. [10-12], Furumura et al. [14], Khoury and Algar [21], and Abrams [1]. Again, NIST test results are shown in thick solid lines and the range is shaded for easy comparison. The followings are some key parameters of these test programs.

- NIST:

- Castillo and Durrani:

- Hammer:

- Diederichs et al.:

- Furumura et al.:

- Khoury and Algar:

- Abrams: $\mathrm{f}_{230 \mathrm{c}}=50 \mathrm{MPa}$ to $100 \mathrm{MPa}, w / \mathrm{cm}=0.22$ to 0.57 , preload $=0$, heating rate $=5^{\circ} \mathrm{C} / \mathrm{min}, 100 \mathrm{~mm} \times 200 \mathrm{~mm}$ cylinders. $f_{230 c}=63 \mathrm{MPa}$ and $31 \mathrm{MPa}, w / \mathrm{cm}=0.33$ and 0.68 , preload $=0$, heating rate $=7^{\circ} \mathrm{C} / \mathrm{min}$ to $8^{\circ} \mathrm{C} / \mathrm{min}, 51 \mathrm{~mm} \times 102 \mathrm{~mm}$ cylinders.

$\mathrm{f}_{230 \mathrm{c}}=68 \mathrm{MPa}$ to $118 \mathrm{MPa}, w / \mathrm{cm}=0.27$ to 0.50 , preload $=0$, heating rate $=2{ }^{\circ} \mathrm{C} / \mathrm{min}, 100 \mathrm{~mm} \times 310 \mathrm{~mm}$ cylinders. $\mathrm{f}_{230 \mathrm{c}}=33 \mathrm{MPa}$ to $114 \mathrm{MPa}, w / \mathrm{cm}=0.26$ to 0.45 , preload $=0$, heating rate $=2{ }^{\circ} \mathrm{C} / \mathrm{min}$ and $32^{\circ} \mathrm{C} / \mathrm{min}, 80 \mathrm{~mm} \times 300 \mathrm{~mm}$ cylinders and $100 \mathrm{~mm} \times 100 \mathrm{~mm} \times 100 \mathrm{~mm}$ cubes.

$\mathrm{f}_{230 \mathrm{C}}=79 \mathrm{MPa}$ and $55 \mathrm{MPa}, w / \mathrm{cm}=0.32$ to 0.41 , preload $=0$, heating rate $=1{ }^{\circ} \mathrm{C} / \mathrm{min}, 150 \mathrm{~mm} \times 300 \mathrm{~mm}$ cylinders. $\mathrm{f}_{230 \mathrm{C}}=85 \mathrm{MPa}, w / \mathrm{cm}=0.32$, preload $=0$, heating rate $=$ $2^{\circ} \mathrm{C} / \mathrm{min}, 60 \mathrm{~mm} \times 180 \mathrm{~mm}$ cylinders.

$\mathrm{f}_{230 \mathrm{c}}=23 \mathrm{MPa}, w / \mathrm{cm}=$ unknown, preload $=0$, heating rate $=$ unknown, $75 \mathrm{~mm} \times 150 \mathrm{~mm}$ cylinders. 
The variations of compressive strength with increasing temperatures observed in the NIST unstressed test data are similar in trend with the NIST stressed test data, except that the strength reductions in the unstressed tests are slightly higher at each target temperature compared with the stressed tests. Also, the compressive strengthtemperature relationships obtained in the NIST program follow the general trend of the HSC tests obtained in studies by Hammer [17] and Diederichs et al. [10-12], which constituted the majority of the test data for HSC under unstressed test condition.

At $100{ }^{\circ} \mathrm{C}$, NIST test data showed a strength loss for all four HSC mixtures in the range of $27 \%$ to $36 \%$ of their room-temperature compressive strengths. The strength losses observed at $100{ }^{\circ} \mathrm{C}$ for HSC in other test programs were less severe and varied over a wider range of between a little more than $10 \%$ to about $30 \%$. This is not surprising given the many differences in test specimens and test procedures used in the various test programs. Data for NSC, compiled from tests by Castillo and Durrani [4], Abrams [1], and Diederichs et al. [10-12], showed a variation between a minor strength loss (7\%)

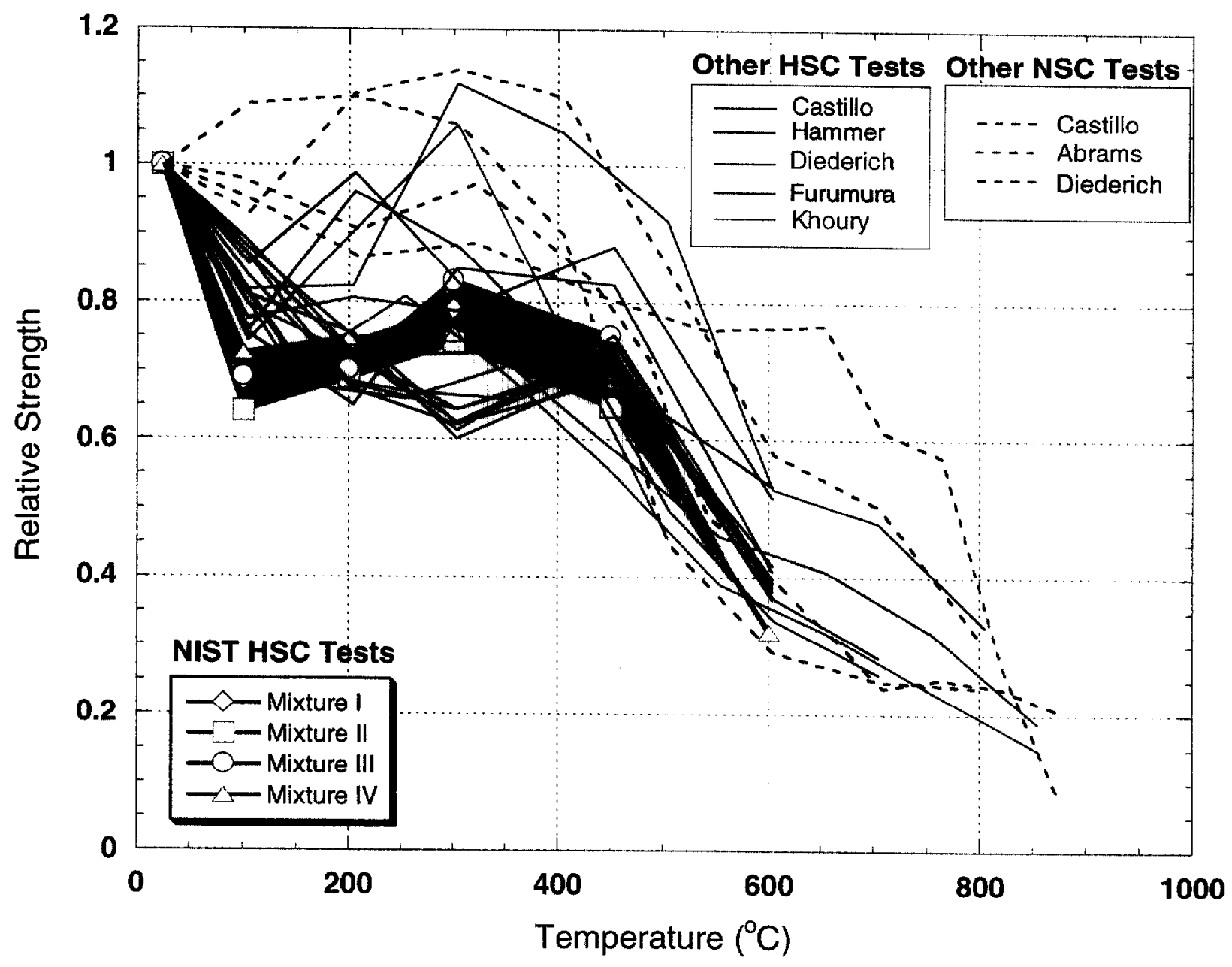

Figure 4.2 NIST Unstressed Test Results Compared with Others 
and a minor gain (9\%), which on average amounts to no significant change in the compressive strength of NSC at $100^{\circ} \mathrm{C}$.

Between $100^{\circ} \mathrm{C}$ and $200^{\circ} \mathrm{C}$, NIST test data showed a minor strength recovery similar to the case of the stressed tests, with the range of strength loss between $26 \%$ to $31 \%$. Results of HSC tests by others are inconsistent, with the majority of data from Hammer [17] and Diederichs et al. [10-12] showing continued strength loss between this temperature range, while data from Khoury and Algar [21], Castillo and Durrani [4], and Furumura et al. 14] showing a strength increase. For NSC, data by Castillo and Durrani [4] and Diederichs et al. [10-12] indicated a $10 \%$ strength increase, while results from Abrams [1] indicated an average $10 \%$ strength loss. Taken together, the changes in compressive strength in NSC due to exposure to $200^{\circ} \mathrm{C}$ are much less pronounced compared with the losses observed for HSC in the NIST test program.

Between $200^{\circ} \mathrm{C}$ and $300^{\circ} \mathrm{C}$, NIST test data showed a continued strength gain that reduced the range of strength loss to between $17 \%$ and $26 \%$. Results of HSC tests by others still showed inconsistent trends of strength variation (see Fig 4.2). Data for NSC indicated no significant variation in strength between these two temperature levels.

Between $300^{\circ} \mathrm{C}$ and $450^{\circ} \mathrm{C}$, NIST test data for HSC mixtures II, III, and IV showed a minor strength loss relative to strengths at $300^{\circ} \mathrm{C}$. This resulted in to a strength loss range of $25 \%$ to $35 \%$ relative to the room-temperature strengths. Despite the inconsistent trends of strength variation reported by others for HSC between room temperature to $450^{\circ} \mathrm{C}$, the majority of the results appeared to have the same range of relative strength loss at $450^{\circ} \mathrm{C}$. Strength data for mixture I concrete at $450^{\circ} \mathrm{C}$ were not obtained due to explosive spalling of the entire group of specimens while being heated to $450{ }^{\circ} \mathrm{C}$. The temperatures at the center of the specimens when explosive spalling occurred were estimated to be between $280^{\circ} \mathrm{C}$ and $310^{\circ} \mathrm{C}$ (see Table 3.2). Explosive spalling failure also occurred to one of the four mixture II specimens being heated to $450^{\circ} \mathrm{C}$, when the specimen center was about $245^{\circ} \mathrm{C}$. For NSC, all available data indicated a consistent strength reduction beginning at $300^{\circ} \mathrm{C}$. The maximum relative strength loss of $20 \%$ for NSC was, however, smaller than the strength loss range of $25 \%$ to $35 \%$ observed for HSC in this test program.

Between $450^{\circ} \mathrm{C}$ and $600^{\circ} \mathrm{C}$, there was a pronounced strength loss for mixture IV concrete, with a mean strength loss of $68 \%$ relative to the room-temperature strength. Results by others for both HSC and NSC, also indicated a similar rate of strength reduction in this temperature range. Strength data for mixtures I, II and III at $600^{\circ} \mathrm{C}$ were not available due to explosive spalling. For mixture II specimens, explosive spalling occurred when the temperatures at the specimen centers were about $230^{\circ} \mathrm{C}$ to $240^{\circ} \mathrm{C}$. For mixture III specimens, explosive spalling occurred when the specimen centers were about $200^{\circ} \mathrm{C}$ to $205^{\circ} \mathrm{C}$. 
Diederichs et al. [10-12], Hammer [17], and Furumura et al. [14] also reported explosive spalling of their unstressed HSC specimens, even though some of these studies used very low heating rates $\left(1^{\circ} \mathrm{C} / \mathrm{min}\right.$ for Furumura et al. and $2{ }^{\circ} \mathrm{C} / \mathrm{min}$ for Hammer). The study by Castillo and Durrani [4], however, indicated that explosive spalling occurred only in their stressed test specimens as reported in section 4.1.1, and none occurred under the unstressed test condition. Both Hammer [17] and Furumura et al. [14] reported that the temperature when explosive spalling occurred was about $300^{\circ} \mathrm{C}$. It is not certain, however, where in the specimen the temperature was measured.

\subsubsection{Unstressed Residual Property Tests}

Figure 4.3 shows the normalized compressive strength versus temperature relationships of HSC (solid lines) and NSC (dashed lines) obtained under the unstressed residual property test condition in the NIST program (solid lines with symbols) and in studies by Hertz [15,16], Morita et al. [23], Felicetti et al. [13], Khoury and Algar [21], and Abrams [4]. The followings are some key parameters of these test programs.

- NIST:

- Hertz:

- Morita et al.:

- Felicetti et al.:

- Khoury and Algar:

- Abrams: $\mathrm{f}_{230 c}=50 \mathrm{MPa}$ to $100 \mathrm{MPa}, w / \mathrm{cm}=0.22$ to 0.57 , preload $=0$, heating rate $=5{ }^{\circ} \mathrm{C} / \mathrm{min}, 100 \mathrm{~mm} \times 200 \mathrm{~mm}$ cylinders. $\mathrm{f}_{230 \mathrm{C}}=150 \mathrm{MPa}, w / \mathrm{cm}=$ unknown, preload $=0$, heating rate $=$ $1^{\circ} \mathrm{C} / \mathrm{min}, 100 \mathrm{~mm} \times 200 \mathrm{~mm}, 57 \mathrm{~mm} \times 100 \mathrm{~mm}$, and $28 \mathrm{~mm}$ $x 52 \mathrm{~mm}$ cylinders.

$\mathrm{f}_{230 \mathrm{c}}=27 \mathrm{MPa}$ to $74 \mathrm{MPa}, w / \mathrm{cm}=$ unknown, preload $=0$, heating rate $=1{ }^{\circ} \mathrm{C} / \mathrm{min}, 100 \mathrm{~mm} \times 200 \mathrm{~mm}$ cylinders. $\mathrm{f}_{230 \mathrm{C}}=72 \mathrm{MPa}$ and $95 \mathrm{MPa}, w / \mathrm{cm}=0.43$ and 0.30 , preload $=0$, heating rate $=0.2^{\circ} \mathrm{C} / \mathrm{min}, 100 \mathrm{~mm} \times 300 \mathrm{~mm}$ cylinders. $f_{230 c}=85 \mathrm{MPa}, w / \mathrm{cm}=0.32$, preload $=0$, heating rate $=2$ ${ }^{\circ} \mathrm{C} / \mathrm{min}, 60 \mathrm{~mm} \times 180 \mathrm{~mm}$ cylinders.

$\mathrm{f}_{230 \mathrm{c}}=23 \mathrm{MPa}$ and $45 \mathrm{MPa}, w / \mathrm{cm}=$ unknown, preload $=0$, heating rate $=$ unknown, $75 \mathrm{~mm} \times 150 \mathrm{~mm}$ cylinders .

NIST test data showed a wider range of strength loss among the four mixtures under the unstressed residual property test method than in the other two test methods. The trend of strength-temperature relationships for the range of $25^{\circ} \mathrm{C}$ to $200{ }^{\circ} \mathrm{C}$ obtained from the NIST tests also differed from the trends observed for HSC and NSC in other studies. At $100{ }^{\circ} \mathrm{C}$, the four mixtures tested at NIST showed a strength loss ranging from $10 \%$ to $30 \%$ of the room-temperature strengths, while HSC data from other studies varied between a little more than $5 \%$ strength loss and some strength gain.

Between $100^{\circ} \mathrm{C}$ to $200^{\circ} \mathrm{C}$, NIST mixtures I and IV showed a strength recovery, while mixtures $I$ and III continued to show further strength loss. In general, the range of strength loss for the NIST mixtures at $200^{\circ} \mathrm{C}$ was lower compared with the range of strength loss at $100^{\circ} \mathrm{C}$. The strength losses observed at $200^{\circ} \mathrm{C}$ in the four NIST 
mixtures are, however, higher than the losses observed for HSC in other studies, which in most cases showed a strength gain except for results obtained by Felicetti et al. [13]. NSC test data showed a continued strength loss at the same rate as observed for the temperature range of $25^{\circ} \mathrm{C}$ to $100^{\circ} \mathrm{C}$.

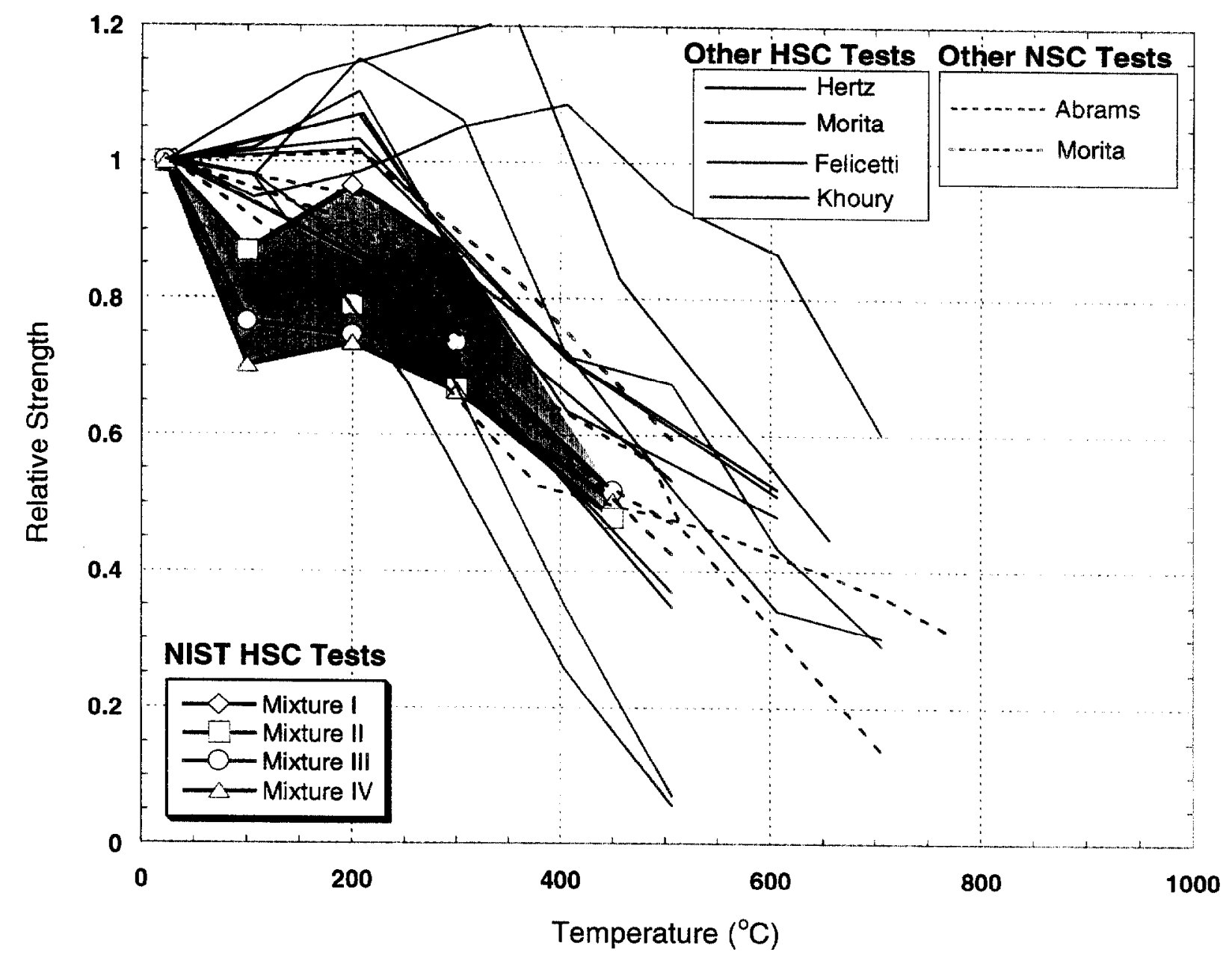

Figure 4.3 NIST Unstressed Residual Property Test Results Compared with Others

Between $200^{\circ} \mathrm{C}$ to $300^{\circ} \mathrm{C}$, further strength losses were observed for all NIST mixtures, with explosive spalling occurring in a mixture I specimen and a mixture II specimen. The exploded specimens belonged to a group of five mixture I specimens and a group of four mixture $\Pi$ specimens being heated together to $300^{\circ} \mathrm{C}$. In the case of the mixture I specimen, explosive spalling occurred when the specimen core temperature was about $235^{\circ} \mathrm{C}$. For the exploded mixture II specimen, explosive spalling occurred when the specimen core temperature was about $250^{\circ} \mathrm{C}$. Test results from other studies showed the rates of strength loss for both HSC and NSC are similar to the strength loss observed for the four NIST mixtures in this temperature range. While explosive spalling occurred in mixtures I and II of this test program, no explosive spalling was reported in this temperature range by the referenced studies. 
Between $300^{\circ} \mathrm{C}$ to $450{ }^{\circ} \mathrm{C}$, mixtures II, III, and IV sustained rates of strength loss similar to those observed in other studies of HSC and NSC. Although the rates of strength loss are similar, the residual strengths at $450^{\circ} \mathrm{C}$ tend to be higher for the other studies. Also, results of Felicetti et al. [13] showed a significant loss of residual strength at $400^{\circ} \mathrm{C}$ and $500^{\circ} \mathrm{C}$ compared with results of other studies. This is probably due to the much longer heating exposure time ( 12 hours at target temperature) used in this study compared with the exposure times used by other studies ( 4 to 5 hours). Mixture I specimens consistently exploded while being heated to $450^{\circ} \mathrm{C}$. The approximate temperature at the centers of the mixture I specimens when explosive spalling occurred was between $240^{\circ} \mathrm{C}$ to $280^{\circ} \mathrm{C}$. Of the referenced studies of residual strengths $[4,13,15,16,21,23]$, only that Hertz $[15,16]$, which involved ultra high-strength concrete, reported explosive spalling. The temperature range of observed explosive spalling in Hertz's study was between $350^{\circ} \mathrm{C}$ to $650^{\circ} \mathrm{C}$. Again, it is not certain whether this temperature range referred to the ambient temperature, the surface temperature, or the temperatures at the center of the concrete specimen.

\subsection{Comparisons of Test Results with codes}

The Comité Européen de Normalisation (CEN ENV 1994, Eurocode 2 - Part 1-2: Structural Fire Design and Eurocode 4 - Part 1-2 General Rules for Structural Fire Design) $[6,7]$ and the Comite Euro-International du Beton (CEB Bulletin D'Information $N^{\circ} 208$, 1991, Fire Design of Concrete Structures) [5] specify design rules for concrete strength at elevated temperature. These codes made no distinction regarding the applicability of these design rules with respect to the type of concrete used (HSC or NSC). The design rules for concrete strength at elevated temperature will be compared with test results obtained in this and other relevant studies for applicability to HSC. This comparison is discussed in section 4.2.1.

A separate comparison of the NIST and other relevant test results with the Finnish rules RakMK B4 (1991) [8], published by the Concrete Association of Finland, is covered in section 4.2.2. While the Eurocode and CEB model code make no distinction between HSC and NSC in their fire design provisions, the RakMK B4 prescibes supplementary rules to be used with the National Building Code of Finland for fire design of highstrength concrete.

Since the design rules by the CEN ENV 1994, CEB 1991, and the RakMK B4 1991 were specified for concrete in service (i.e., concrete under service load), they will be compared with the stressed test results. 


\subsubsection{Comparisons with the Eurocode and CEB}

Figure 4.4 shows the compressive strength-temperature relationships obtained under the stressed test method for the HSC mixtures in this test program and in studies by Castillo and Durrani [4], Khoury and Algar [21] and Abrams [1]. Again, the range of NIST test results is shaded for convenience. The design rules for estimating concrete compressive strength at elevated temperatures, prescribed by the Eurocodes for calcareous aggregate concrete (thick dark blue line) and siliceous aggregate concretes (thick light blue line), and by the CEB model code (thick dashed red line), are superposed to assess their applicability to HSC. It should be noted that since crushed limestone was used as coarse aggregate in the NIST mixtures, the Eurocode's provision for calcareous aggregate concrete (thick dark blue line) is to be used for comparison with the NIST test results.

According to the NIST results shown in Figure 4.4, the Eurocode's strength-temperature relationship for calcareous aggregate concrete is unconservative for estimating

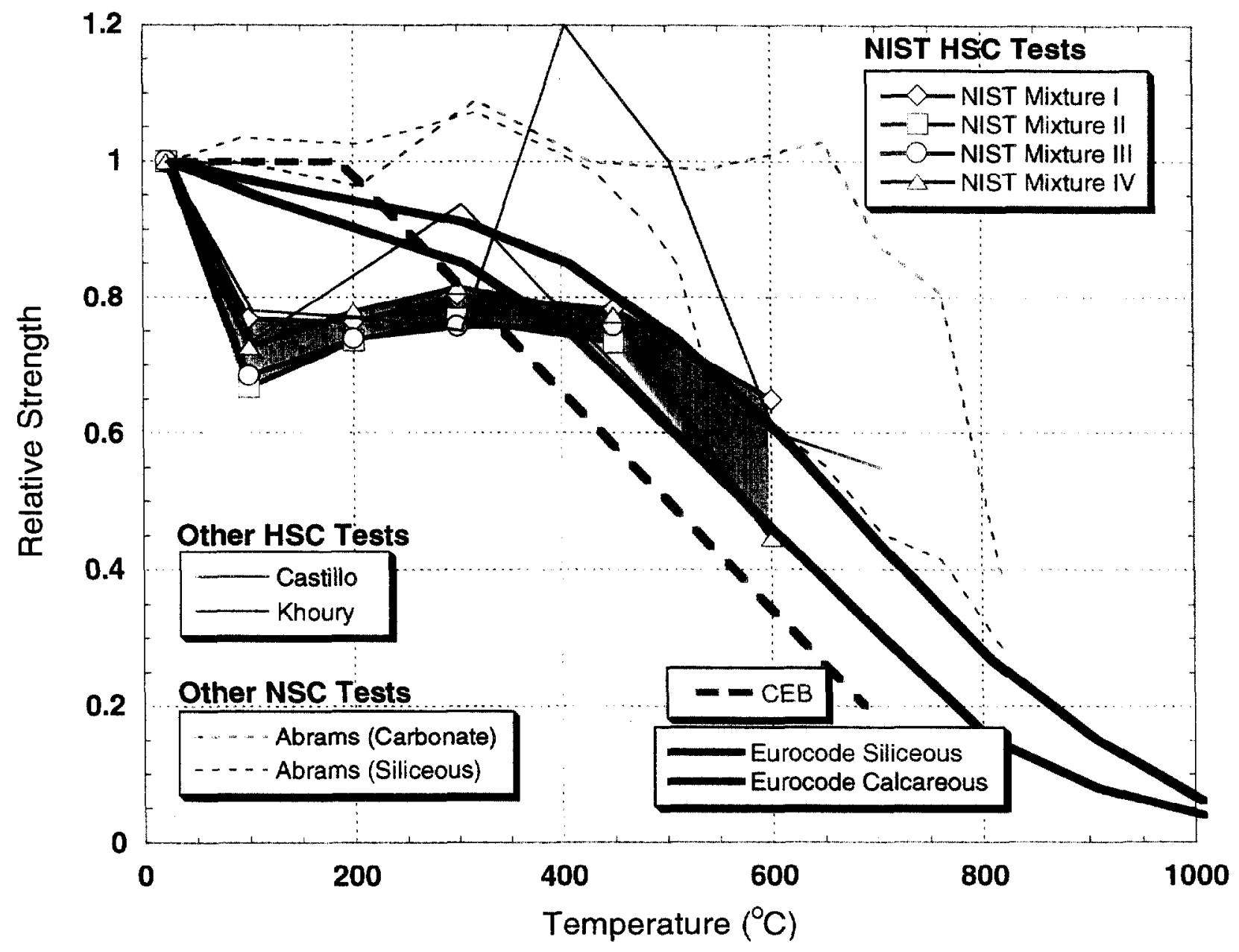

Figure 4.4 Comparison of stressed test results versus the Eurocode and CEB 
compressive strength of $\mathrm{HSC}$ at temperatures less than $450^{\circ} \mathrm{C}$. The largest overestimation by the Eurocode was by about $20 \%$ at $100^{\circ} \mathrm{C}$ exposure. Between $450^{\circ} \mathrm{C}$ and $600^{\circ} \mathrm{C}$, the strength loss prescribed by the Eurocode is more consistent with the NIST results. The unconservative estimation of HSC's compressive strength by the Eurocode at temperatures less than $450^{\circ} \mathrm{C}$ is even more significant when explosive spalling, which is not addressed by the current Eurocode is considered.

The strength-temperature relationship prescribed by the CEB model code was based on NSC data obtained by Abrams [1], Malhotra [22], and Schneider [28]. Compared with the NIST data, the CEB provision is unconservative when used for estimating compressive strength of $\mathrm{HSC}$ at temperatures less than $350^{\circ} \mathrm{C}$. The largest overestimation by the CEB provision is about $25 \%$ in the temperature range between $100^{\circ} \mathrm{C}$ and $200^{\circ} \mathrm{C}$. At temperatures above $350^{\circ} \mathrm{C}$, the CEB relationship underestimates compressive strength of concrete based on the NIST data and that of others. The rate of strength reduction for the CEB relationship at temperature above $350^{\circ} \mathrm{C}$ is consistent with that observed in this test program and with the Eurocode provisions. Similar to the Eurocode, the unconservative estimation of compressive strength by the CEB provision at temperatures less than $350^{\circ} \mathrm{C}$ is more significant because the CEB provision does not address the explosive spalling problem observed for HSC in this temperature range.

\subsubsection{Comparison with the Finnish Code}

Finland's RakMK B4 (1991) [8] prescribes supplementary fire design rules for NSC, HSC, and light weight aggregate concrete with and without preload (stressed and unstressed tests, respectively). HSC are concretes with designated strength grades of K70 to K100 (concretes with 70 MPa to $100 \mathrm{MPa}$ compressive strength if $150 \mathrm{~mm}$ cubes are used, or $62 \mathrm{MPa}$ to $90 \mathrm{MPa}$ if $150 \mathrm{~mm} \times 300 \mathrm{~mm}$ cylinders are used). NSC are concretes with designated strength grades of K10 to K70 (concretes with $10 \mathrm{MPa}$ to 70 $\mathrm{MPa}$ compressive strength if $150 \mathrm{~mm}$ cubes are used, or $7 \mathrm{MPa}$ to $62 \mathrm{MPa}$ if $150 \mathrm{~mm} x$ $300 \mathrm{~mm}$ cylinders are used). The preload levels prescribed in RakMK B4 are between $0 \%$ (unstressed) and $30 \%$ of the concrete room temperature strength (stressed). Since RakMK B4 deals with stressed and unstressed conditions, two comparisons (stressed and unstressed tests) will be made to assess the applicability of the RakMK B4 provisions. As is the case of the Eurocode and the CEB model code, the RakMK B4 also does not address the issue of explosive spalling of HSC even though its provisions for strength reduction take into account the different fire performance of HSC and NSC.

\subsubsection{Stressed Tests}

The RakMK B4 provision for NSC with $30 \%$ preload is shown as the thick solid green line in Figure 4.5. This provision for NSC is also applicable to preloaded light weight aggregate concrete. The RakMK B4 provision for HSC with $0 \%$ to $30 \%$ preload is shown as the thick soild brown line in Figure 4.5. 
As shown in Figure 4.5, the RakMK B4 provision for compressive strength of NSC at elevated temperatures matches the stressed test results for NSC extremely well. In comparison with the NIST data, the RakMK B4 provision appears to be slightly unconservative for $\mathrm{HSC}$ at temperatures below $150^{\circ} \mathrm{C}$. The Finnish provision, however, is not as unconservative as the Eurocode and the CEB provisions. Between $150^{\circ} \mathrm{C}$ and $350^{\circ} \mathrm{C}$, the RakMK B4 provision is consistent with the measurements obtained in this test program. From $350^{\circ} \mathrm{C}$ to $800^{\circ} \mathrm{C}$, RakMK B4 appears to be conservative compared with the measurements obtained in this test program. This is similar to the strength estimation prescribed by the CEB model code in this temperature range.

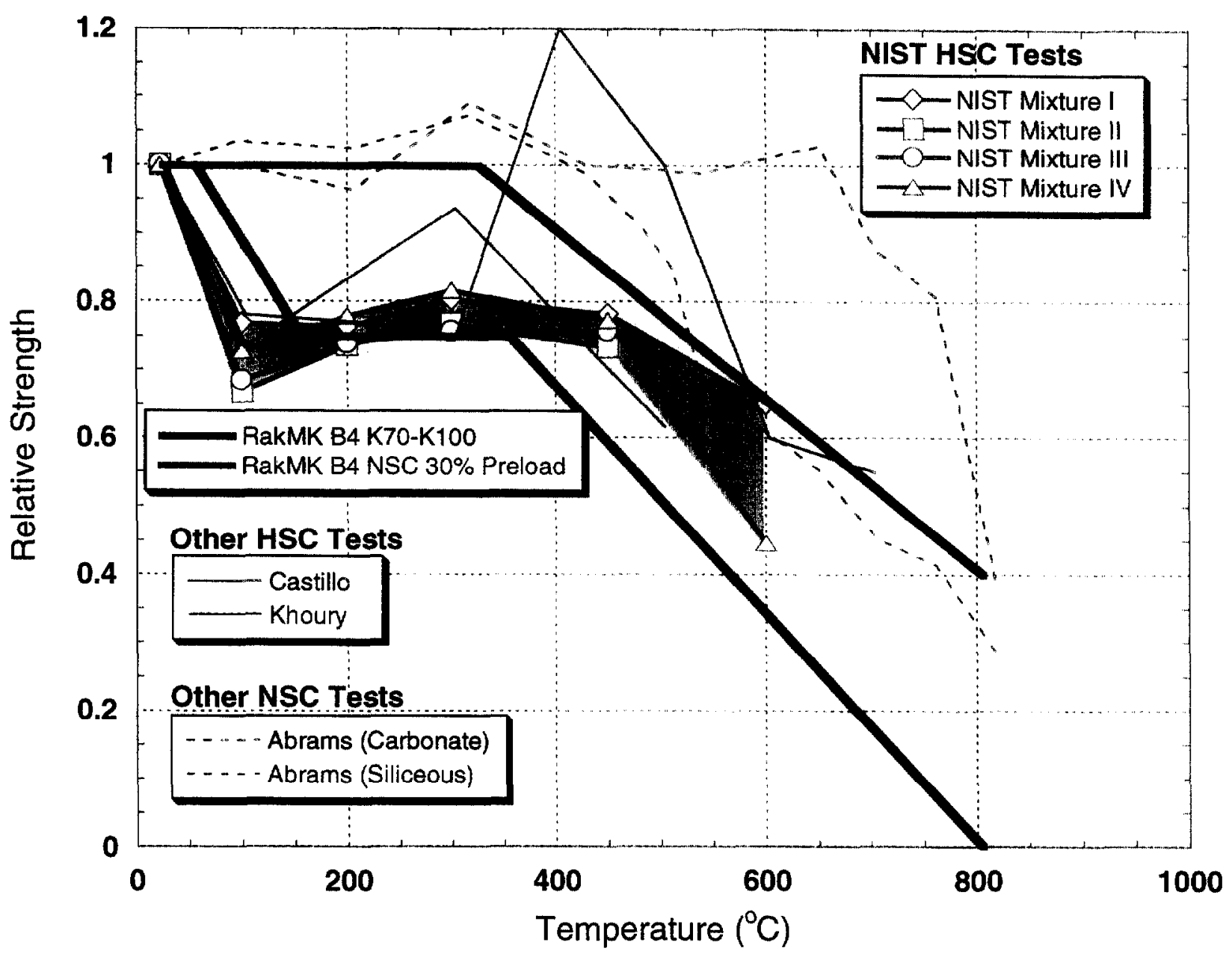

Figure 4.5 Comparison of stressed test results versus the Finnish Code

\subsubsection{Unstressed Tests}

The RakMK B4 strength-temperature relationship for HSC under unstressed conditions is the same as that for stressed conditions. This relationship is superposed over the unstressed test data on Figure 4.6 as the thick solid brown line. The relationship for 
NSC under unstressed conditions differs from the relationship under stressed conditions shown previously in Figure 4.5. This is superposed on Figure 4.6 as the thick solid black line.

Similar to the stressed conditions, the RakMK B4 provision for HSC appears to be slightly unconservative at temperatures below $150^{\circ} \mathrm{C}$ when compared with the NIST data. The RakMK B4 provision for HSC, however, appears to be consistent with the average of all test results summarized in Figure 4.5. Between $150^{\circ} \mathrm{C}$ and $350{ }^{\circ} \mathrm{C}$, the RakMK B4 provision is consistent with the NIST test data and the average of other unstressed test results for HSC. At temperatures above $350^{\circ} \mathrm{C}$, the RakMK B4 relationship indicates a progressive strength loss that is a reasonable lower bound to the strength losses observed in the NIST and other studies.

The RakMK B4 relationship for unstressed NSC prescribes no strength loss between room temperature and $220^{\circ} \mathrm{C}$. This is consistent with the average results of tests by Castillo and Durrani [4], Abrams [1], and Diederichs et al. [10-12]. Above $220^{\circ} \mathrm{C}$, RakMK B4 prescribes a rate of strength reduction that is similar to that for HSC. The prescribed strength loss is on the conservative side of the test data. 


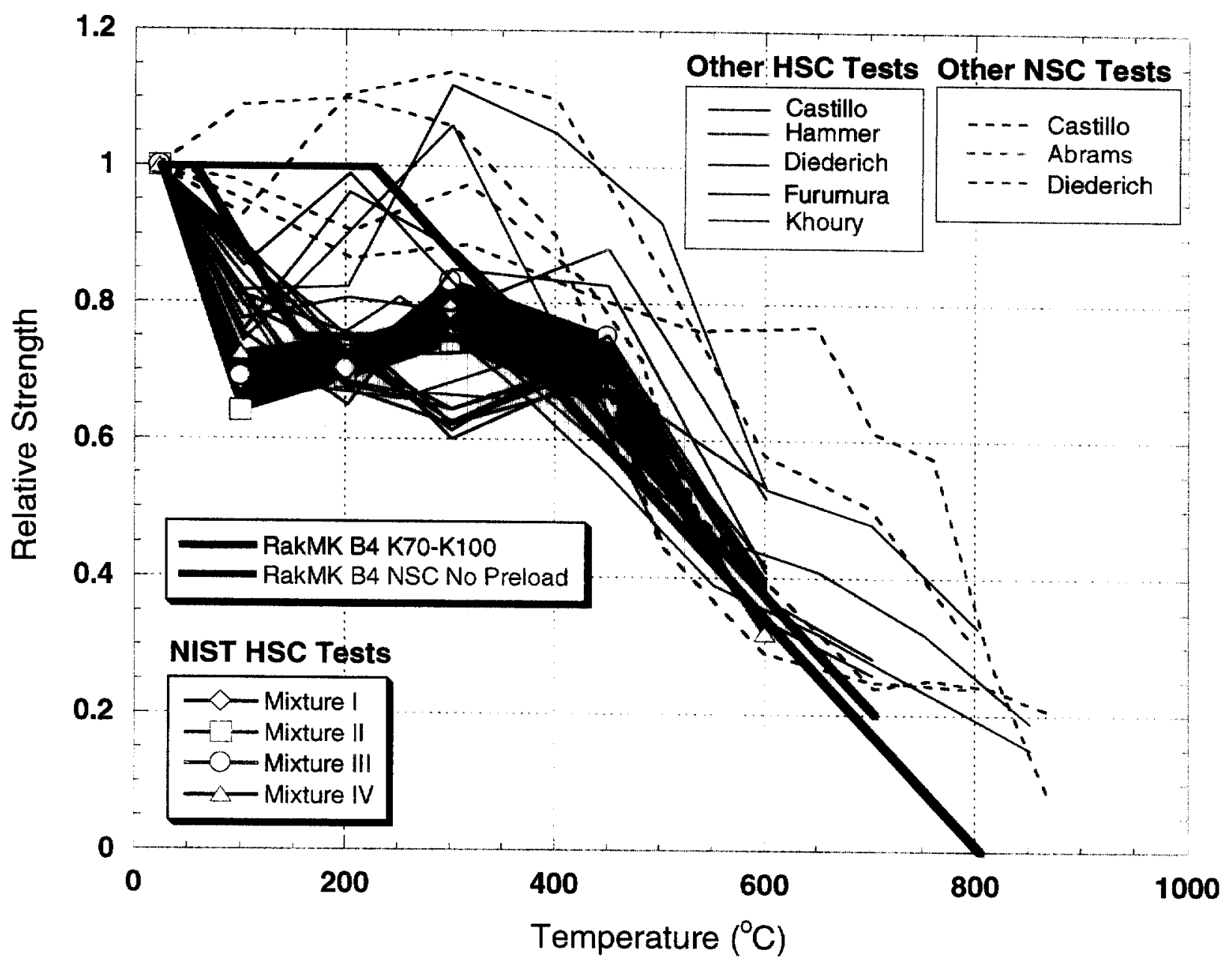

Figure 4.6 Comparison of unstressed test results versus the Finnish Code 


\section{SUMMARY AND CONCLUSIONS}

\subsection{Summary}

An experimental program was developed for quantifying the effects of three variables, test method, water-cementitious materials ratio $(w / \mathrm{cm})$, and inclusion of silica fume, on the mechanical properties and on the potential for explosive spalling of HSC.

Three series of tests, corresponding to the three steady-state temperature test methods, namely stressed, unstressed, and unstressed residual strength, were performed. The stressed and unstressed test methods were designed to provide measurements of property data at elevated temperatures, and required simultaneous application of loading and heating. In the stressed test method, the specimens were restrained by a preload equal to $40 \%$ of the room-temperature strength prior to heating. This preload was maintained throughout the heating process. In the unstressed test method, the specimens were heated without restraint and loaded to failure under uniaxial compression at elevated temperature after the steady-state target temperature was reached. The unstressed residual strength test method was designed to provide measurements of residual properties after the specimens had cooled down to room temperature. Thus, the specimen is loaded to failure at room temperature.

Three $w / \mathrm{cm}$ values of $0.22,0.33$, and 0.57 were used in four HSC mixtures. Mixture I has a $w / \mathrm{cm}$ value of 0.22 and compresive strength of $98 \mathrm{MPa}$ at test time. Mixtures II and III have the same $w / c m$ values of 0.33 and compressive strengths of $88 \mathrm{MPa}$ and $75 \mathrm{MPa}$, respectively. Mixture IV has a $w / \mathrm{cm}$ value of 0.57 and a compressive strength of $50 \mathrm{MPa}$.

Two amounts of silica fume, $0 \%$ and $10 \%$, used as cement replacement, were used. Mixtures I and II contained $10 \%$ of silica fume by mass. Mixtures III and IV contained no silica fume.

The specimens for the stressed and unstressed tests were heated to steady-state thermal condition at five target temperatures, $100^{\circ} \mathrm{C}, 200^{\circ} \mathrm{C}, 300^{\circ} \mathrm{C}, 450^{\circ} \mathrm{C}$, and $650^{\circ} \mathrm{C}$. Specimens for the unstressed residual property test were heated to four target temperatures, $100^{\circ} \mathrm{C}, 200^{\circ} \mathrm{C}, 300^{\circ} \mathrm{C}$, and $450^{\circ} \mathrm{C}$. A set of at least three specimens was tested for each test condition. All specimens were heated using a constant heating rate of $5^{\circ} \mathrm{C} / \mathrm{min}$ for the ambient furnace temperature. The heating exposure time was controlled at $5 \mathrm{~h}: 15 \mathrm{~min} \pm 15 \mathrm{~min}$ for all tests. The total heating and cooling time for residual property test specimens was controlled at $24 \mathrm{~h} \pm 60 \mathrm{~min}$. It should be noted that the heating rate prescribed for the first $850^{\circ} \mathrm{C}$ of ASTM E 119 standard fire exposure was approximately $28^{\circ} \mathrm{C} / \mathrm{min}$ (or $30 \mathrm{~min}$ to reach temperature of about 850 $\left.{ }^{\circ} \mathrm{C}\right)$.

The specimens were $100 \mathrm{~mm} \times 200 \mathrm{~mm}$ cylinders, made with type I portland cement, 13 $\mathrm{mm}$ maximum size crushed limestone, and natural river sand. All specimens were stored under water until a few hours before testing. Loading was applied following the deformation control procedure with a constant test machine deformation rate of 0.25 $\mathrm{mm} / \mathrm{min}$. For the stressed and unstressed tests, strains at elevated temperature were 
measured using a high temperature compressometer mounted on the outside of the split-tube furnace. For the unstressed residual property test, an averageing axial strain compressometer with a gage length of $130 \mathrm{~mm}$ was used. In addition, resonenat frequency tests were used to calculate the dynamic elastic modulus before and after heating in the residual property test. A limited number of specimens were instrumented with type $\mathrm{K}$ thermocouples to monitor temperature development on the surface and at points inside the specimen. The internal temperature profiles measured in a select number of specimens were used to control the heating of all other specimens to ensure that steady-state thermal conditions existed before loading the specimens to failure.

\subsection{Conclusions}

Conclusions regarding the temperature development in HSC, the effects of test method, $w / \mathrm{cm}$, and presence of silica fume on mechanical properties and tendency for explosive spalling of HSC, and the applicability of existing fire design provisions for estimating strength of HSC at elevated temperatures are drawn based on the results of this study. These conclusions are described in the following sections.

\subsubsection{Temperature Development}

- The NIST test program provided important insights into the complex heat-induced moisture transport process in HSC. The instances of heat-induced moisture transport are indicated by perturbations observed in the rates of temperature rise on the surface and at center of the concrete cylinder. The first major perturbation occurred when the concrete temperature (at center) reached temperature slightly above $100{ }^{\circ} \mathrm{C}$. The second occurred at above $150^{\circ} \mathrm{C}$. These perturbations are caused by the releases (vaporization and movement) of free water and chemically bound water beginning approximately at these two temperatures. The releases of most of the free water and chemically-bound water in the HSC matrix at slightly above $150^{\circ} \mathrm{C}$ is also corroborated by reduction in the rate of mass loss at temperatures above $150^{\circ} \mathrm{C}$. Accurate modeling of temperature development in concrete should to take into account this complex behavior.

\subsubsection{Effect of Test Method}

- Preload (of up to $40 \%$ of the concrete room-temperature strength) has no effect on the strength reduction of $\mathrm{HSC}$ at elevated temperatures (up to $600^{\circ} \mathrm{C}$ ). Even though test results indicated slightly smaller strength loss at elevated temperatures for the stressed tests than unstressed tests, the difference in strength loss between $40 \%$ and $0 \%$ preload is statistically insignificant according to statistical analysis of the test results.

- HSC retains a higher residual strength when exposed to between $100^{\circ} \mathrm{C}$ and $300{ }^{\circ} \mathrm{C}$ and allowed to cool (residual property test) compared to strength measured at 
elevated temperatures (stressed and unstressed tests). This difference is more pronounced in silica fume HSC, and is less significant in non-silica fume HSC. At $450{ }^{\circ} \mathrm{C}$, the trend was reversed. $\mathrm{HSC}^{\prime}$ 's residual strength became consistently less than strength measured at elevated temperatures. Thus the temperature range of between $200{ }^{\circ} \mathrm{C}$ and $300{ }^{\circ} \mathrm{C}$ marks a heat-induced transformation in the thermalhygral process above which more severe damage to HSC occurs. HSC will retain higher residual strength loss after exposure to temperatures above this range.

\subsubsection{Effect of $w / \mathrm{cm}$}

- For the $w / \mathrm{cm}$ values of 0.22 and 0.33 , the HSC mixture with $w / \mathrm{cm}=0.22$ sustains less strength loss than the HSC mixture with $w / \mathrm{cm}=0.33$, regardless of the test methods used.

- In the $w / \mathrm{cm}$ range of 0.33 to 0.57 , the effect of $w / \mathrm{cm}$ on the compressive strengthtemperature relationships of non-silica fume HSC is inconclusive. The test results showed that lower $w / \mathrm{cm}(0.57) \mathrm{HSC}$ sustained less strength loss in the stressed test, less strength loss up to $300{ }^{\circ} \mathrm{C}$ in the unstressed test, and more strength loss in the unstressed residual property test. This inconsistent trend made it difficult to assess with confidence the effect of $w / \mathrm{cm}$ on the variation of compressive strength for the $w / \mathrm{cm}$ range of 0.33 and 0.57 . However, while the differences in strength losses in this range of $w / \mathrm{cm}$ were inconsistent between the test methods, these differences were relatively small compared with the consistent differences observed in silica fume HSC with lower range of $w / \mathrm{cm}$. Thus, it may be concluded that the effect of $w / \mathrm{cm}$ between the 0.33 and 0.57 level on HSC's elevated temperature strength is insignificant.

\subsubsection{Effect of Silica Fume}

- The presence of silica fume had no effect on the elevated temperature performance of HSC that was preloaded during heating, as evidenced by the insignificant difference in the strength-temperature relationships of mixtures III and III under the stressed test, and by the occurrences of explosive spalling in specimens of both mixtures while undergoing similar heating conditions $\left(600^{\circ} \mathrm{C}\right)$. There was also an insignificant effect in unrestrained specimens that were tested hot (unstressed test) up to $300{ }^{\circ} \mathrm{C}$. Beyond $300{ }^{\circ} \mathrm{C}$, the specimens with silica fume appeared to sustain larger strength loss (about $8 \%$ at $450^{\circ} \mathrm{C}$ ).

- Silica fume has a positive effect on residual strength of HSC when the concrete has not yet been exposed to temperature that causes the release of chemmically-bound water from the cement matrix (approximately between $150^{\circ} \mathrm{C}$ and $250^{\circ} \mathrm{C}$ ). When exposed to temperatures higher than this temperature, the damage to HSC with silica fume, in terms of residual strength, will be about 5 percent on average higher than that of HSC without silica fume. Concerning explosive spalling, the presence 
of silica fume has an insignificant effect on the potential for explosive spalling of unrestrained HSC.

\subsubsection{Explosive Spalling}

- Explosive spalling occurred when the temperature of the specimen center measured approximately between $200^{\circ} \mathrm{C}$ and $325^{\circ} \mathrm{C}$. This temperature range coincides with the time when high temperature differences between the specimen surface and center. This suggested that, while internal pore pressure may be the primary cause for the explosive spalling of the specimens, the buildup of thermally induced strain energy was also large at this time, and thus thermal stress might have a secondary role in this failure.

- The presence of preload appears to have a mitigating effect on the occurrence of explosive spalling and a delaying effect on the temperature level when explosive spalling might occur in HSC.

- HSC mixture with $w / \mathrm{cm}=0.22$ appears to have higher potential for explosive spalling when heated under unrestrained conditions (unstressed and unstressed residual property tests) compared with $\mathrm{HSC}$ mixture with $w / \mathrm{cm}=0.33$. The opposite tendency was observed, however, in the stressed tests where explosive spalling occurred only in the $w / \mathrm{cm}=0.33$ specimens (mixture II at $600^{\circ} \mathrm{C}$ ) and none occurred in the $w / c m=0.22$ specimens. HSC mixture with $w / c m=0.57$ did not sustain any incidence of explosive spalling in any of the tests. A $w / \mathrm{cm}$ value between 0.33 and 0.57 is thus the threshold above which the possibility of explosive spalling is substantially reduced.

- The presence of silica fume had no significant effect on the potential of explosive spalling in HSC with (stressed test) and without preload (unstressed test).

\subsubsection{Comparison with Code Provisions}

- The Eurocode strength-temperature relationship was developed based on NSC test data and is found to be unconservative when used for estimating compressive strength of HSC. The largest overestimation was by about $20 \%$ at temperatures less than $450^{\circ} \mathrm{C}$. The unconservative estimation by the Eurocode at temperatures less than $450^{\circ} \mathrm{C}$ is even more significant when explosive spalling, which is not addressed by the current Eurocode but observed in this test program when concrete was heated to between $195^{\circ} \mathrm{C}$ and $325^{\circ} \mathrm{C}$, is considered.

- Similarly, the provisions of CEB model code were also based on NSC test data and are found to be unconservative when used for estimating HSC compressive strength at temperatures less than $350^{\circ} \mathrm{C}$. The largest overestimation by the CEB model code is by about $25 \%$ at temperatures less than $200^{\circ} \mathrm{C}$. Also similar to the Eurocode, the 
unconservative estimation of HSC compressive strength by the CEB at temperatures less than $350^{\circ} \mathrm{C}$ is more significant since the CEB does not address the explosive spalling problem observed for HSC in this temperature range.

- The Concrete Association of Finland's RakMK B4, which prescribes estimations for concrete strength at elevated temperatures with considerations for the differences in concrete strength grades and in the preload levels, is found to be only slightly unconservative when compared with the results of HSC tests by NIST and other studies. The slightly unconservative estimates by the RakMK B4 is temperatures below $150^{\circ} \mathrm{C}$. However, this is to a much lesser degree compared to the levels of unconservative estimation by the Eurocode and the CEB model code.

- The RakMK B4's strength prediction for NSC at elevated temperatures is found to be consistent with the results of available NSC test data. 


\section{ACKNOWLEDGEMENTS}

The authors wish to extend their gratitude to colleagues at NIST. Mr. J.R. Lawson of the Fire Research Division is acknowledged for his assistance in conducting the unstressed residual property test series, Mr. Frank L Davis of the Structures Division is recognized for his numerous contributions to various facets of the experimental program, and Mr. Kenneth A. Snyder of the Building Materials Division is thanked for his review of this paper and the valuable comments he provided. The authors also wish to extend their gratitude to colleagues at the Portland Cement Association (PCA), particularly Mr. David A. Fanella, for the collaboration and input they provided through Advanced Fire Solutions International, Inc. (AFS) to assist with the planning of this study as part of the NIST-PCA Cooperative Research and Development Agreement (CRADA). 


\section{REFERENCES}

[1] Abrams, M.S., "Compressive Strength of Concrete at Temperatures to $1600{ }^{\circ} \mathrm{F}$," American Concrete Institute (ACI) SP 25, Temperature and Concrete, Detroit, Michigan, 1971.

[2] ASTM C 215-97, "Standard Test Method for Fundamental Transverse, Longitudinal, and Torsional Frequencies of Concrete Specimens," Annual Book of ASTM Standards, 1999, Vol. 04.02, ASTM, West Conshohocken, P.A.

[3] ASTM C 469-94, "Standard Test Method for Static Modulus of Elasticity and Poisson's Ratio of Concrete in Compression," Annual Book of ASTM Standards, 1999, Vol. 04.02, ASTM, West Conshohocken, P.A.

[4] Castillo, C. and Durrani, A. J., "Effect of Transient High Temperature on High-Strength Concrete," ACI Materials Journal, v. 87, no. 1, Jan-Feb 1990, p 47-53.

[5] Comité Euro-International du Beton, "Fire Design of Concrete Structures - in accordance with CEB/FIP Model Code 90 (Final Draft)," CEB Bulletin D'Information No. 208, July 1991, Lausanne, Switzerland.

[6] Comité Européen de Normalisation (CEN), “prENV 1992-1-2: Eurocode 2: Design of Concrete Structures. Part 1 -2: Structural Fire Design," CEN/TC 250/SC 2, 1993.

[7] Comité Européen de Normalisation (CEN), “Eurocode 4: Design of Composite Steel and Concrete Structures. Part 1 -2: General Rules - Structural Fire Design," CEN ENV 1994.

[8] Concrete Association of Finland, "High Strength Concrete Supplementary Rules and Fire Design," RakMK B4, 1991.

[9] Deutsches Institut Fur Normung E.V. (German Institute for Standardization), DIN 4102, "Behavior of Building Materials and Components in Fire," May 1981.

[10] Diederichs, U., Jumppanen, U.M., Penttala, V., "Material Properties of High Strength Concrete at Elevated Temperatures," IABSE 13th Congress, Helsinki, June 1988.

[11] Diederichs, U., Jumppanen, U.M., Penttala, V., "Behavior of High Strength Concrete at High Temperatures," Helsinki University of Technology, Department of Structural Engineering, Report \#92, 1989. 
[12] Diederichs, U., Jumppanen, U-M., Schneider, U., "High Temperature Properties and Spalling Behavior of High Strength Concrete," Proceedings of the Fourth Weimar Workshop on High strength Concrete: Material Properties and Design, Hochschule für Architektur und Bauwesen (HAB), Weimar, Germany, October 4th and 5th, 1995, pp. $219-236$.

[13] Felicetti, R., Gambarova, P.G., Rosati, G.P., Corsi, F., Giannuzzi, G., “Residual Mechanical Properties of HSC Subjected to High-Temperature Cycles," Proceedings, 4th International Symposium on Utilization of HighStrength/High-Performance Concrete, Paris, France, 1996, pp. 579-588.

[14] Furumura, F., Abe, T., Shinohara, Y., "Mechanical Properties of High Strength Concrete at High Temperatures," Proceedings of the Fourth Weimar Workshop on High strength Concrete: Material Properties and Design held at Hochschule für Architektur und Bauwesen (HAB), Weimar, Germany, October 4th and 5th, 1995, pp. 237 - 254.

[15] Hertz K., "Danish Investigations on Silica Fume Concretes at Elevated Temperatures," Proceedings of ACI 1991 Spring Convention, Boston, MA, March 17-21.

[16] Hertz K., "Heat Induced Explosion of Dense Concretes," Institute of Building Design, Report No. 166, Technical University of Denmark, 1984.

[17] Hammer, T.A., "High-Strength Concrete Phase 3, Compressive Strength and Emodulus at Elevated Temperatures," SP6 Fire Resistance, Report 6.1, SINTEF Structures and Concrete, STF70 A95023, Trondheim, Norway, February 1995.

[18] Hammer, T.A., "High-Strength Concrete Phase 3, Spalling Reduction through Material Design," SP6 Fire Resistance, Report 6.2, SINTEF Structures and Concrete, STF70 A95024, Trondheim, Norway, February 1995.

[19] Hammer, T.A.; Justnes, H.; Smeplass, S., A Concrete Technological Approach to Spalling during Fire," Paper presented at a Nordic mini-seminar, Trondheim, 1989, SINTEF Report STF65 A89036.

[20] Iding, R., Bresler, B., and Nizamuddin, AZ., "FIRES-T3, A Computer Program for the Fire Response of Structures - Thermal (Three Dimensional Version)," Building and Fire Research Laboratory, National Institute of Standards and Technology, NIST-GCR-95-682 (1996). 
[21] Khoury, G., and Algar, S., "Mechanical Behavior of HPC and UHPC Concretes at High Temperatures in Compression and Tension," Paper presented at ACI International Conference on State-of-the-Art in High Performance Concrete, Chicago, Illinois, March 1999.

[22] Malhotra, H.L., "The Effect of Temperature on the Compressive Strength of Concrete," Magazine of Concrete Research (London), V.8, No. 22, 1956, pp.85-94.

[23] Morita, T.; Saito, H.; and Kumagai, H., "Residual Mechanical Properties of High Strength Concrete Members Exposed to High Temperature - Part 1. Test on Material Properties," Summaries of Technical Papers of Annual Meeting, Architectural Institute of Japan, Niigata, August 1992 (in Japanese).

[24] Noumowe, A.N., Clastres, P., Debicki, G., and Costaz, J.-L., "Thermal Stresses and Water Vapor Pressure of High Performance Concrete at High Temperature," Proceedings, 4th International Symposium on Utilization of High-Strength/HighPerformance Concrete, Paris, France, 1996.

[25] Phan, L.T., "Fire Performance of High-Strength Concrete: A Report of the Stateof-the-Art," NISTIR 5934, Building and Fire Research Laboratory, National Institute of Standards and Technology, Gaithersburg, Maryland, December 1996.

[26] Phan, L.T.; and Carino, J.N., "Review of Mechanical Properties of HSC at Elevated Temperature," Journal of Materials in Civil Engineering, American Society of Civil Engineers, February 1998, Vol. 10, No. 1, pp. 58-64.

[27] Phan, L.T.; Lawson, J.R.; and Davis, F.L., "Effects of Elevated Temperature Exposure on Heating Characteristics, Spalling, and Residual Properties of High Performance Concrete," RILEM Materials and Structures Journal, Vol. 34, March 2001, pp 83-91.

[28] Schneider U., "Concrete at High Temperatures - A General Review", Fire Safety Journal, The Netherlands, 1988, pp 55-68.

[29] Schneider, U., and Franssen J-M, "A Concrete Model Considering the Load History Applied to Centrally Loaded Columns Under Fire Attack," Proceedings of the Fourth International Symposium, Fire Safety Science, pp 1101-1112.

[30] Sullivan, P. J. E.; Sharshar, R., "Performance of Concrete at Elevated Temperatures (as Measured by the Reduction in Compressive Strength," Fire Technology, v. 28, n. 3, August 1992, p. 240-250. 
[31] Consolazio, G.R.; McVay, M.C.; and Rish, J.W., "Measurement and Prediction of Pore Pressure in Cement Mortar Subjected to Elevated Temperature," NIST SP 919, Proceedings of International Workshop on Fire Performance of High Strength Concrete, NIST, Gaithersburg, MD, February 13-14, 1997. Phan, L.T., Carino, N.J., Duthinh, D., Garboczi, E., Editors. February 1997, pp. 125-148. 
8. APPENDIX 
Table A.1 Data for Dynamic Modulus of Elasticity for Stressed Test Specimens

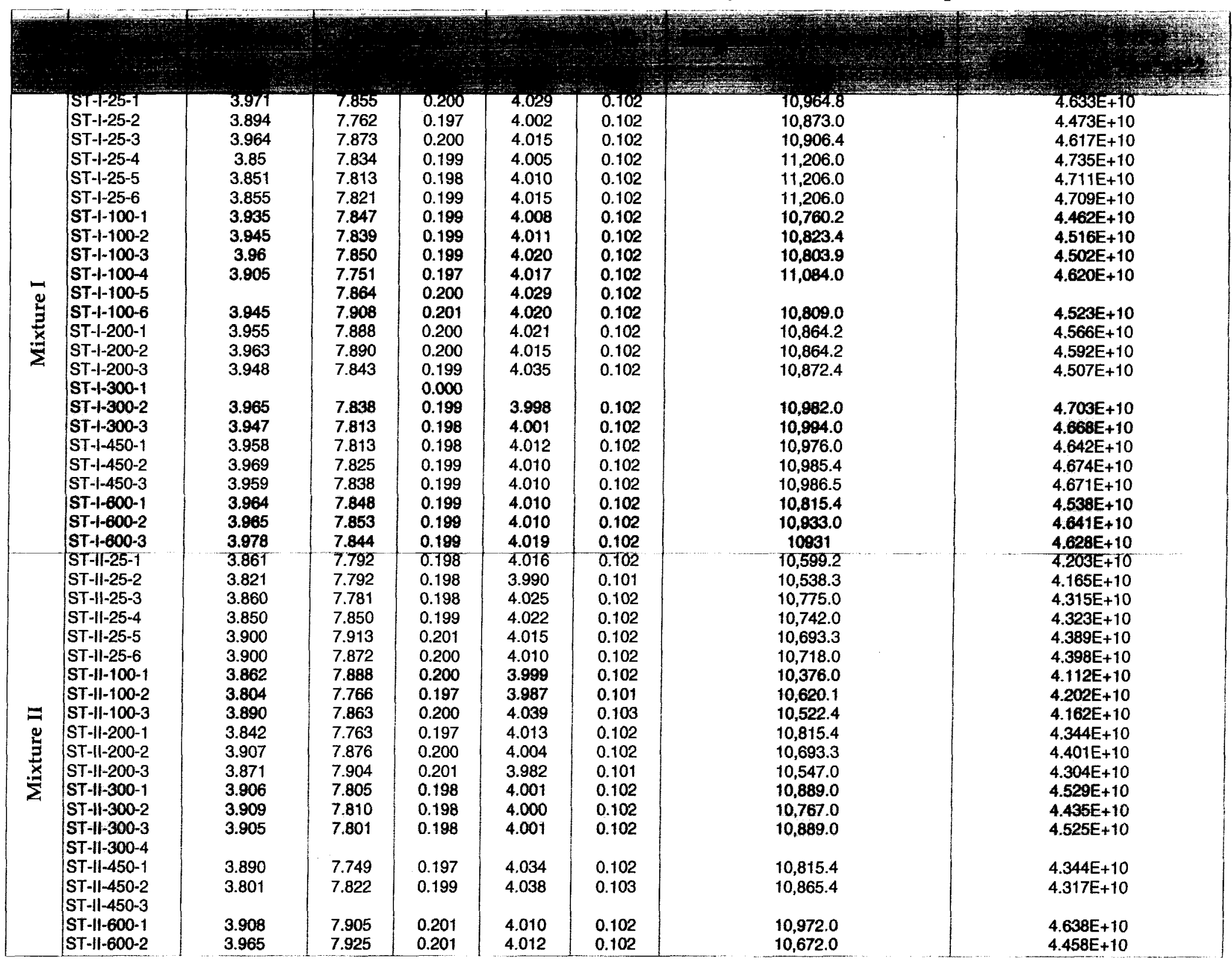


Table A.1 Data for Dynamic Modulus of Elasticity for Stressed Test Specimens (continued)

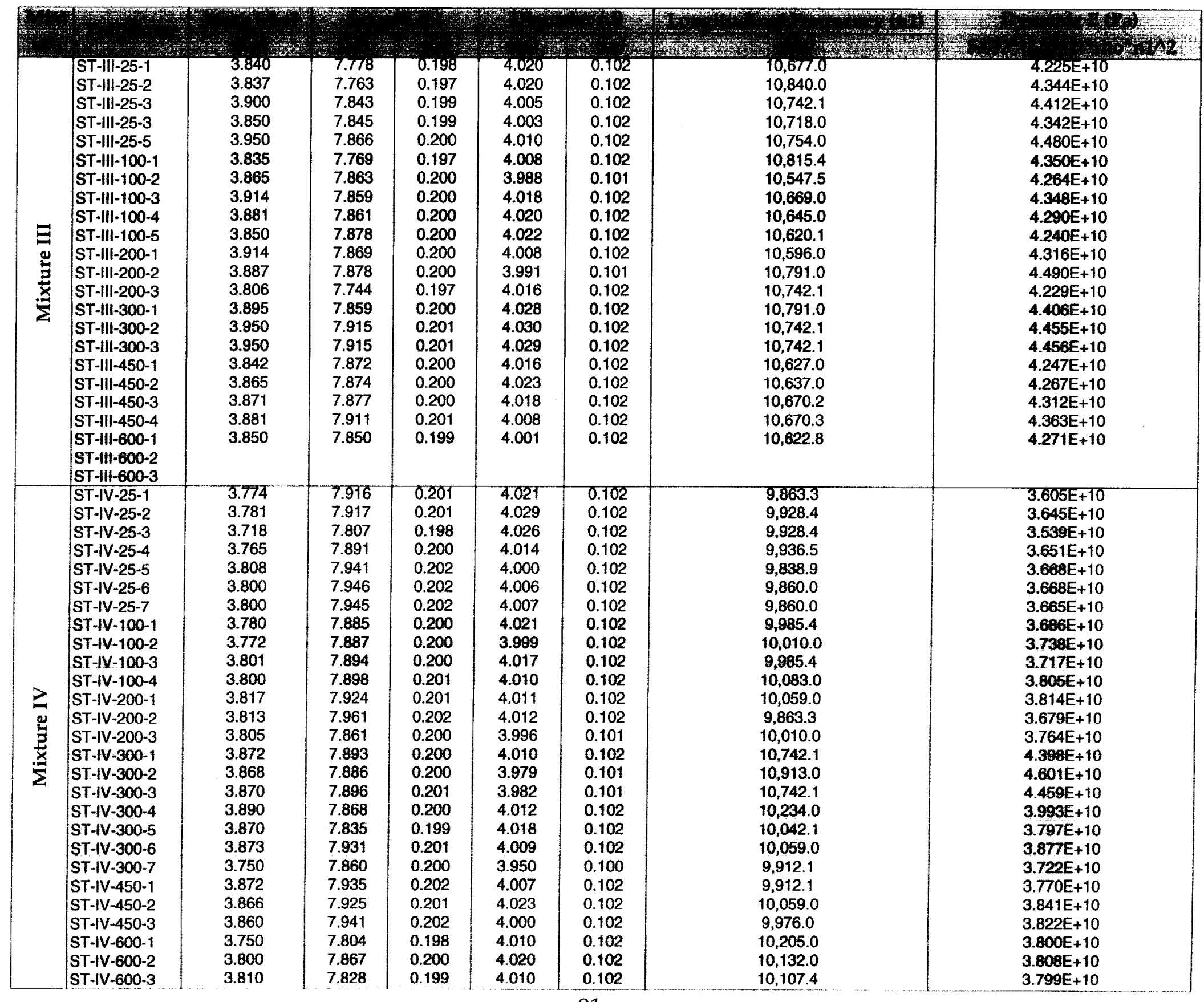

91 
Table A.2 Data for Dynamic Modulus of Elasticity of Unstressed Test Specimens

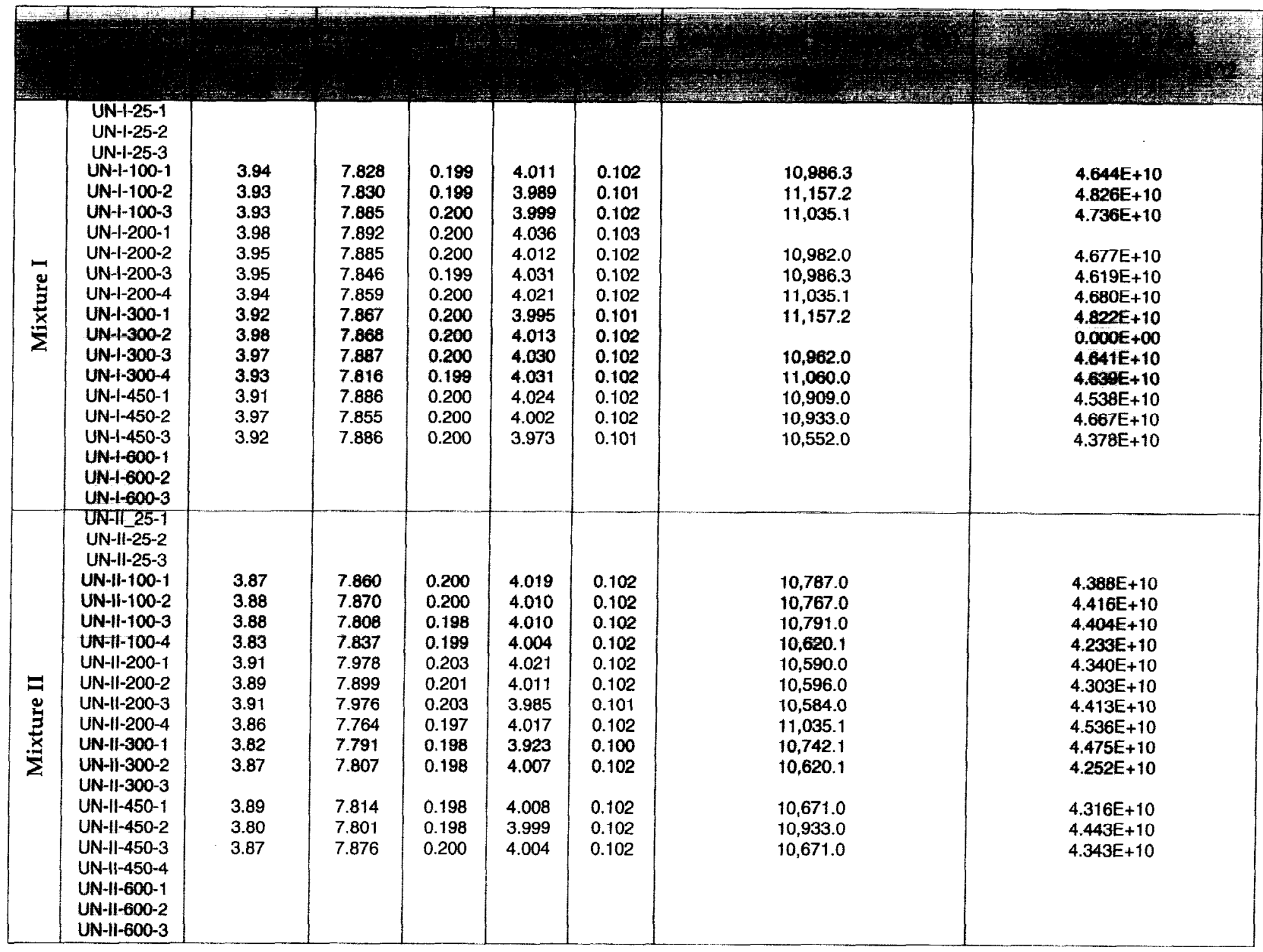


Table A.2 Data for Dynamic Modulus of Elasticity of Unstressed Test Specimens (continued)

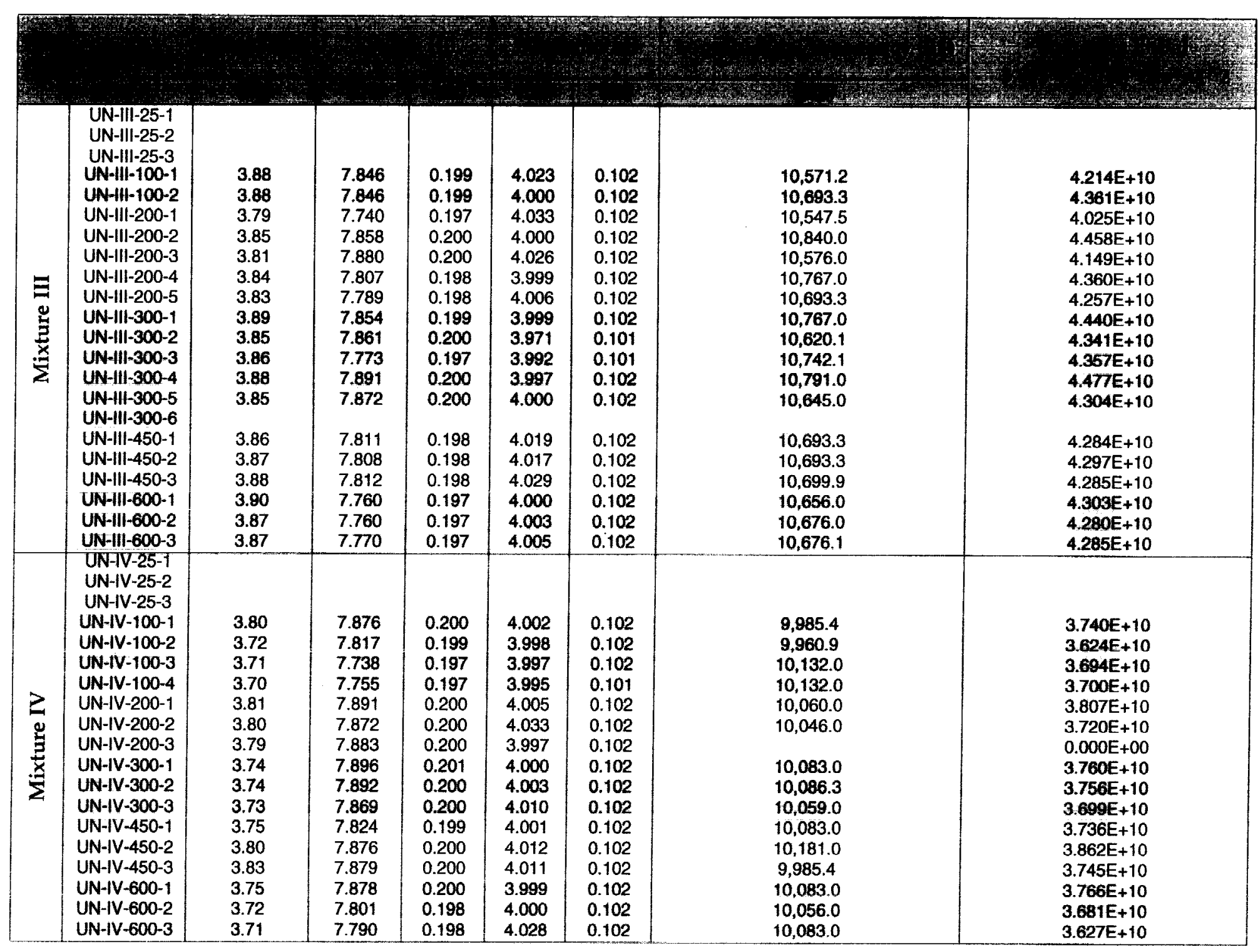


Table A.3 Data for Dynamic Modulus of Elasticity of Residual Property Test Specimens

\begin{tabular}{|c|c|c|c|c|c|c|c|c|c|c|c|c|}
\hline & $\therefore$ & & & & & & & & & & & $\therefore$ \\
\hline 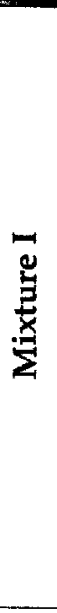 & $\begin{array}{l}\text { RS-I-25-1 } \\
\text { RS-I-25-2 } \\
\text { RS-I-25-3 } \\
\text { RS-I-100-1 } \\
\text { RS-1-100-2 } \\
\text { RS-1-100-3 } \\
\text { RS-1-200-1 } \\
\text { RS-I-200-2 } \\
\text { RS-1-200-3 } \\
\text { RS-1-300-1 } \\
\text { RS-1-300-2 } \\
\text { AS } 1800-3 \\
\text { RS } 1300-4 \\
\text { RS } 1300-6 \\
\text { AS-I-450-1 } \\
\text { RS- }-450-2 \\
\text { AS-I-450-3 }\end{array}$ & $\begin{array}{l}4.01 \\
4.02 \\
4.03 \\
3.92 \\
3.89 \\
3.90 \\
3.89 \\
3.96 \\
3.90 \\
3.94 \\
3.96 \\
3.92 \\
3.94 \\
3.90 \\
\end{array}$ & $\begin{array}{l}3.97 \\
3.99 \\
3.99 \\
3.75 \\
3.75 \\
3.75 \\
3.65 \\
\\
3.67 \\
3.70 \\
3.72\end{array}$ & $\begin{array}{l}0.00 \\
0.00 \\
0.00 \\
1.02 \\
0.75 \\
0.84 \\
4.38 \\
3.57 \\
3.85 \\
6.19 \\
\\
6.02 \\
6.07 \\
5.94\end{array}$ & $\begin{array}{l}7.987 \\
\mathbf{8 . 0 9 7} \\
\mathbf{8 . 0 0 5} \\
7.835 \\
7.770 \\
7.803 \\
7.816 \\
7.858 \\
7.809 \\
7.834 \\
7.884 \\
7.838 \\
7.810 \\
7.791 \\
\end{array}$ & $\begin{array}{l}0.203 \\
0.206 \\
0.203 \\
0.199 \\
0.197 \\
0.198 \\
0.190 \\
0.200 \\
0.199 \\
0.199 \\
0.200 \\
0.199 \\
0.198 \\
0.198 \\
\end{array}$ & $\begin{array}{l}4.006 \\
3.997 \\
4.000 \\
4.041 \\
3.996 \\
4.000 \\
4.015 \\
4.093 \\
4.003 \\
4.015 \\
4.001 \\
4.007 \\
4.037 \\
4.028 \\
\end{array}$ & $\begin{array}{l}0.103 \\
0.102 \\
0.102 \\
0.103 \\
0.101 \\
0.102 \\
0.102 \\
0.102 \\
0.102 \\
0.102 \\
0.102 \\
0.102 \\
0.103 \\
0.102 \\
\end{array}$ & $\begin{array}{l}10,798.2 \\
10,394.5 \\
10,238.3 \\
10,872.4 \\
11,100.2 \\
11,068.0 \\
11,065.1 \\
11,068.0 \\
10,908.0 \\
11,084.0 \\
10,986.3 \\
11,206.0 \\
11,084.0 \\
11,060.0 \\
\end{array}$ & $\begin{array}{l}9,433.6 \\
9,628.9 \\
9,517.7 \\
9,082.0 \\
9,700.5 \\
9,537.0 \\
7,543.9 \\
\\
7,397.5 \\
7,446.3 \\
7,470.7\end{array}$ & $\begin{array}{l}4.597 E+10 \\
4.411 E+10 \\
4.236 E+10 \\
4.461 E+10 \\
4.679 E+10 \\
4.672 E+10 \\
4.606 E+10 \\
4.699 E+10 \\
4.543 E+10 \\
4.711 E+10 \\
4.710 E+10 \\
4.813 E+10 \\
4.652 E+10 \\
4.594 E+10\end{array}$ & $\begin{array}{l}3.472 E+10 \\
3.757 E+10 \\
3.629 E+10 \\
2.977 E+10 \\
3.446 E+10 \\
3.335 E+10 \\
2.019 E+10 \\
\\
1.965 E+10 \\
1.997 E+10 \\
2.052 E+10 \\
0.000 E+00 \\
0.000 E+00 \\
0.000 E+00 \\
\end{array}$ \\
\hline 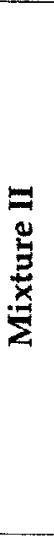 & 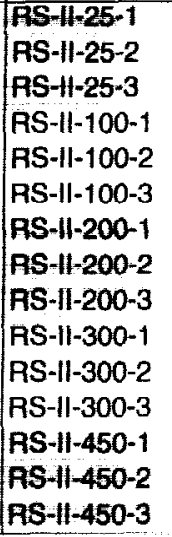 & $\begin{array}{l}3.94 \\
3.97 \\
3.96 \\
3.76 \\
3.82 \\
3.78 \\
3.83 \\
3.91 \\
3.83 \\
3.85 \\
3.89 \\
3.89 \\
\end{array}$ & $\begin{array}{l}3.90 \\
3.92 \\
3.92 \\
3.54 \\
3.63 \\
3.57 \\
3.52 \\
3.61 \\
3.53 \\
3.50 \\
3.53 \\
3.45 \\
\end{array}$ & $\begin{array}{c}0.00 \\
0.00 \\
0.00 \\
1.22 \\
1.13 \\
1.09 \\
6.03 \\
5.08 \\
5.55 \\
8.09 \\
7.80 \\
7.91 \\
9.16 \\
9.30 \\
11.17 \\
\end{array}$ & $\begin{array}{l}8.066 \\
8.087 \\
8.085 \\
7.667 \\
7.788 \\
7.655 \\
7.816 \\
7.961 \\
7.819 \\
7.830 \\
7.842 \\
7.843 \\
\end{array}$ & $\begin{array}{l}0.205 \\
0.205 \\
0.205 \\
0.195 \\
0.198 \\
0.194 \\
0.199 \\
0.202 \\
0.199 \\
0.199 \\
0.199 \\
0.199\end{array}$ & $\begin{array}{l}3.993 \\
4.000 \\
3.995 \\
4.004 \\
3.969 \\
4.009 \\
4.003 \\
4.000 \\
4.001 \\
4.010 \\
3.996 \\
4.030\end{array}$ & $\begin{array}{l}0.101 \\
0.102 \\
0.101 \\
0.102 \\
0.101 \\
0.102 \\
0.102 \\
0.102 \\
0.102 \\
0.102 \\
0.101 \\
0.102\end{array}$ & $\begin{array}{c}10,311.7 \\
10,187.5 \\
10,409.4 \\
10,970.0 \\
10,645.0 \\
11,003.0 \\
10,840.0 \\
10,514.3 \\
10,710.0 \\
10,767.0 \\
10,840.0 \\
10,767.0\end{array}$ & $\begin{array}{l}9,985.4 \\
9,936.5 \\
9,985.4 \\
9,179.7 \\
9,277.3 \\
\mathbf{9 , 3 4 2 . 4} \\
7,397.5 \\
7,421.9 \\
7,617.2 \\
5,761.7 \\
5,688.0 \\
5,737.0 \\
\end{array}$ & $\begin{array}{l}4.252 E+10 \\
4.172 E+10 \\
4.362 E+10 \\
4.344 E+10 \\
4.293 E+10 \\
4.374 E+10 \\
4.403 E+10 \\
4.312 E+10 \\
4.304 E+10 \\
4.361 E+10 \\
4.504 E+10 \\
4.361 E+10\end{array}$ & $\begin{array}{l}3.939 E+10 \\
3.924 E+10 \\
3.970 E+10 \\
2.858 E+10 \\
3.095 E+10 \\
2.978 E+10 \\
1.884 E+10 \\
1.981 E+10 \\
2.005 E+10 \\
1.134 E+10 \\
1.125 E+10 \\
1.100 E+10\end{array}$ \\
\hline
\end{tabular}


Table A.3 Data for Dynamic Modulus of Elasticity of Residual Property Test Specimens (continued)

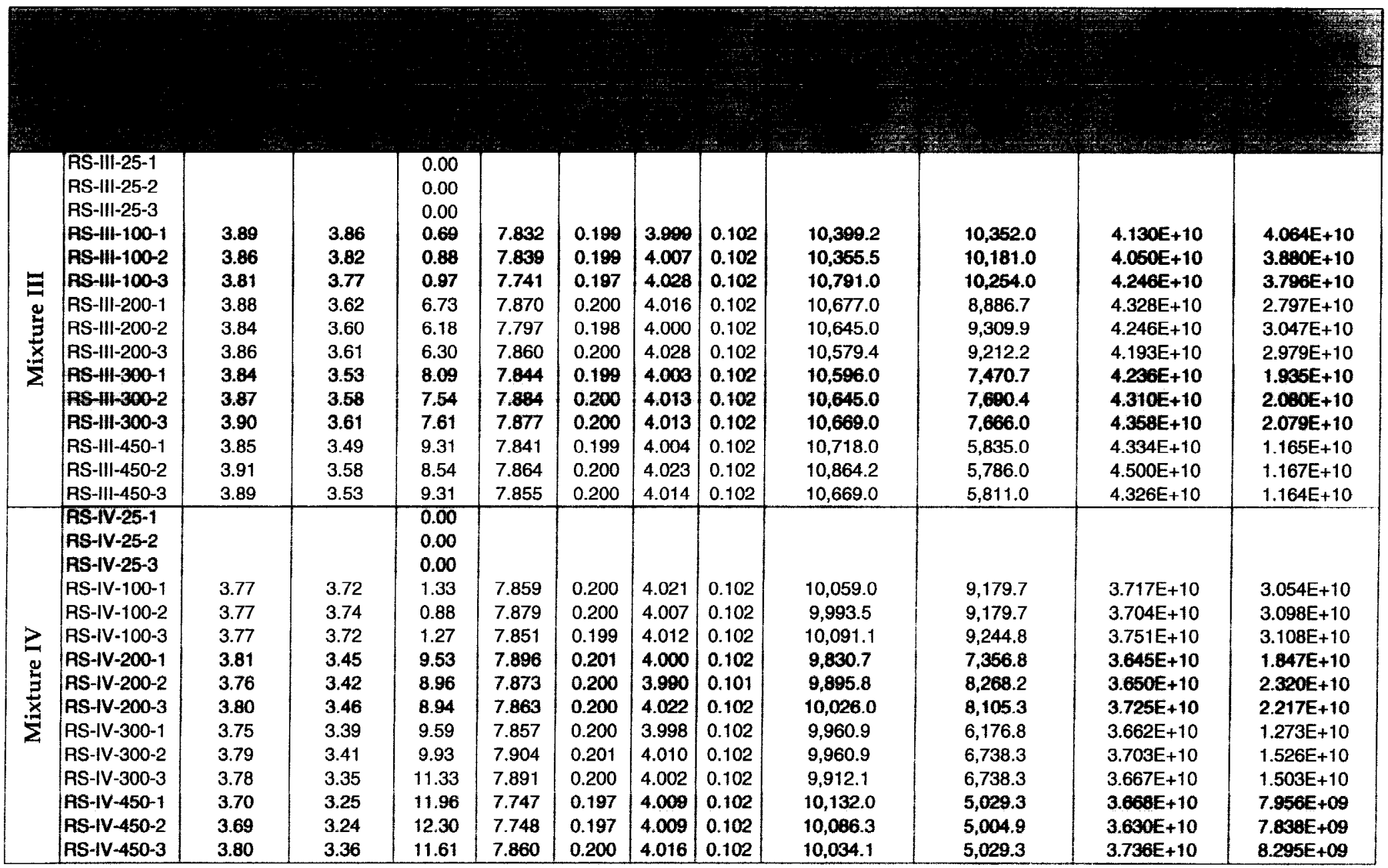



